nordon 



\section{Nordic Prison Education}

A lifelong learning perspective

Translated by Linda Schenck

TEMANORD 2005:526 
Nordic Prison Education

A lifelong learning perspective

TemaNord 2005:526

(C) Nordic Council of Ministers, Copenhagen 2005

ISBN 92-893-1147-9

Cover and graphic production: Kjell Olsson

Design: Zakrisson, www.polytype.dk

Cover photo: INA/O.W. Nickel

Copies: 1,100

Translation: Linda Schenk

Print: Aka print A/S, Århus 2005

Printed on environmentally friendly paper

This publication can be ordered on www.norden.org/order

Other Nordic publications are available at www.norden.org/publications

This translation has been funded by the Nordic Council of Ministers, the Danish, Finnish and Swedish Prison and Probation Service and the County Governor of Hordaland, Norway, as well as by a grant from the European Prison Education Association (EPEA).

Printed in Denmark

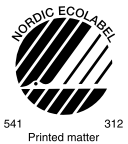

\section{Nordic Council of Ministers}

Store Strandstræde 18

DK-1255 Copenhagen K

Phone $(+45) 33960200$

$\operatorname{Fax}(+45) 33960202$

www.norden.org

\section{Nordic co-operation}

Nordic co-operation, one of the oldest and most wide-ranging regional partnerships in the world, involves Denmark, Finland, Iceland, Norway, Sweden, the Faroe Islands, Greenland and Åland. Co-operation reinforces the sense of Nordic community while respecting national differences and similarities, makes it possible to uphold Nordic interests in the world at large and promotes positive relations between neighbouring peoples.

Co-operation was formalised in 1952 when the Nordic Council

\section{Nordic Council}

Store Strandstræede 18

DK-1255 Copenhagen K

Phone (+45) 33960400

$\operatorname{Fax}(+45) 33111870$

was set up as a forum for parliamentarians and governments. The Helsinki Treaty of 1962 has formed the framework for Nordic partnership ever since. The Nordic Council of Ministers was set up in 1971 as the formal forum for co-operation between the governments of the Nordic countries and the political leadership of the autonomous areas, i.e. the Faroe Islands, Greenland and Åland.

\section{Nordic "Folkeoplysning" and Adult Education}

The Steering Group for Nordic "Folkeoplysning" - FOVU - is to advise the Nordic Council of Ministers and to contribute and further policy discussions in the fields of education and training in the Nordic countries. The Steering Group is to promote innovation and development in this field through Nordic projects, conferences, information material and a grant system of its own, and to monitor developments in this area in the Nordic countries and adjacent areas, as well as in the EU and Europe. 


\section{Contents}

Foreword 9

1 Summary and recommendations 13

Introduction 13

The Nordic prisoner 13

The right to education and training 14

Lifelong learning 15

Education and training options 15

The role of the teacher and methodology $\quad 16$

The role of education and training in the Prison

and Probation Services 18

Administrative cooperation 19

Documentation and research 19

Financial aspects 19

International recommendations/ conventions on imprisonment 20

Recommendations 20

2 Descriptions of prison education in the Nordic countries

DENMARK 2.1 History 25

2.2 Legislation and regulatory documents 31

2.3 Description of prison education and its relation to the state education system 33

2.3.1 Description of prison education 34

2.3.2 Education for individuals held in remand 35

2.3.3 Education for convicted prisoners 37

2.3.4 The transition from prison education to education in the state school system 42

2.3.5 Financial aspects 44

2.4 The results of prison education 44

2.4.1 Quantitative results 44

2.4.2 Qualitative results 45

2.4.3 Greenland and the Færoe islands 46 
FINLAND 2.1 History 46

2.2 Legislation and regulatory documents 49

2.3 Description of prison education and its relationship to the state education system 54

2.3.1 Description of prison education and its relationship to society at large 54

2.3.2 Education for remand prisoners 57

2.3.3 Description of prison education 58

2.3.4 The transition from prison education to education in the community 60

2.3.5 Financial aspects 62

2.4 The results of prison education 62

2.4.1 Quantitative results 62

2.4.2 Qualitative results 63

2.4.3 The Åland islands 66

NORWAY 2.1 History 66

2.2 Legislation and regulatory documents 72

2.2.1 The principles underpinning the work of the Prison and Probation Service 72

2.2.2 The 2002 Enforcement of Sentences Act 73

2.2.3 The Education Act 77

2.3 Description of the relationship of prison education

to the state education system 78

2.3.1 Description of prison education 78

2.3.2 Education for individuals in remand 80

2.3.3 Education for prisoners and individuals in remand 81

2.3.4 The transition from prison education to education/work in the community 87

2.3.5 Financial aspects 90

2.4 The results of prison education 90

2.4.1 Quantitative results 90

2.4.2 Qualitative results 92

SWEDEN 2.1 History 97

2.2 Legislation and other regulatory documents 101

2.3 Description of prison education and its place in relation to adult education in society 105 
2.3.1 Description of prison education 106

2.3.2 Education for individuals in remand 107

2.3.3 Education for prisoners 108

2.3.4 The transition from prison education to education in the community 111

2.3.5 Ongoing development work regarding prison education 113

2.3.6 Financial aspects 115

2.4 The results of prison education 116

2.4.1 Quantitative results 116

2.4.2 Qualitative results 118

ICELAND 2.1 History and legislation 121

2.2 Description of prison education 123

2.3 Financial aspects 124

2.4 The prison population 124

3 The prison population 125

3.1 Descriptions of the prison populations in Denmark, Finland, Norway and Sweden 125

3.2 Key developmental trends 129

4 Relevant international recommendations 131

4.1 The European Prison Rules (1987) 131

4.2 Education in Prison (1989) 132

4.3 UNESCO Recommendations for adult education (UNESCO 1985) 134

4.4 The United Nations Convention on the Rights of the Child (1989) 135

4.5 The European Convention for the Protection of Human Rights and Fundamental Freedoms 136

5 Assessment, analysis and recommendations 137

5.1 Legislation and prisoners' rights to education 137

5.2 Models for implementation of education in prisons 141 5.2.1 Models for education in prisons 142 
1 The export model 142

2 The self-supply model 144

3 The import model 146

4 The contract model 149

5 The combination model 151

5.2.2 Equal opportunities in prison education 152

5.3 Description of education in prison facilities 153

5.4 Educational opportunities 155

5.4.1 The abusers - "once and never again" prisoners the professional criminals 158

\subsection{Methods 161}

5.6 The place of education in the Prison and Probation Services 166

5.7 Options and needs for lifelong learning 169

5.8 Documentation and research 172

5.9 Cooperation between the Prison and Probation Service and other stakeholders 174

5.10 The cost of prison education 176

6 Crime prevention in the short and long term 180

6.1 Crime prevention in prisons 180

6.2 Programme activities in Danish prisons 186

6.3 Programme activities in Finnish prisons 187

6.4 Programme activities in Norwegian prisons 189

6.5 Programme activities in Swedish prisons 190

6.6 Crime prevention outside the prison and probation services 192

6.7 Society and criminality 197

6.7.1 Urbanisation 198

6.7.2 Alcohol and violence 199

6.7.3 Unemployment 199

6.7.4 Marginalisation and stigmatisation 200

6.7.5 Other explanations 200

6.7.6 Concluding comments 201

7 Joint Nordic recommendations 202

Bibliography 210

Figures 218

Tables 218 


\section{Foreword}

\section{The assignment to the project group}

In 1999, the Nordic Council adopted a recommendation (16/1999) on prison education in a Nordic Perspective (A 1199/nord), by which the Nordic Council recommended to the Nordic Council of Ministers that: “... a study be made of the possibilities of cooperating on projects relating to prison education in a Nordic perspective, and that the results of the study presented to the Nordic Council include proposals for measures to be implemented".

In light of this recommendation, the Nordic Council of Ministers issued the following statement:

In 2000, the Nordic Council of Ministers adopted a position in favour of regarding the earmarking of funds for a systematic survey of the work done by the Prison and Probation Service of each respective country.

The authorities responsible at national level for prison education in the Nordic countries cooperate closely through their network.

The Nordic Council of Ministers assigns this Nordic network to draw up the necessary basic material to enable a final decision to be made regarding joint Nordic initiatives in the area of prison education. A futureoriented Nordic survey with a lifelong learning perspective from the point of view of crime prevention might be one Nordic initiative. Education in the Prison and Probation Service faces many of the same challenges as the entire state education system in relation to society as a whole, not least in terms of fulfilling the needs of the weakest target groups. It is therefore natural for a survey of education in prisons to describe and analyse the initiatives taken by each respective country as part of an exchange of experience, and to see developments in a holistic perspective in relation to the general education system and to what is being done to meet the needs of the weakest groups there.

The contributions of the Council of Ministers will take place as cooperation between the relevant areas of both education and legislation, and will result in a Nordic report. 
At a meeting held in Bergen, Norway on 18 July 2001, the project group revised the project description, which was then submitted to the Nordic Council of Ministers.

At a meeting on 26 September 2001, The Steering Group for Nordic Adult Education Co-operation (FOVU), the Nordic Executive Committee on Education \& Research (EK-U) and the Nordic Senior civil servants' committee for legislation (EK-LOV) adopted the following decision:

... that a Nordic level study would be made regarding education and the correctional services, that the National Education Office in Hordaland (from 1 January 2003 the County Governor of Hordaland) be asked to have the overall responsibility for the implementation of this project in accordance with the project description, and that the Nordic project group have the actual responsibility for assuring the quality of the material.

In accordance with the project description, each country appointed one member of the project group, as well as a reference group for assuring the quality of the material. The project has been directed by the County Governor of Hordaland, Norway.

\section{The composition and work of the project group}

The members of the project group were:

The project director was Senior Adviser Torfinn Langelid, Office of the County Governor of Hordaland, Norway. The other members were:

Education Manager Kaj Raundrup, Danish Prisons and Probation Service,

Chief Inspector Vuokko Karsikas (15 April 2002-15 August 2003), Finnish Criminal Sanctions Agency and Chief Inspector Kirsti Kuivajärvi (17 January 2002-17 March 2002), Finnish Criminal Sanctions Agency

Regional programme coordinator Svenolov Svensson, The Swedish National Prison and Probation Administration, Regional office in Göteborg. 
In addition, each country appointed a reference group to assure the quality of the material.

The project group met nine times, including one meeting in October 2002 with Sigrun Røstad, adviser from the Nordic Council of Ministers.

The work underpinning this report was primarily carried out by each member of the project group presenting his or her findings to the group as a whole for discussion. Each member's findings were also discussed and commented on by that country's reference group. It was the responsibility of the Project Director to compile and summarize the report. In the original language report, parts of chapter two were written in three languages: Danish, Norwegian and Swedish (the Swedish and Finnish contributions). The rest of the report is in Norwegian. The English translation was done by Linda Schenck, Sweden.

Iceland was not represented in the project group, but Division Director Erlendur S. Baldursson provided the contribution on education in the Icelandic prison system. The descriptions of prison education in Greenland and the Færoe islands is included as part of the description of Danish prison education, and correspondingly, the Åland islands are described as part of the section on Finnish prison education. Chapter 6 , on crime prevention in the short and long term was written by Deputy Director Inger Marie Fridhov of the Norwegian Council for Crime Prevention.

In spite of the differences in the systems and reporting methods of the various countries, the project group has made every effort to make the material as comparable as possible. The numerical data is mainly from 2001 and 2003. All currencies have been converted from the respective Nordic currencies to Euro, using 28 February 2005 conversion rates. It is the hope of the project group that this report satisfies the assignment of providing a survey of the situation in the Nordic countries.

The contents of the report have been presented at various international conferences, and we have received requests for an English translation. This translation has been funded by the Nordic Council of Ministers, the Danish, Finnish and Swedish Prison and Probation Service and the County Governor of Hordaland, Norway, as well as by a grant from the European Prison Edu- 
cation Association. The English text is a somewhat abridged and edited version of the original report.

In my capacity as project director I would like to thank the representatives of each country and their employers for the effort they put into making this report reality. I am also indebted to advisers Sigrun Røstad, Margrethe Hernes and Kjell Olsson from the Nordic Council of Ministers for all their help and support throughout the process.

Bergen, Norway March 2005

Torfinn Langelid

Project Director 


\section{Summary and recommendations}

\section{Introduction}

The purpose of the project Education, Training and Prison and Probation Service in a Lifelong Learning Perspective, a Nordic Study of Structures and Models, is to provide a concise, overall and updated comparative view of education and training in prisons in Denmark, Finland, Norway and Sweden, as well as a brief description of the situation in Iceland. Based on these observations, general analyses of strengths and weaknesses were then made in order to identify a common basis for progress in the field. The project group has put forward joint Nordic recommendations for improvements. The results and recommendations can also be applied to the Adjacent Areas, and to other countries in their efforts to develop their prison education systems.

The numerical data is mainly from 2001 and 2003. Statistics and reporting methods may differ in the various countries but the project group has tried to make the material as comparable as possible.

\section{The Nordic prisoner}

The typical Nordic prisoner can be described as: over 30, having left school quite early, with a very little experience of the labour market and, in many cases, a substance abuse problem. Not a surprising picture, and readily recognizable.

In an attempt to look into the future, a Swedish report has drawn up a model categorising the expected future prisoners into three main groups: abusers, "once and never again" prisoners and professional criminals (In Swedish: English equivalent title: The Prison and Probation Service and Prisoners - a future and societal trends analysis regarding prisoner development and prison populations, 1998). 
According to the report abusers are, and will remain, the dominant category. The second category, "once and never again", comprises prisoners who, although they tend to come from orderly backgrounds, may have been convicted to crimes of a relatively serious nature, but who are not recidivists. The last category is quite broad and contains members of known criminal gangs and individuals who have been involved in carrying out planned crimes. It is important to generate debate about the activities that can be offered to this group because their primary need is not for social support according to the authors of the report.

Although many prisoners need formal education and training, the report also identifies a need for training in informal skills (life mastery, teamwork skills, functioning in the community, the family, etc.). Official efforts to promote lifelong learning must also include individuals serving prison sentences under the auspices of the Prison and Probation Service. (See also 5.7)

The overall question is: what type of education and training does the altered prison population need?

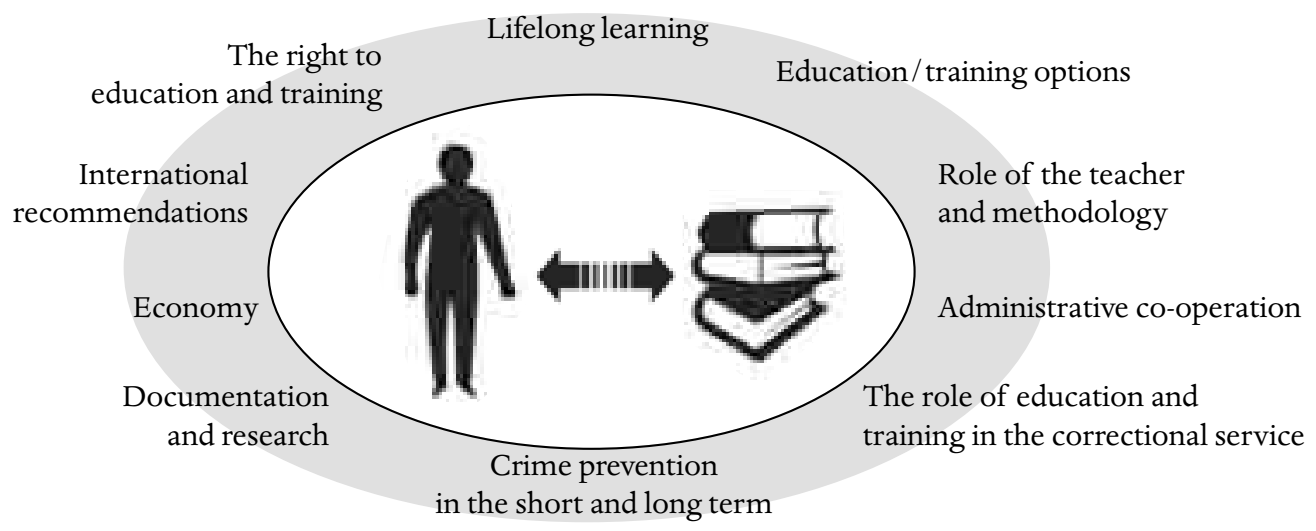

FIGURE 1.1 Prisoners and prison education in relation to society

The right to education and training

If prisoners are to receive education and training on the same terms as the rest of society, then it is a basic prerequisite that their rights must be clearly stipulated in the legislation. While the 
authorities in all of the Nordic countries actively advocate lifelong learning and skills enhancement for adults, our study reveals that prisoners' rights to education and training are not as clearly defined. Legislation governing the Prison and Probation Service must also stipulate, therefore, that the only thing of which a prisoner is deprived is his or her liberty. In principle, all other rights must be upheld.

Based on the principles of normalisation, integration, openness and responsibility, the project group is in favour of prisoners taking part in the general education system to a much larger extent, by making greater use of day release privileges, etc. This would allow prisoners to participate in the ordinary school system, with its different approach than teaching in confinement. Choice is also greater in the local educational system.

\section{Lifelong learning}

In the work of the European Union and in the individual European countries, efforts are being made to ensure that young people and adults get the knowledge and skills they need to face new employment situations in a society in a state of constant change. It is clear that without these skills and knowledge, individuals will be excluded from the ordinary educational system and the labour market. The prison population is a vulnerable group in this respect. One precondition for meeting the needs of the different groups of prisoners for education and training is that the educational authorities possess the tools to assess their needs and the options available.

\section{Education and training options}

Prison education and training must reflect the ordinary educational system. Research shows that many prisoners have had inadequate schooling compared with the rest of the population. In terms, for example, of the right to education and training, the humanitarian perspective and in terms of rehabilitation, education and training in prisons should be defined broadly. Good prison education and training is considered as an investment in crime prevention in the sense that more prisoners will continue their education and find jobs after release. 
Our study of prison education and training in the Nordic countries shows that definitions vary from country to country. Considering the importance attached to lifelong learning and the attention paid to the need for continuous skills enhancement and to the increasingly multicultural nature of Nordic society, all these elements need to be acknowledged in prison education and training.

Despite the different models for prison education and training, a joint Nordic starting point does exist in the sense that education and training are perceived as being both for the benefit of the individual prisoner, for personal development, and as a step on the way to the ability to cope upon release - hopefully to a life free from crime and drugs. The organisation, courses, methodology and prioritisations should, therefore, be based on the prisoner's situation.

The education and training needs may be formal in nature to a great extent but a major need for informal skills has also been identified (life skills, the ability to function in a team at work, in society, in the family, etc.). Official efforts to promote lifelong learning must also include prisoners.

\section{The role of the teacher and methodology}

Prison teachers need skills that meet the special needs of the prison population for education and training. They must be able to recognise the different learning needs of the individual prisoners, and be able to handle foreign prisoners' needs in terms of language, religion and culture. They must be certified teachers, and also be given updated information regarding the Prison and Probation Service s, in order to promote proper pedagogical dialogue and avoid institutionalisation.

In Denmark most of the teaching in prisons is done by full-time teachers appointed by the Ministry of Justice. Over half of the teaching in county prisons is provided by prison staff teachers, and the remainder by part-time teachers appointed by the local authorities.

In Finland, most of the teaching is done by teachers appointed by local education institutions, but there are also teachers appointed by the Ministry of Justice (in three prisons) and contracted teachers (very few).

In Norway, all prison teachers are either full or part-time teachers appointed by the educational authorities. 
In Sweden prison teaching has been outsourced to a large number of different adult education centres. In 2001, there were 21 different contracting parties, with contracts of 1-2 years with a renewal option of one or two years. In 2003, an experiment was launched using teachers appointed by the correctional service under the pedagogic direction of the Swedish Agency for Flexible Learning.

Is there a dimension to teaching in a prison setting that distinguishes the prison teacher from other teachers? According to Claesson it may be related to social aspects. She goes on to report on an interview with a prison student who said:

There are three things that make a good prison teacher: firstly being devoted to the teaching profession, really keen to teach, as well as being aware of the social dimension. Secondly, being extremely hands-on and practical, and prepared to be flexible about learning and teaching methods. Thirdly, making you feel it's ok to be bad at schoolwork. Many people in this setting, myself included, have mixed experience of school. And maybe we think that a person who is bad at schoolwork is a bad person. In which case we end up skipping school or dropping out or not giving a damn. But it's ok not to be good at everything. It's oK to say I didn't do my assignment if you hear: "All right, well, just sit down and give it a try now." I think the feeling that you are welcome anyway, that the teacher isn't going to give up on you, is important (Claesson, Dahlgren 2002. In Swedish. English equivalent title: Studying in Prison: education in three prisons).

According to Skaalvik et al., if there were a spectrum with the students' points of departure at one end and long-term goals at the other, one would also span the spectrum of opinions about the objectives of prison education amongst prison school administrators and teachers and other prison staff.

$\begin{array}{llll}\begin{array}{l}\text { Individual points } \\ \text { of departure }\end{array} & \rightarrow \begin{array}{l}\text { Educational } \\ \text { objectives }\end{array} & \rightarrow & \begin{array}{l}\text { Formal } \\ \text { objectives }\end{array} \rightarrow \begin{array}{l}\text { Long-term } \\ \text { objectives }\end{array} \\ \text { - Feeling comfortable } & \bullet \text { Knowledge } & \text { - Examinations } & \text { • Mastering } \\ \text { in the classroom } & \text { - Skills } & \text { • Course } & \text { life skills } \\ \text { - Motivation } & \text { - Social } & \text { certificates } & \\ \text { - Self-confidence } & \begin{array}{l}\text { development } \\ \text { - Attitudes }\end{array} & \end{array}$

FIGURE 1.2 The objectives of prison education seen over time 
For the teacher, the person who works with the students in practice, it is essential to be familiar with the individual's starting point in order to find the appropriate means of achieving the long-term objectives. For the prison school administrator, on the other hand, coming from experience of the state school system, "formal objectives" are central. In any case, each new inmate must be approached with awareness of all this in mind, and from the perspective of lifelong learning, without bias and in an honest attempt to see where on the spectrum (s)he is starting out, in order to use the most appropriate methods in working with that individual. For one prisoner, working towards a specific goal may be just right, while for another the most important thing is to start with basic skill improvement. It is very likely that prison teachers face greater challenges than "regular" adult education teachers when it comes to finding the right keys to unlock each individual student's learning abilities.

Thus, in the prison setting, too, optimal education will help the student to develop as a person, to have more self-confidence, be better able to solve problems, be creative, better able to learn new things and to find and assess information.

\section{The role of education and training in} the Prison and Probation Services

A prison sentence is one of the ways in which society can react to undesirable actions. This reaction builds on the instruments available to the Prison and Probation Service to promote the re-integration of the prisoner into society. Many different professional categories contribute to this effort. In other words, institutions run by the Prison and Probation Service is staffed by representatives of various stakeholders who may also have different, contradictory, objectives. The educational authority is one of the national agencies meant to ensure that convicted prisoners receive the education to which they have a legal right. The Prison and Probation Services have responsibility for coordinating the measures implemented by the various state authorities so that prisoners have wellorganised, positive options. 


\section{Administrative cooperation}

Close co-operation between the correctional service and the various authorities is an important prerequisite for satisfying prisoner's needs regarding education and training. Strategic plans are needed for the extension of prison education and training. Close co-operation and good internal planning will provide a broader view of the needs of the different prison groups for education and training, help develop good programmes and ensure better utilisation of resources.

From the perspective of society as a whole, it is important to encourage co-ordination of efforts that will make it easier for prisoners to return to society.

\section{Documentation and research}

Our study shows that the Nordic countries, except Denmark, collect systematic reports about prison education and training. Apart from in Norway and Sweden, little evaluation and research has been done into prison education and training. At the same time, quality assurance is a general requirement in the Nordic education systems, and it entails various types of reporting, evaluation and research. This helps ensure that the resources invested correspond to the options available, as well as providing a very clear picture of the overall situation.

\section{Financial aspects}

At present, demand far outstrips supply. Those with the greatest need are often a group that is also difficult to reach on the outside. Therefore, it is a high priority to make a start towards fulfilling society's ambition of enhancing these individuals' skills and encouraging them to join in the process of lifelong learning while they are serving prison terms. At present, education and training accounts only for a small fraction of the total cost of each prison place. It would probably be more profitable in purely socio-economic terms to increase investments in education and training in prisons. 
The cost of prison education and training is small compared to the total cost of a prison place, in spite of the total cost of the education and training in the Nordic countries being millions of Euro. The proportion of total costs is approximately $2-5 \%$. In other words, the Prison and Probation Service in the Nordic countries provide prison education and training for the price of one pack of cigarettes per prisoner per day.

\section{International recommendations / conventions on imprisonment}

Legislation is often based on international recommendations and conventions. Existing and future prison education and training must comply with international recommendations and conventions.

\section{Recommendations}

The project group has drawn up a number of recommendations for the future of prison education and training in the Nordic countries (for further details see chapters 5 and 7). The project group has made the following core recommendations:

\section{LEGISLATION}

The project group recommends that the educational authorities in the Nordic countries ensure that their legislations clearly state the legal right and obligation to provide prisoners with the same right to education as other citizens. The legal authority stipulated in the Education Acts should also be stipulated in the legislation of the different countries relating to enforcement of sentences. When the right to education has been elucidated, this will have consequences in terms of resource allocation.

\section{EDUCATIONAL OPPORTUNITIES}

The project group recommends the following proposals to meet the need for formal and informal skills. 


\section{Theoretical education}

- Comprehensive education (corresponding to nine years of basic education, through secondary school, in Finland only needed to a limited extent).

- Remedial education in literacy and numeracy skills, with special priority given to prisoners with the most inadequate educational background (as it is a unique opportunity to meet and motivate these individuals while they are in prison).

- Further education (corresponding to upper secondary education) with a broad range of educational options, corresponding to those offered in the community.

- Day release privileges for educational activities is important, both in terms of offering prisoners more educational options and in giving them the opportunity to study in a "normal" study environment.

- Education and training that meets the needs of foreign prisoners.

- There must be opportunities for independent study with tutoring, to meet individual needs.

\section{Vocational training}

- Vocational training in collaboration with the employment service in order to offer training that will prepare the individuals for the labour market.

- Cooperation should be encouraged between schools (theory) and prison workshops (practice). As a result of such cooperation, some activities could earn educational credits. When educational needs assessed, inmates' previous experience should also be taken into account. This can mean a great deal to individuals who have positive testimonials.

- Some vocational training could be given in other languages. This could also be useful to inmates who are going to be deported after release, and who could thus gain competence that will be of value to them when they return to their home countries. 


\section{New technology}

- The introduction of new technology (Internet-based solutions adapted to prison security needs) might be a simple way of giving more inmates access to a broad range of further education, university and other higher education.

- ICT courses of the same kinds offered in the regular schools in the community (both to master the techniques themselves and to use the new technologies in other subject studies). The new technology is also a necessary tool to be able to access various educational options outside the prison - a natural tool in relation to the expanding range of Internet-based adult education possibilities in society.

Creative activities, libraries, etc.

- Education in the arts with a view to improving self-development, life skills and motivation raises individuals' social skills. Participation in both creative activities and well-rounded physical activities often encourage prisoners to go on to other kinds of education.

- There should be access to a well-stocked library and its services in collaboration with the library services available in the community.

Women prisoners

- All the items above apply equally to women prisoners who, precisely like their male counterparts, must be offered a wide range of educational opportunities adapted to their individual needs. For women, who otherwise run the risk of being considered a small, costly target group, the new technologies may be particularly important in terms of opening up a large number of options (unless the possibility of mixed groups men and women at prison schools is considered).

\section{Education as one piece of the puzzle}

- Education can be more effective if it is combined with work, treatment programmes, and other approved activities. Very few prisoners can cope efficiently with full-time studies. Great flexibility and "tailor-made" weekly schedules should be avail- 
able for each prisoner. Education is one important piece of a larger puzzle. If that piece falls into place, it may be decisive both for the success of the inmate's schooling and for his or her life as a whole.

\section{General}

- There must be access to suitable premises and modern equipment which bears comparison with adult education elsewhere in society.

\section{ADMINISTRATIVE COOPERATION}

The project group proposes that concrete plans and routines be drawn up for cooperation between the Prison and Probation Service and the various stakeholders at national, regional and local levels.

DOCUMENTATION AND RESEARCH

The project group proposes that systematic reporting, evaluation and research on education in prisons be carried out with a view to:

- documenting the work being done on education in prisons in comparison, for example, with treatment programmes and other activities,

- evaluating whether the range offered as prison education corresponds to the educational needs of the prison population,

- obtaining a clear picture of which prisoners do and do not participate in, how students are recruited to prison education,

- assessing teaching methods and quality,

- obtaining a systematic evaluation of prison workshops in relation to the applying curricula,

- determining the place of prison education in the correctional services,

- expressing an opinion regarding whether new programmes, etc., such as classes and treatment programmes, should be evaluated, or whether research into them should be carried out.

CRIME PREVENTION IN THE SHORT AND LONG TERM

There are many crime prevention programmes focusing either on individuals or on groups - both within and outside the correctional services. There is far less awareness of and will to change funda- 
mental aspects of society which may be a breeding ground for crime. If crime prevention is to have any clout, all these programmes must be seen in their societal contexts.

There is a striking absence of effect evaluations of such programmes both within and outside the correctional services. The fact that such evaluations cannot always be carried out under strictly scientific conditions should not prevent the initiation of joint Nordic projects with a holistic view: behaviour modification work, situational prevention and social planning. 


\section{Descriptions of prison education in the Nordic countries}

Chapter 2 describes the four Nordic countries: Denmark, Finland, Norway and Sweden separately. In this chapter, each section is divided into subsections accounting for historical developments from the mid-nineteenth century until the present day, the legislation and regulatory documents applying to prison education, the educational options currently available, and the transition arrangements in anticipation of release and return to society. The concluding subsection of each section details the costs of prison education, the sources of funding, and the results achieved. The statistics and research results referred to mainly come from national reports not available in English. These references are given in brackets in the running text, at first occurrence, by their author and year of publication and with an English equivalent title, by way of information. They are detailed in the bibliography in their original languages, see page 210 .

\section{DENMARK}

\subsection{History}

In the second half of the 1850s, children under the age of 15 could be placed in houses of detention for reasons of education and correction. At the time, the minimum age for conviction of a penal offence was 10. In 1905 the minimum age was raised to 14. Prison education was offered during the winter half of the year, while during the summer season young offenders worked the prison farm/gardening. 
The Danish Criminal Code, which came into force in 1866, established two types of long-term deprivation of liberty, known as penitentiaries and houses of correction. It was generally accepted that when an individual was sentenced to a house of correction this was intended not only to safeguard society from the criminal, but also to fill a cautionary function of general prevention. While houses of correction were dormitory-like facilities, penitentiaries were prisons with cells. Prison education began at the penitentiaries, where the teachers were staff members. Prison education is still an important aspect of sentence enforcement, although over the years its form has changed in relation to the prevailing theories of education and the practical facilities available.

\section{Youth penitentiaries}

Organised prison education moved into a new phase on 15 April 1930, when the Danish Civil Criminal Code was adopted, resulting in the establishment of youth penitentiaries in 1933. The underlying principle was to have a treatment system for young offenders, between the ages of 15 and 21, who were considered as requiring counselling and guidance and, not least, vocational and educational training, in order to become law-abiding citizens.

At youth penitentiaries, education was compulsory. Prison teachers taught Danish, mathematics, writing, etc. The new insight underpinning the introduction of compulsory education was that many prisoners had serious problems, attributable to various factors including inadequate educational backgrounds.

The educational options focused on the basics, for the reasons given above, as well as on expanding prisoners' horizons by strengthening their self-confidence, ability to reflect, and self-image, began as individual teaching in the prisoners' cells. Classroom teaching began at Danish prisons in 1932.

\section{Open prisons}

During the years after World War II, for reasons of capacity, a large number of new, open prisons were constructed. These facilities had a good geographical spread, and housed the majority of convicted prisoners. There were advantages to having open prisons in terms of criminal policy: prisoners were able to utilise the educational and vocational options available in the community to a much greater extent than previously. 
Regulations regarding education

Not until 1952 were regulations for prison education adopted, stating that:

as a rule education is to be offered on a group basis and, whenever possible, outside working hours. All prisoners under the age of 30 are required to participate in the basic education courses in written and oral proficiency in Danish, and in mathematics, writing and civics, arranged by the prison where they are serving their sentences. The prison Governor may determine, after consultation with the head teacher, to include other subject areas in the obligatory courses.

In addition to the establishment of remedial education, the regulations also ensured that credit-giving courses would be offered, as well as short vocational courses.

Criticism of sentences of indeterminate length

The treatment regime described above was subject to increasing criticism in the 1950s and 60s from criminologists and experts and gradually also from politicians, particularly in relation to prisoners sentenced to serve sanctions of indeterminate length. Thus the way was paved for abolition of some of the sanctions of indeterminate length, and eventually the entire Criminal Code was revised. The revised Code was adopted in 1973.

The 1973 report of the Danish government commission on education In 1968, the Ministry of Justice announced the appointment of an education commission whose task was to analyse the scope, content and organisation of educational activities for prisoners, including vocational training and the problems associated with how prisoners spend their non-working hours. The report of the commission was published in 1973. It was written mainly from a societal point of view, based on the assertion that although recent years had seen major developments regarding access to education for young and old, prison education had not kept pace owing to resource constraints. The authors of the report formulated the following objective: 
The prison authorities should strive to provide prisoners with a range of educational options corresponding to that available to the citizens in society at large. Whenever possible, this teaching should take place as participation in courses, etc. held outside the prison. However when necessary, for reasons of security or other special, prison-related considerations, educational opportunities should be offered on the prison premises.

The commission also proposed that the educational options described should be offered all year round and during the day, as full-time schooling. Thus the foundation was laid for education to be on equal terms with other prison activities, and for abolition of compulsory education.

\section{The Skadhauge plan}

In 1971, two years before the publication of the government commission report, a working party had been asked to draw up a proposal for establishment and implementation of an educational reform in and outside prisons.

In August 1974, after referral to and comments from many different parties, the proposal was adopted. It was known as the "Skadhauge plan", named after the educational consultant employed by the Prisons and probation Service. The main proposal was that prison education should be integrated into the state educational system, primarily by prisoners being granted day release privileges from open prisons, so they could participate in the educational opportunities available in the community. The secondary proposal was that a corresponding educational system would be established in closed prisons. For prisoners, this meant that as early as while they were in remand, they could begin planning how to best utilise their incarceration time, and that they would have access to a far broader range of educational opportunities. The plan emphasised the importance of taking the prisoner's own educational interests into account. Information material was published, describing the educational and vocational options at the two pilot project prisons, as well as how prisoners' educational and/or vocational needs and interests were analysed. The Skadhauge plan was influential in the 1970s and 80s not only in the Nordic countries but in the rest of Europe as well (Gerhard Deimlich: Strafvollzug, Randgruppen, 
Sociale Hilfen, Verlag Peter Lang, 1982). Once the pilot projects had been completed, the plan was intensified and launched at all Danish prisons. Developments were followed up and evaluated by researchers (see also section 2.3.4 on the transition from prison education to education in the state school system).

The 1986 AUF report

The "AUF" report (AUF stands for the Danish words Arbejde, Undervisning og Fritid, in English "Work, Education and Leisure Time". Report 1058 on activities for prisoners serving sentences in the custody of the Prisons and Probation Service), published in 1986, drew attention to a number of system weaknesses in the Danish prison system with regard to educational and other activities for prisoners. This report proposed that there should be equivalence of work and education in terms of the allowance paid for participation. This proposal was also included in the recommendation on prison education from the Council of Europe in 1989.

The report found that although the individual prisons had gradually developed a broad range of vocational and educational options, the activities themselves were not appropriately suited to the target groups. It was therefore proposed that the existing areas for activities in prisons (production, maintenance work and education) be supplemented with a new area, to be known as "production schools", which would correspond to the "production schools" for young people that were part of the state education system. These had no connection to the employment services, nor were they traditional vocational upper secondary school programmes. The AUf committee felt that this new type of municipal institution was a step in the direction of finding activities that would attract young people with no stable work experience, and who did not want to and were not capable of embarking upon a proper vocational programme. It would focus on several kinds of work, and on integrating basic education into the working process.

The 2002 report on activities for convicted prisoners Spring 2002 saw the publication of yet another report on activities and treatment for prisoners under the auspices of the Prisons and probation Service. The proposed reorganisation of all areas of 
activities described below, with more integration of work, education and treatment, was actually never adopted. Implementation of the recommendations in the report was postponed owing to financial constraints, but has been recommenced in 2005 .

\section{- Lower and upper secondary education} The report recommends that education of prisoners in the custody of the Prisons and probation Service should be carried out part-time and on the basis of the same principles as govern other lower and upper secondary education. The aim of the recommendation regarding part-time education is to ensure that relevant educational options are offered to as many prisoners as possible.

- Flexible, adapted teaching Many adult education centres have experimented in recent years with different kinds of flexible, adapted teaching, with a view to tailoring the education to the changing living and working conditions of the population. Such new approaches in prison education include, for example, having courses begin at different times, since prison sentence serving is not scheduled in consideration of the school term, and making it possible for individuals who are about to be released to sit their exams. After release, former prison inmates will be able to continue the courses that were tailored to fit their needs at local adult education centres, sit exams there, and get their grades.

- ICT as integrated into teaching (referred to below as "distance courses")

ICT can be used as an integral part of the education sector. In many curricula today, this is already assumed to be the case. In open prisons, ICT (referred to elsewhere as the Internet) can be one aspect of education in prison classrooms, which is not possible in high security prisons today. The report recommends that security aspects be worked through so as to enable even prisoners in high security prisons to use personal computers with Internet access as part of their educational work. 
- Giving priority to ICT as an independent subject

Because IT skills are increasingly needed for anyone wanting to be active on the labour market or in society in general, the report proposes that IT should be given priority as a separate subject, rather than being considered an integral part of prison education.

- Production schools/project activities

The report recommends that existing "production schools" be phased out in their present form and replaced by "project activities" of limited duration and scope, to provide prisoners with the necessary competence to be able to participate in the prison activity/ordinary programmes. The main subjects to be offered as "project activities" would be social skills, remedial education, and special or general education. The project length proposed is 8 weeks.

\subsection{Legislation and regulatory documents}

The Enforcement of Sentences Act

The right to education is stipulated in Article 38 of the Enforcement of Sentences etc., Act (Act 432 from 2003):

A prisoner has the right and obligation to be occupied with participation in work, education or other approved activities.

General Adult Education

There is a long tradition of cooperation between prison education and the state education system, and thus there is a link to the Ministry for Education. For many years, prisoners in Danish prisons have sat the same exams and received the same kind of grades as other adult groups in society.

When the Adult Education Act came into force (in 2000), the Prisons and Probation Service gained a status of its own under the auspices of the Ministry for Education (see also Article 3, paragraph 2 of the Act): "Subject to the approval of the Minister of Education, other educational institutions, including those within the Prisons and probation Service, may offer general adult educa- 
tion". Most prison schools have been granted the status of "local adult education centres". Staff members employed by the Directorate of the Prisons and probation Service serve as directors and assistant directors of these centres. All the teaching and all exams are structured for adult target groups (ages 18 and over), in order to be purpose-oriented and relevant.

\section{Preparatory Adult Education}

The Act on Preparatory Adult Education (Act no. 487 from 31 May 2000) gave the Prisons and Probation Service a special status in that all prison schools can now develop and phase out preparatory adult education (cf. Chapter 6, Article 13 of the Executive Order): "Preparatory adult education may be offered by educational institutions operating under the auspices of the Prisons and Probation Service. These institutions may also run examinations."

Cooperation with the state education system

In the area of the labour market, the Executive Order stresses that prisoners nearing the end of their sentences may participate in labour market courses for unskilled labourers on equal terms with other citizens. Prisoners in halfway houses who are studying (see section 2.3.4 below regarding the transition from prison education to education in the state school system) have the same right to a study grant as other students when the course they are taking makes them eligible for support under the Danish Students' Grant and Loan Scheme. Thus cooperation with the state education system is a basic element of the ambition of the Prisons and Probation Service today, with a view to integrating prisoners in the vocational and educational options in the community whenever possible. This is most clearly expressed in the Programme and Principles for Prisons and Probation Work in Denmark from1993, where the activities of the Prisons and Probation Service is described in line with six principles: Normalisation, Openness, Exercise of Responsibility, Security, Least possible intervention, Optimum use of resources (see below section 2.3), and most recently in the Act on Enforcement of Sentences, etc. mentioned above. 


\subsection{Description of prison education and its relation to the state education system}

\section{The Programme and Principles for Prisons and Probation Work in Denmark}

The Prisons and Probation Service has given special priority in recent years to adapting to the rapidly changing society in which we live. From a treatment point of view, it is important for sentence enforcement time to be as "normal" as possible for the prisoner, in order to avoid harmful effects of imprisonment. The monotony which is one element of everyday life in prison may give the prisoner a sense of the futility of prison life, in sharp contrast to the world (s)he will be returning to, and the demands society places on its citizens. The Prisons and Probation Service continues working to adapt, and to be constantly ready to change in ways that will benefit the prisoner. One aspect of prison life considered extremely important today is prison education. This is described in detail in the Programme and Principles for Prisons and Probation Work in Denmark.

In relation to the principle of "normalisation", the Prisons and Probation Directorate defines prison education as follows:

\section{Normalisation:}

1. The Directorate will strive to ensure that prisoners are given the opportunity to exercise their civil rights and to the greatest possible extent are given equivalent opportunities as other citizens for training and education, with a relatively broader range of options to compensate for the fact that they have to attend school behind bars.

2. On the basis of the "proximity principle", the Directorate will strive to disburse resources so that all prisoners have the same educational options.

3. The Directorate will strive to ensure that educational materials and all other materials correspond to and are in agreement with the conditions at institutions of education under other auspices than those of the Prisons and probation Service.

4. The Directorate will strive, wherever possible, to ensure that the community education system is used, via day release privileges or the import model. When it is impossible for prisoners to make use of 
community services, the Prisons and Probation Service will endeavour to provide prison education in collaboration with institutions of education in the community.

5. The Directorate will ensure that prisoners held in solitary confinement or in special wings are offered education.

6. The Directorate will strive to ensure that the educational activities offered are adapted to the needs of the prisoners.

Education for prisoners is thus acknowledged as a rehabilitating factor, and put into practice by actively involving prisoners in planning their educational work, offering them a wide range of options, and enabling them when possible to have day release privileges and leave the premises to attend school. Education is also offered at the 37 Danish remand centres (as prison education for individuals in remand) and at eight open and five closed prisons (as prison education for convicted prisoners).

\subsubsection{Description of prison education}

Danish prisoners are required to work. This requirement can be satisfied in various ways, including participation in prison education. Prisoners make their own choices, of course often under the influence and motivation of the staff. Prisoners have many good reasons to become involved in educational activities. Some have drawn up very detailed "sentence plans" which include education, and are very goal-oriented. Others may choose to attend school because they think it is a good idea but with no specific plans of what they would like to do with a better education - although such plans may materialize as they study. There are also prisoners who elect education as the least distasteful of the various activities being offered to them by the prison.

\section{Recruitment of prison teachers}

In order to be employed as a prison teacher, an applicant must be a qualified teacher with a degree from a college of education or the equivalent. Experience of adult education is often an advantage, particularly from working with adults in a social service capacity, since being a prison teacher required social commitment as well as educational skills. 
The role of the teacher

A higher degree of social commitment is often required of the prison teacher than of many other teachers at adult education institutions, because prison teachers tend to have other functions beyond simply being classroom teachers. A "holistic" interest in the individual as a person rather than simply as a student or course participant is a desirable characteristic.

\section{Case management work}

Teachers are expected to attend regular wing meetings where issues relating to individual prisoners' sentence serving are discussed, including leave, day release privileges, transfer and release on parole. Teachers are also very much involved in working on the "sentence plan", which extends beyond release:

The institution shall also, in cooperation with the prisoner himself, draw up a plan ("sentence plan") as soon as possible after the prisoner begins to serve his or her sentence, to cover both the sentence enforcement time and the time after release. This plan is to be regularly revised to be kept relevant to the sentence serving and, if necessary, be adapted to changes in the prisoner's situation.

Employment of teachers directly or imported teaching

The Prisons and Probation Service has traditionally employed prison teachers whose duties include both teaching and participation in case management. In May 2004, there were approximately 70 prison teachers / specialised teachers and 13 administrators, with responsibility for day-to-day management, adaptation and phasing out of prison education. In addition to the staff teachers mentioned above, there are also a large number of teachers working in prisons on an hourly basis. Part-time teachers in remand centres and prisons amount to the equivalent of 18 additional full-time positions.

\subsubsection{Education for individuals held in remand}

There are 37 remand centres in Denmark, usually in the main provincial towns. The largest is the Copenhagen remand centre, with a capacity of 523 places. Three of the closed prisons also have "remand halls". 
Day-to-day management of each provincial remand centre is in the hands of a director, who is responsible to the local chief of police, with the exception Copenhagen remand centre, which is run like a state prison, with a prison Governor and deputy director. The school at the Copenhagen remand centre is also structured along the same lines as the schools at the state prisons, with the status of a local adult education centre.

In addition to individuals in remand, these centres house convicted prisoners serving short terms and convicted prisoners pending transfer to state prisons. The duration of a stay at a remand centre may vary greatly - from a few days to many months.

Many of the older, smaller remand centres have no proper educational facilities. This means that teaching often has to take place in the prisoner's rooms, and is therefore on a one-to-one basis. Sometimes this is advantageous, but often it means missing out on the dynamic, social side of the classroom situation. Newer remand centres have much better facilities for education.

The larger remand centres have staff teachers, while the smaller ones use teachers hired on an hourly basis. Individuals being held in remand have shown very positive interest in education. This can, of course, be seen as a desire to show that one is on one's best behaviour, but the need for a social context is probably also a major factor. Individuals in remand often sit locked up for most of the day, and their only contact is with the prison officers when they need something. For this reason, education provides individuals in remand with some relief. In addition to learning, they also have the opportunity to talk with someone they do not consider a member of the remand centre staff.

The educational options offered at remand centres are primarily for individuals in remand who need basic education in Danish and mathematics. In addition to learning these subjects, they also gain motivation to continue their education when they go on to serve their sentences. When the teacher comes from one of the state prisons, it becomes particularly natural to ensure that the individual goes on with an educational programme after being transferred, thanks both to the fact that the teacher will have known them personally in advance, and to the fact that the teacher can prepare the individual with information about the school at the state prison where (s)he is employed. 
Some individuals in remand are able to take a correspondence course or pursue some other kind of independent study under the tutoring of the remand centre teacher. However, it requires great mental fortitude to be able to concentrate on independent studies in this phase of incarceration, often experienced as the most difficult.

\subsubsection{Education for convicted prisoners}

Prison education is available in all Danish prisons where convicted prisoners are serving sentences. In both open and closed prisons, day-to-day administration is carried out by a director of prison activities in consultation with a trained director of education, deputy director of educational activities (with a degree from a college of education). The course modules offered generally follow the same pattern of start and end dates as for state adult education in the community.

\section{Open prisons}

Prisoners in open prisons participate, as a rule, in educational programmes in the community on the basis of day release privileges. Such privileges are generally associated with the last part of a prison sentence, and so prison education on site is still needed for the early part of the sentence. Thus even open prisons have staff teachers and/or hourly teachers working on the premises. This education takes the individual prisoner's abilities as its point of departure. This means that the open prisons therefore offer remedial education and short introductory courses as well as both on site and external examinations organised in collaboration with the local adult education centre.

In the last few years, a number of open prisons have introduced mixed open and closed cell halls. These halls tend to have a fulltime teacher on staff. Prisoners in these halls have the same possibility of obtaining day release privileges for work or school as other prisoners in open prisons, unless there is an evident risk of drink or drug abuse.

\section{"Production schools"}

The report on work, education and leisure time drew attention to a number of consistent weaknesses relating to the various areas 
of activity in the prisons, particularly with regard to a group of 300-400 prisoners whom it had been difficult to place in any activity, primarily because their educational backgrounds and work experience were so poor. The authors of the report recommended that there be special retraining for this group - the aim of which would be to offer them both preparatory vocational training and remedial education. Such programmes had already been launched in the community for young, unemployed individuals between the ages of 18 and 25 with special socialisation problems. These young people, owing to difficulties when they were growing up, had never been able to adjust to vocational training or education in "normal" settings. When they were offered the recommended type of integrated teaching and work situation, the results appeared to be so good, that the authors of the report felt that the model should be tried out in some prison environments for the young offenders who had been short-changed by the traditional educational and vocational training system. By replacing the activities these young people normally ended up doing in prison - along the lines of occupational therapy or assembly work - with a purpose-structured introduction to education and vocational training, they could become involved in pedagogical activities relevant to their situations.

Thus a number of "production schools" were established in open prisons. At present, there are very few workshop schools in closed establishments, mostly because it has proven to be difficult to find the appropriate premises in the existing physical structures.

\section{Internet-based education}

Most educational programmes now consider ICT, particularly use of the Internet, an essential tool. For prison education, there is an inherent contradiction between the need of the educators to use the Internet as an integral aspect of teaching, and the reservations of the administration in terms of the risk of abuse of the system and other associated security risks.

On the basis of the recommendations of a working party on educational issues, in 2000 the Prisons and Probation Directorate adopted a decision that on-line Internet access should be set up in the educational facilities at open prisons (In Danish. English equiv- 
alent title: On use of the Internet in education, Prisons and probation Service Directorate, 2000). This approval, however, had a number of conditions attached relating to security, with a view to avoiding abuse of the system.

Of course, the acceptance of the use of the Internet in teaching in open prisons must be seen in light of the opportunities for prisoners to exercise day release privileges in order to attend educational institutions where there is substantial need to use the Internet, not only in the classroom situation but also in order to complete assignments. This being the case, some prisoners in open prisons have been given permission - usually in conjunction with schooling - to have Internet access in their own rooms. Such permission is now also granted if the prisoner wishes to take a correspondence or distance course in the form of guided independent study in a subject the prison school is unable to offer (On Inmates' Right to Bring with them Possess and Dispose of their own Property and Money in the Institutions of the Prisons and probation Service (Property Order), no. 370, 17 May 2001).

\section{Closed prisons}

With one single exception, all the closed prisons in Denmark were constructed in the late nineteenth and early twentieth century.

This means that the physical facilities in many prison schools are far below the level required in the twenty-first century in terms of the classrooms and their furnishings, group rooms, facilities for other kinds of study (tutoring), ICT and audio visual aids. Prison schools, therefore, may find it difficult to offer their students the same range of options they would have outside the prison. Security considerations in closed prisons also affect the everyday running of prison schools, of course, and are frequently an inhibiting factor in terms of adapting education to the prisoner's needs, such as, access to the Internet, which is a prerequisite for most educational programmes today, including programmes offered by prison schools (adult education, upper secondary education, etc.). The prison schools have to find alternative, often very unusual, solutions, which may weaken the position of prisoners in anticipation of their continued education. 


\section{Educational options}

All closed prisons offer comprehensive adult education, equivalent to primary and lower secondary school (Pursuant to the Act on General Adult Education). The courses offered always include the basics of Danish, mathematics and English. Some prisons offer other subjects as well.

The courses are concluded with tests, developed and checked by the Ministry of Education, and corrected by censors appointed by them, or censors from other adult education centres. Completed basic adult education makes a person eligible for a large number of vocational and educational programmes at upper secondary level.

The Act on Preparatory Adult Education from 2000 has resulted in new possibilities for prison schools and prisoners. Education may be offered in two subjects - reading and mathematics - at two and four levels, respectively, in short, intensive courses (60-80 teaching hours). The courses are concluded with national comprehensive tests. Their aim is to raise the functional level of the participants in the two subject areas so that they will be able to satisfy the basic requirements of the labour market. Preparatory adult education under the auspices of the Prisons and Probation Service was evaluated in 2004 (Preparatory Adult Education in the Prisons, by Mette Lindgaard Adamsen in cooperation with Kaj Raundrup and Irene Olsen).

\section{Remedial teaching (for individuals with dyslexia)}

Numerous studies have shown that many boys and men have reading and writing difficulties. This applies not least to male prisoners who, for various reasons, often have inadequate educational backgrounds. There are also prisoners who have been diagnosed as dyslexic. It is a major challenge for prison schools to interest these individuals in school and, not least, to keep them attending. All Danish prisons have allocated teacher's working hours to dealing with the problem, although different strategies are being used.

There are also numerous examples of prisoners whose prison education began as remedial work and who have gone on to remarkably high levels. 
Upper secondary school adult education diploma

An upper secondary school adult education diploma entitles the holder to apply for higher education. This diploma programme can be completed by prisoners in the form of independent study with tutoring or as study groups. Very few prisoners manage to complete the programme while serving their sentences, but many of them continue first on day release privileges from the prisons and then, after release, at adult education centres in the community.

Education for foreigners

Foreigners comprise an increasingly large proportion of the prison population, resulting in a growing number of prisoners with special needs for courses in Danish. Some foreigners in Danish prisons have never lived in Danish society. Others have taken the occasional language course or only have basic education in Danish. All these considerations are taken into account, of course, when prison schools adjust their course options to the relevant groups of prisoners. Some of the foreigners attend remedial education with Danish prisoners. Others attend courses in Danish for foreigners, like those offered by language schools. Experience indicates that some foreign prisoners go on to compulsory or even upper secondary school.

\section{Independent study}

There will always be prisoners with particular abilities and needs regarding education, which the prison school is unable to satisfy immediately. These individuals can be offered an independent study option after concrete, educational assessment and in collaboration with study counsellors from educational institutions outside the prison. Experience indicates that a great deal of discipline is required by a prisoner to complete independent studies, and that not all subjects are suitable. Usually, independent study works for further and higher education. It is followed up with day release privileges for study at the educational institution that provided the independent study material. 


\section{Vocational training}

In the past, prisons have been able to offer individually-adapted vocational programmes. However, owing to technological developments, prisons are now unable to satisfy the necessary requirements. If a prisoner wishes to pursue a vocational programme while serving his or her sentence, this has to be done in cooperation with an industry outside the prison. Often it is possible for the prisoner to complete the first parts of the programme at the prison workshop and later have day release privileges to work in the industry in question.

\section{Labour market training schemes}

At one closed prison, short courses in welding are offered by the labour market training authorities. These courses follow a creditgiving syllabus and are concluded with an examination. The courses are between 1 and 3 weeks in length. They are held at a purpose-built "workshop schools", and run by specialised teachers.

Prisoners with day release privileges can attend a broad range of labour market training courses outside the prisons.

\section{Summer activities}

Prison schools follow the same school terms as the state school system, with vacation periods including a 6 or 7 week summer holiday. Many prison schools offer alternative activities for prisoners during these periods, mainly sports activities run by the prison teachers in collaboration with teachers from the outside employed on an hourly basis. There are also courses for prisoners with an interest in the creative arts.

2.3.4 The transition from prison education to education in the state school system

\section{Day release privileges}

Day release privileges for school or work are important elements of the efforts being made to provide smoother transitions from prison to release. The time frame for permission to have day release privileges is described in detail in the Act on Enforcement of Sentences, etc. According to these stipulations, a prisoner may be allowed day release privileges when the purpose is clearly estab- 
lished as being for education, work, treatment or family needs or other personal consideration.

One of the main justifications for the introduction of day release privileges is the importance of encouraging prisoners to develop a social identity, for instance by studying alongside other students. However, the subject matter is restricted, and the subject must be one the individual has both the personal and the educational ability to complete.

A prerequisite for all kinds of day release privileges is that the institution receiving the prisoner makes a staff member available to supervise the prisoner to the required extent.

\section{Cooperative education}

A study of the educational environment in open and closed prisons indicates that co-operative education is the main factor affecting recidivism (Svend Ellehammer Andersen, Bjørn E. Holstein and Flemming B. Skadhauge. In Danish. English equivalent title: The Educational Setting in Open and Closed Prisons, 1979). Cooperative education in conjunction with day release privileges for education outside the prison led to better self-esteem, confidence in the future and relieved the boredom of sitting in a prison room. One of the main elements of co- operative education is "learning something about yourself while you are in prison by attending school".

Prisoners in the closed system felt primarily like prisoners even while they were in the classroom. Only rarely did they glimpse themselves as students, or as individuals wanting to get an education. They felt there was no difference between themselves and the other prisoners either when they were in the classroom or when they were in the cell hall, in spite of the assurance from the prison teachers that they were receiving quite individualised teaching. The prison staff - in both closed and open prisons - were quick to point out that they did not distinguish in other prisonrelated respects between prisoners attending school and other prisoners.

Prisoners in open prisons had a very different situation. They attended educational institutions where they were treated exclusively as students. They experienced personally that they were treated exactly the same as the other students by their teachers. "At home" in the prison, on the other hand, they felt like nothing 
but prisoners and, as mentioned above, they were treated by the prison staff in precisely the same way as all other prisoners.

\section{Stationing}

Prisoners who satisfy the requirements for day release privileges can also be transferred to halfway houses: (Executive Order on Leave for Inmates Serving a Sentence of Imprisonment or Safe Custody in the Institutions of the Prisons and probation Service (Leave Order), 4 March 2002).

A prisoner may be stationed at a halfway house for up to four weeks of the last part of his or her sentence enforcement or, when special circumstances call for it, for up to 3 months. If the offender is under the age of 21 at the beginning of his or her sentence serving, more time may be spent in a halfway house when special circumstances call for it. While stationed at a halfway house, a prisoner is subject to the particular rules and regulations applicable to that establishment.

\subsubsection{Financial aspects}

The Ministry of Justice is responsible for financing all prison education. Allocations are disbursed to the individual correctional institutions via the Directorate of the Prisons and Probation Service.

\subsection{The results of prison education}

\subsubsection{Quantitative results}

\section{Number of students}

There are 325 full-time educational places in Danish prisons, although more prisoners attend educational activities, since 45 of the equivalent of full-time places are occupied by prisoners studying part-time. This figure does not include individuals in remand, who usually only have a few hours of education per week. Approximately 100 prisoners per day have day release privileges for education. (See section 2.3.4.)

The number of places for vocational training in Danish prisons is 280 , including the places at "production schools". 


\section{Dropout rates}

There are no statistics regarding dropout rates from prison schools. Students who choose to terminate a course often do so because of lack of motivation. Prisoners can also be suspended from education if substance abuse or disciplinary problems arise. The general impression is that dropout rates from prison schools are not higher than from other adult education institutions.

\section{Number of tests/examinations}

Current experience regarding prisoners who sit tests and examinations indicates that many prisoners choose not to complete their courses by sitting an exam. The report from the Ministry of Education referred to above states that there is a $32 \%$ general dropout rate in Denmark for students who take a whole course of study but do not sit the final exam, a figure the Ministry finds excessive. The dropout rate does not seem to be higher in prisons, if anything lower, but a large number of prisoners still decide at the last moment not to take a final test or examination.

For education provided pursuant to the Preparatory Adult Education Act, which came into force in 2001, the rate of prisoners completing the final test or examination has increased dramatically. It is still to early to say whether this is attributable to the fact that the only grades given for education run pursuant to this Act are pass and fail.

The Prisons and Probation Service has no statistics regarding the sitting of tests or examinations by prisoners who attend school outside the prison on day release, and who continue their education after release from prison.

\subsubsection{Qualitative results}

It is difficult to pinpoint the qualitative results of prison education. Although prisoners completing their final exams do get a grade reflecting their knowledge of the subject, this grade cannot tell us whether (s)he is able to apply that subject knowledge in other contexts. The general impression is that attending school improves prisoners' social skills and teaches them things about society, and that this has a long-term effect of discouraging recidivism. There are research results showing that schooling on the basis of day 
release privileges has a recidivism-reducing effect. (Andersen, Holstein, and Skadhauge 1979. In Danish. English equivalent title: Research report 10 - On the educational settings in open and closed prisons). This study concludes that there is a clear correlation between day release privileges and recidivism - the longer the period of day release privileges, the less recidivism.

\subsubsection{Greenland and the Færoe islands}

Denmark has the overall responsibility for judicial matters in Greenland and the Færoe islands. Greenland has a Criminal Act rather than a Prisoners Act, where the framework for the correction of individuals who violate the law is set out. In the Færoe islands, the regulations in the older Danish Criminal Code are followed, as the Act on Enforcement of Sentences, etc. has not yet come into force there.

The total number of places in the three open prisons in Greenland is 93. In the Færoe islands there is a remand centre with 14 places. Prisoners sentenced to sanctions of long duration are transferred to prison in Denmark.

In Greenland, day release privileges for schooling outside the prison are more the rule than the exception. One of the prisons offers 20 hours of prison education per week. The remand centre in the Færoe islands offers 4-6 hours of prison education per week.

\section{FIN LAND}

\subsection{History}

Education has been provided for all children in Finland since 1898. According to the constitution, enacted in 1919, the public administration is obligated to organize or fund general education, vocational education and higher education. In 1921, legislation on compulsory education saw the light of day. Later, the system underwent a number of reforms, and compulsory education was extended to six years. After four years of primary education, some pupils were selected to go on to five-year secondary school and three-year upper secondary school. In the 1970s, primary and sec- 
ondary school were merged, and nine years of compulsory education introduced under the designation of "comprehensive school". (www.minedu.fi).

Religious education central to the reform of the penal system According to the Philadelphia model, central to the nineteenth century reform of the penal system, prisoners could be fostered to become honest working people and upstanding citizens through discipline, compulsory work and religious education. The absence of religious and ethical upbringing was considered a breeding ground for criminality. The use of imprisonment as the only sanction required the building of new prisons and a more efficacious system for enforcement of sentences. A progressive system was introduced, by which prisoners who demonstrated good behaviour while serving their sentences gained more and more privileges, in accordance with a strict structure. Early in the sentence serving period, it was considered important to keep prisoners isolated in solitary confinement, in order to eliminate the bad influence these individuals were considered to have on each other. As a rule, convicted prisoners came from the lower social classes, which meant that they were often illiterate. The general opinion was that they needed, above all, to gain the skills they required to function as citizens, as well as vocational training (Kallinen,1982. In Finnish. English equivalent title: Educating and centralising).

Prior to the mid-nineteenth century, the only prison education was provided by the prison chaplain, in addition to his other duties. The Act on Enforcement of Sentences, adopted in 1866, stipulated that prisoners were to receive elementary education. However, as there was a shortage of teachers, this gave rise to practical difficulties. Classrooms were crowded and sentences short (Kallinen, 1982).

Beginning in 1889, prisoners were obliged to work while serving their sentences, and education was not set on equal terms with work. Prisoners sentenced to a house of correction or a prison for more than three months were to receive religious education or education in other school subjects. In addition, they were to receive training in a vocation the prison found suitable, preferably according to the individual prisoner's abilities or the job (s)he might be expected to hold after release. Prisoners who were illiterate or over the age of 40 were not subject to compulsory education. This reg- 
ulation remained unchanged until the reform in 1975 . The Prison Administration Decrees of 1925 and 1936 established that the objective of education was to increase prisoners' knowledge and awaken their interest in uplifting reading and individual studies.

Vocational training for young prisoners began in the 1940 s

During the 1940s, special attention was paid to providing young offenders with training in a vocation that corresponded to their abilities and talents. Youth prisoners were also subject to the obligation to work, although those who had not completed comprehensive school were sent to school. All prisoners were also given general education in civics (Mohell, 2002. In Finnish. English equivalent title: Prison education regulations. Unpublished memo for a Nordic prison education survey. The Criminal Sanctions Agency).

The Act on Vocational Training Institutions entered into force in 1942. The new law made it possible to begin vocational training in prison. A mechanical engineering workshop was opened in 1948 at the juvenile unit of the Riihimäki central prison. The school provided vocational training mainly in metalwork until the 1960s, when a programme for automotive and engine technology was set up (Hartoneva \& Kuivajärvi \& Muilu 1999. In Finnish. English equivalent title: The vocational Training of Prisoners 1948-1997).

\section{Normalisation in the 1970s}

In the 1970s, the general trend in society was to expand adult education. In 1978, the Finnish government adopted a decision to plan and develop a system for adult education based on the principle of lifelong learning and regular returns to the classroom. A flexible educational system was established which provided citizens with access to suitable education throughout their lifetimes.

The orientation of criminal policy also reflected the economic, political and spiritual structures of society. A period of reform of the Prison Service began. The idea that prisoners could be "cured" was abandoned, and focus shifted to determining how a prisoner could be best integrated into a pluralistic society (Numminen 1995. In Finnish. English equivalent title: The development of education in Huittinen Open Prison in 1935-1995).

In 1975 there was a comprehensive reform of the enforcement of prison sentences in Finland. This was the end of the penitentiary and progressive system, as well as the authoritarian princi- 
ples that underpinned them. The new ambition was to modernise and develop the system of work, educational options, vocational training, and rehabilitation. In accordance with the principle of normalisation, these functions were to reflect society at large.

The new legislation retained the principle by which prisoners were obliged to work, adding the obligation to participate in vocational training. Prisons were to offer suitable vocational training and any other teaching they found necessary. A government bill (1972) stressed that instead of the previous emphasis on elementary education in prison schooling, the emphasis was to be shifted to vocational training.

It was argued that various other countries had found that providing prisoners with vocational training was one of the most effective means of reducing recidivism. Consequently, it was proposed that vocational training should be offered on regular working hours. The bill also stipulated that it would be made possible for prisoners to work and study outside the prison.

A government commission on prison regulations proposed in 1975 that the regulations applying to education throughout society, including the quality of education, course options and textbooks and other pedagogical aids, should also apply to prison education (In Finnish. English equivalent title: Prison regulation commission report). Since 1985, it has been possible to arrange general educational courses for prisoners in collaboration with adult upper secondary schools.

\subsection{Legislation and regulatory documents}

Programme of Principles sets out the objectives for correctional care According to the Programme of Principles for the Prison Service adopted in 1998, the aim of the services is to contribute to the security of society by maintaining a legal, secure system for enforcement of sanctions, and to reduce criminal recidivism and break the cycle of exclusion that maintains criminality.

The Prison Service has committed to complying with the values considered important in Finnish society, including respect for human dignity and justice. Their work is also guided by the view that human beings possess the capacity to change and grow. The commitment to these values also implies that: 
- fundamental and human rights are complied with,

- prisoners are treated humanely, objectively, and on equal terms with each other,

- all activities are structured in compliance with the law, and that justice and fairness prevail, and

- sentences are enforced so as to promote the individual growth and development of each prisoner, as well as his or her intention to return to a life free from crime.

When sentences are enforced, the principle of normalisation is observed, as well as the following principles: goal-orientation, individuality, individual accountability, professionalism, cooperation, and good administration. Individuality and individual accountability imply, inter alia, that when a sentence is enforced the prisoner's situation and individual needs are assessed. Sentences are to be enforced so as to reinforce the ability of the individual to take responsibility for his or her own life and to take the consequences of his or her own actions. One of the measures taken to achieve this is the provision of prison education.

\section{Regulations regarding education}

Prison education is governed by the general statues on education. The Finnish constitution establishes the universal right to basic education free of charge. According to the constitution, every citizen has an established, subjective right to basic education at no cost to him or herself. The right to other forms of education is not correspondingly established as a subjective right. However, this stipulation obligates society to ensure that citizens of lesser means are actually able to receive education.

\section{Basic education}

Education is compulsory for children from the year they turn 7 until approximately the age of 17 if they have not previously completed the curriculum for comprehensive school (primary and lower secondary). Municipalities must offer basic education to children of compulsory school age living in the municipal catchment area. Very few prisoners are of compulsory school age, owing to the fact that unless there are very special circumstances, offenders under the age of 18 are not sentenced to serve an unconditional 
prison sentence. Some $6 \%$ of Finnish prisoners have not completed comprehensive school. Prison education is organised as adult education, because adult education methods are generally best suited to the education of prisoners. Both basic and upper secondary education are usually offered under the auspices of adult education upper secondary schools, or state upper secondary schools with special programmes for adults.

The Ministry of Education may authorise a municipality, a group of merged municipalities, or a registered association or foundation to offer upper secondary education. This education may be offered partly or entirely as independent study, classroom education or distance study. Course or sub-course examinations may be arranged under the auspices of an approved educational institution.

Reform of vocational programmes

The reform of the basic qualifications in vocational education was implemented in Finland between 1991 and 2001. The basic qualifications in vocational education comprise three-year study programmes after nine-year comprehensive education. Basic vocational education can be arranged as classroom education or distance study as a combination of educational forms or as apprenticeship training. Diplomas are awarded on the basis of independent examinations, irrespective of how the vocational skills or the education preparing the individual to learn these skills or other vocational supplementary courses were acquired.

The Ministry of Education issues authorisation for education providers to arrange vocational courses, as well as establishing the objectives, subjects to be covered, and number of students to be accepted for these courses.

Apprenticeship training is defined as contract-based vocational studies carried out at a workplace and implemented as practical work, combined with theoretical studies. Apprenticeship training may be arranged for basic and further vocational education for young people or for adults. Local management and supervision of the training is the responsibility of the municipalities.

In Finland, adult education is also offered under the auspices of the employment services and its main aim is to improve adults' vocational skills and thus their ability to get a job or to be kept on 
at their workplace, as well as to promote access to skilled manpower on the labour market. Today, employment training is only a small part of prison education, although it was a very important aspect of prison education in the 1970s and 80s.

\section{Special provisions regarding education for prisoners}

There are special provisions regarding education for prisoners in the Enforcement of Sentences Act. At the time of the sentence enforcement reform in 1995, the obligation of prisoners to participate in work or education was abolished and replaced with a general obligation to participate in activities. On regular working hours, prisoners must work or participate in education or other activities arranged or approved by the prison. This general obligation to participate in activities applies identically to both open and closed prisons. According to the Act, the correctional authorities must undertake to arrange work or some other activity for the prisoner, commensurate with his or her abilities and with a view to maintaining and developing his or her vocational skills or otherwise promoting his or her ability to cope in society. Suitable vocational education and other useful education are to be offered in the prison.

Prisoners who have not completed compulsory comprehensive (primary and lower secondary) education are to be given the opportunity to do so. Whenever possible, prisoners are also to be given the opportunity to study at an adult education centre or some other appropriate educational establishment. Course certificates must not indicate that the course was completed in prison.

When enforcing sanctions for young offenders, particular attention is to be paid to needs relating to the prisoner's age and developmental phase. Whenever possible, young offenders shall be given work that can be reconciled with studies for a vocation commensurate with their abilities and potential.

\section{Remand prisoners}

In Finland, remand prisoners are held in ordinary prisons, or in other facilities approved by the Ministry of Justice. Remand facilities are not part of the prison system in Finland, but of the Police Administration. This report only takes into account education given 
to individuals held in remand in ordinary prisons. A remand prisoner is not obligated to work or to participate in any activities. However, should (s)he wish to take part in an activity, (s)he is to be given the opportunity to do so if possible.

Developmental goals in educational policy

The government has established developmental goals in educational policy for the period from 1999 to 2004. The main goal is to offer high quality basic education to all on equal terms. Everyone domiciled in Finland has the same right to education. Particular efforts are made to support children and young people with problems and to prevent exclusion.

A parliamentary working party under the Ministry of Education proposed in 2002 that basic resources for adult education for the coming decade are to be focused on vocational supplementary education and adult education arranged by universities and vocational polytechnics, in line with demographic developments in terms of age structure and educational level, as well as changes in the labour market. Finland has introduced a national programme aiming to lift the educational level of adults. Some parts of the prison education system are now funded by this programme.

Reform of the Enforcement of Sentences Act

The remit of the Prison Sentence Committee, who submitted their report in 2001, was to draft a proposal for a thorough revision of the enforcement of prison sentences and remand periods. The aim was to improve prisoners' opportunities to return to society after release by increasing their chances of living a life without crime, equipping them to find their place on the labour market, promoting their better functioning in society, and discouraging drink and drug abuse. The proposal stated that the obligation to participate in activities should be more clearly linked to the individual sentence plan drawn up for every prisoner.

Prison education would be subject to the same regulations applying to education in general. For example, the Act would be supplemented with new provisions stating that illiterate prisoners are to be given the opportunity to receive the education they need, and that foreign prisoners have the right to study Finnish or Swedish. 
In autumn 2004, the Finnish government presented a bill for a new Imprisonment Act and a new Remand Act to the Parliament. The reform will also include a reform of the Prison Service Administration. There will be 5 regions, all with their own assessment and allocation units and closed and open prison units. The enforcement of sentences is planned so that all the activities in the different units support the aim of encouraging prisoners to live their lives free from crime.

\subsection{Description of prison education and its relationship to the state education system}

\subsubsection{Description of prison education and its relationship} to society at large

Objectives of prison education

Sanctions are to be enforced so as to promote, if possible, or at least not to exacerbate, the adaptation of the prisoner to society. The only deprivation is the deprivation of liberty. Prison education can promote a prisoner's individual growth and development, improve his or her skills for coping in society, and assist him or her to live a life free from crime. Prison education is an activity in line with the principle of normalisation, and with the same objectives as all adult education.

\section{Organisation}

In Finland, most prison education is organised by educational institutions under the administrative management of the educational authorities. In 2001, a total of 46 educational institutions arranged teaching at prison facilities. Eight of these were upper secondary schools for adults, one was an adult education centre, and 37 were institutions for vocational training. Three prisons have staff teachers qualified from a college of education. At these prisons, too, education is organised in cooperation with and under the supervision of educational institutions.

At prisons with no educational activities offered by external institutes of education, either teachers are employed on an hourly basis or there are study counsellors who are members of the prison 
staff and whose job is to encourage prisoners to work on their basic skills through independent study. Other prison staff members help the prisoners with their studies, running courses such as ICT, preparatory education, or apprenticeship training.

Prison education and its relationship to society at large

Prison education is basically organised as part of the regular education system, which means that it stands in a close relationship with society at large. However, some courses organised by members of the prison staff, such as ICT courses, are organised at their own initiative and without cooperation with any educational institution.

As a rule, prison education follows regular school curricula. Certificates and grades issued correspond to those issued outside prisons. Studies pursued by prisoners are credit-giving at schools they attend after release. Certificates of course completion are issued by the cooperating institutes of education.

Prisoners with day release privileges for education receive student grants according to the national student grant system. In some cases, prisoners who are studying are also eligible for student benefits under the Finnish Social Insurance Institution. When prisoners receive student benefits, these are taken into account when the prison pays their work allowance.

Number of teachers and teachers' roles

In 2001, 290 external full or part-time teachers were involved in prison education. Teachers are recruited by the cooperating educational institutions. The same eligibility requirements apply to prison teachers as to all other teachers. The cooperating educational institutions are responsible for pedagogical guidance and management of the teachers. Some teachers work both in prison schools and at other schools, some only at prison schools. In prisons, teachers are not normally involved in case management of prisoners except in relation to their education, and so they do not generally attend staff meetings.

Three prisons have some trained vocational teachers on staff. Approximately 100 ordinary prison staff members, generally not trained as teachers, also help with teaching and tutoring of the prisoners. All but one of the closed prisons have a study counsel- 
lor who helps prisoners draw up study plans, provides tutoring, and serves as a liaison officer between the prison and the cooperating institutes of education. Some prison workshop foremen are also involved in on the job training, as workplace trainers. The Deputy Governor of each prison is responsible for education administration.

Prison education and its relationship to other prison activities Since 1975, daytime educational activities have been accepted as an alternative to work. Other types of rehabilitation activities have been accepted as an alternative to work since 1995, when prisoners' obligation to work was replaced by prisoners' obligation to participate in activities. Many activities have been developed by the members of various staff groups. They differ greatly and have come into being at different times, which explains why, as a rule, they are seldom coordinated. Traditionally, prisoners have only participated in one activity at a time. Most of the prisoners who are involved in studies still study full-time.

Vocational education and prison work have always gone hand in hand. In recent decades, a closer relationship has developed between prison education and prison work activities, in pace with the increased use of apprenticeship training. Under such arrangements, practical vocational education is given by the foreman of the prison workshop, while the educational institution is responsible for theoretical education.

Rehabilitation work requires close cooperation between various personnel groups, as well as integration of activities. On the basis of long-term prisoners' needs assessments, sentence plans are drawn up, including participation in activities. The study counsellor represents the prison in planning discussions with the educational institution. (S)he also cooperates with the staff members responsible for enforcement of sentences in order to have the necessary information regarding sentence duration and possibilities of study outside the prison. Cooperation with the supervisory staff is also necessary to determine security needs in relation to educational options.

The National Board of Education evaluated prison education at two prisons in early 2003. Their report indicates that prison staff members have generally become more positive about education in 
recent years. Prison managements are supportive of arranging education and striving to develop educational options (In Finnish. English equivalent title: Assessment Report on Prison Education, Unpublished report, Finnish National Board of Education, 2003).

\section{The Prison Service}

Finland has three prison districts: South, West, and East/North. Whenever possible, prisoners are placed at prisons in the district where they are domiciled. Thus all three districts are meant to have sufficient numbers of places with varying degrees of openness and different activity options for the prisoners. There are a total of 21 independent prisons under the management of the Prison Service: 16 closed and 5 open prisons. There are also open prison units associated with some of the closed prisons. Remand and convicted prisoners are held at the same facilities, and there are no separate figures for these two categories.

\subsubsection{Education for remand prisoners}

The average number of individuals per day held in remand in Finnish prisons in 2003 was 490 . This figure is strikingly higher than just a few years ago. Remand prisoners are sent to prisons located in the district where their cases are being heard, as a rule as close to their municipality of domicile as possible. The average duration of a remand period in Finland is close to three months.

If a remand prisoner wishes to participate in prison activities, (s)he will be allowed to do so whenever possible, unless there is a need to keep him or her in isolation from other inmates. Because of the large numbers of prisoners, not all prisons are able to offer all prisoners activities at present.

Comprehensive and upper secondary education are arranged by upper secondary schools for adults or education centres in approximately half the prisons where remand prisoners are also held. In the other prisons, equivalent education can be arranged as independent study with tutoring. Tests are given and grades issued by a local educational institution.

At one prison, some university courses are offered. University education and other higher education can also be pursued at other prisons as "distance courses". Virtually all prisons where indi- 
viduals are also held in remand offer some form of vocational education, such as short ICT courses. Other courses include preparatory vocational courses or courses, for example on communication, marketing, business administration, electronics, and decontamination of industrial sites.

Remand prisoners are not allowed day release privileges, and their studies must take place in the prison. This may restrict their course options in comparison with those of convicted prisoners. Because their status is unclear they may also find it more difficult concentrate on studying.

\subsubsection{Description of prison education}

The term "prisoners" as used here covers remand prisoners, prisoners whose fines have been commuted to prison sentences, and convicted prisoners sentenced to a prison term. The latter category includes young offenders, lifetime prisoners and prisoners in solitary confinement. The majority of individuals in prison education activities (70-75\%) are convicted prisoners. However, the statistics given below also contain remand prisoners, since there are no separate statistics for the two categories.

An assessment is made of each prisoner's ability to work and his or her general functional competence with a view to being able to offer a purpose-oriented activity suited to individual needs and that will improve the capacity to cope in society. For prisoners serving long sentences (two years or more at present) a risk and needs analysis is made, and a sentence plan drawn up on the basis of this analysis in order to prevent his or her return to a life of crime. If the pending government bill for a new Imprisonment Act is accepted by the Parliament, a risk and needs assessment and a sentence plan will be made for every prisoner.

In 2003 , an average of $57 \%$ of the prisoners participated in activities during working hours. Participation rates were highest in open prison units and lowest among remand prisoners. An average of $10 \%$ of the total prison population participated in educational activities.

A total of 1,655 prisoners participated in education in 2003. The main focus was on obtaining or improving vocational competence, for which there is a broad range of course options. Thus $60 \%$ of 
the students were studied vocational subjects. According to the 2003 evaluation report published by the National Board of Education, however, there is poor correlation between the educational options offered and educational options that correspond to the real interests of individual prisoners. What tends to govern the vocational options offered is more the work situation at the prison, its traditions, and the professional backgrounds of the staff members.

\section{Vocational education}

Vocational training and preparatory courses for vocational training, are arranged at virtually all prisons as short course modules that can be combined into credit-giving segments that can be counted towards diplomas.

In 2003, vocational and preparatory courses were offered in 15 vocational areas, such as the construction, computers, mechanical engineering, metal work, wood work, automotive, transport technology, carpentry, industrial arts and gardening. Other subject areas in which courses are offered are hairdressing, massage, gym instruction, and business and administration, as well as tourism, nutrition, and domestic science.

Education given at workplaces (apprenticeship training)

This type of education has become an integral part of the work activities offered at prisons since 1994. The prison workshop foreman is responsible for the work training, while a teacher from an external educational institution usually holds the theoretical parts of the courses. Because the practical teaching tends to take place as part of the work activity at the prison, prisoners basically learn a future occupation as learning-by-doing.

\section{General education}

It is possible to receive comprehensive and upper secondary education at almost all prisons. At nine prisons, education is arranged by upper secondary schools for adults or adult education centres. At other prisons, education is arranged as independent study with tutoring. One prison offers university courses. Some prisoners, mainly prisoners serving their sentences in open prisons, have day release privileges to study at a university. 


\section{Education for women prisoners}

In one prison with both women and men prisoners, education is offered in mixed groups and women prisoners have good opportunities to participate in education. At other prisons, women have fewer educational opportunities than men.

\section{Education for young offenders}

In Finland, a young offender is defined as an individual who has been convicted of a crime committed between the ages of 15 and 20. Young offenders with sanctions of prison sentences between six months and four years in duration may be placed in a youth penitentiary by a special court decision. Most young offenders are placed in prisons where they can receive comprehensive education arranged by an upper secondary school for adults.

\section{Education for foreign prisoners and Roma prisoners}

In Finnish prisons there are foreign prisoners from 30 to 40 different countries. Foreign prisoners may participate in all prison education for which their language skills suffice which, in practice, is quite restricted. A small number of prisons offer courses in Finnish for foreigners. Literacy courses for Roma prisoners as well as courses in their language and culture and in civics, are offered at 6 prisons. Education for Roma prisoners is financed mainly by the National Board of Education.

\subsubsection{The transition from prison education to education} in the community

Day release privileges

In practice, individuals eligible for day release privileges for studies at schools outside the prison are prisoners in open prisons and prisoners approaching the end of their sentence time. In 2003, a total of 142 prisoners had day release privileges. Twenty-eight per cent of them studied at adult education centres and $43 \%$ at establishments for vocational training. Nearly one fifth of the students were studying at university or other institutions of higher education. Over the last ten years, the number of prisoners granted day release privileges for studies outside the prison has decreased quite substantially. 
Placement at an external facility

Since 1999, prisoners with drug or alcohol abuse problems or who have special problems related to managing life in society can be placed in an external facility. These are usually residential abuse treatment or rehabilitation facilities, but prisoners can also be placed at educational institutions if suitable residential arrangements can be made.

Continued studies and employment after release

If a prisoner is doing a course of study at the time of release, (s)he is encouraged to continue in the community. Prisoners studying in a programme that could lead to a diploma draw up a study plan together with the prison staff to ensure completion of the programme. According to one study, approximately one third of the prisoners who were studying in prison said they planned to continue their studies after release (Autio \& Hautamäki, 1991. In Finnish: Being a student in prison. Study experiences of prisoners attending basic or upper secondary education). More prisoners stated that they wanted to study after release than the number who had studied before their imprisonment. In practice, according to the 2003 evaluation report from the National Board of Education, more active support is needed after release to encourage former prisoners to go on with their studies.

Introductory courses are offered at some prisons to give an overview of different occupations, teach prisoners how to acquire information about the labour market and working life, and gain the necessary skills for applying for work.

Under certain conditions, prisoners may be granted day release privileges for work in civil society. In 2003 a total of 92 prisoners had such privileges. Over the last few years, the number of prisoners with day release privileges for work in civil society has decreased.

\section{Internet-based education}

Finnish prisoners do not have access to the Internet. Only prisoners with day release privileges are allowed access to the Internet, and only at their schools. Prisoners can have access to textbooks for "distance courses" of study at upper secondary school level but only through the prison's study guidance counsellor printing it out 
for them. The study guidance counsellor can also download study materials from the Internet for prisoners.

\subsubsection{Financial aspects}

The education arranged in prisons under the auspices of external schools or vocational institutes is financed by allocations from the educational authorities with supplementary funding from the prison budgets. In 2001, the educational authorities covered approximately $75 \%$ of the costs of comprehensive and upper secondary education, and The Prison Service for approximately $25 \%$.

Financing from sources external to The Prison accounted, in 2001 , for $54 \%$ of the vocational training courses offered in prisons. Courses may be funded partly or totally by the educational authorities. The educational authorities defrayed $43 \%$ of the total costs of prison education in 2001.

\subsection{The results of prison education}

\subsubsection{Quantitative results}

Approximately $10 \%$ of the prisoners participate daily in educational activities. In addition, many prisoners participate in various rehabilitation programmes or recreational activities with a social skills promoting content. Preparatory employment courses give basic skills for employment. Thus, far more prisoners are involved in learning than the number involved in prison education in the narrow sense of the term.

The results of study activities have been quantified as to the number of educational grades and certificates issued, the number of educational courses completed, and the number of certificates issued for vocational training courses. There are no dropout statistics available.

In 2003, prisoners completed over 1,000 courses in various basic educational subjects, and 850 upper secondary school courses. The most popular subjects included foreign languages, Swedish, mathematics and Finnish. Approximately 700 vocational courses were also completed. 
Quite often, prisoners are unable to complete a course during their prison term, not least because the sentence is often too short to allow for completion. Transfer to a different prison or changing from one course of studies to another are counted as dropping out. The evaluation performed by the National Board of Education at two prisons in 2003 indicates that student performance otherwise corresponds fairly well to that in society in general.

\subsubsection{Qualitative results}

A study counsellor at one prison has described the objective of her work as being to encourage prisoners to leave their cells and become interested in what the classroom has to offer. Initial positive classroom experience and communication with a prison teacher can also promote an interest in independent study. Studies contribute to making everyday life fuller for prisoners, and give them new things to think about. The ambition underpinning studies is for each student to explore his or her potential and to see the mental link between life in civil society, his or her individual future, and his or her goals regarding the time spent in prison. Later it should be possible to work on self-esteem, personal resources, growth, self-confidence, and interaction skills (Toivonen, 2002. In Finnish. English equivalent title: Studying in prison - maximising misery or providing a key to better future?).

Prisoner's opinions of prison education

In an evaluation made by the National Board of Education, prisoners stated that studies were very important in helping them adapt to society and to working life. Education also gave their time in prison greater meaning. They stated that the studies corresponded to their expectations and that the teachers were competent. Many teachers were able to individualise in a way that was supportive for the students.

Preliminary results from an ongoing study being carried out by the Finnish Criminal Sanctions Agency indicate that prisoners who study while serving their sentences cope better after release. Studies resulting in certificates also pave the way for entry into new areas of the labour market. Prisoners who study also have better potential for coping well after release because, in terms of 
background, they tend to have better employment history, better finances, better family relations and better living conditions than other categories of prisoners. Prisoners who study are, as a group, both in better physical and mental shape and have fewer housing problems than other categories of prisoners. Studying while serving a prison term contributes to maintaining both mental and physical health. Studies also appear to be more motivating than other activities, with less absenteeism and more positive attitudes.

\section{Learning difficulties}

More research is needed regarding learning problems prisoners encounter. As part of the assessment of prisoners convicted to sentences of over two years, carried out at the assessment and allocation units learning problems have begun to be taken into account. The results, based on assessment of some 160 prisoners, indicate that approximately one fourth of prisoners with sentences of long duration have learning difficulties (Hypén 2002 / 2. In Finnish: Risk and needs assessment in assessment and allocation institutions). Other reports indicate even higher proportions. According to Kivi and Malmberg, at least one third of the prisoners had serious reading and writing difficulties, and with the exception of a very few well education prisoners, virtually every individual who had ended up in prison had some kind of learning skills problem, with dyslexia being most widespread (Kivi \& Malmberg, 2002. In Finnish. English equivalent title: Out and participate. Rehabilitation experimentation in Riihimäki Prison).

Some studies indicate that the pace of school work is quite fast in prisons, causing special problems for the prisoners who found their previous schooling outside prison difficult. Individually-adapted solutions, such as individual time plans, were often conspicuously lacking. The best learning performance was demonstrated by prisoners with the ability, the will power and the opportunity to learn (Kyngäs, 2000. In Finnish. English equivalent title: Imprisonment in the course of a man's life. A study on the childhood, prison time, and life after imprisonment of men sentenced to prison as young offenders). Ulvinen's study indicates that the pace of prison school work give the impression of "forced labour". Because the educational backgrounds of prisoners are so heterogeneous, the curriculum-based prison education situation only contributes to increasing inequali- 
ty, and to frustration in relation to the objectives of prison education (Ulvinen, 1996. PhD thesis in Finnish with an English abstract: Educational Regions of Prison Life in a Setting Provided with Objectives of Correctional Treatment - Pictures at an Inhibition?).

The evaluation report from the National Board of Education also points out that the differences amongst prisoners involved in studies, in terms of their different points of departure, are not taken into account, and the reasons for study difficulties are not analysed adequately. There are insufficient financial resources to provide support measures, such as remedial teaching. One research project indicates that prison teachers felt that passivity and apathy are the greatest obstacles to be overcome when attempting to kick start the re-socialisation process (Siika-aho, 1994. In Finnish. English equivalent title: The re-socialising function of prison schools. The study is based on prison hierarchy).

The study environment

The study environment contributes to the problems. In one research report, more than half of the students surveyed described the atmosphere at the prisons as tense and jittery (Autio \& Hautamäki, 1991. In Finnish. English equivalent title: Being a student in prison. Study experiences of prisoners attending basic or upper secondary education). They described the prison school situation as understimulating, with no long-term planning. They found it difficult to concentrate, found the teaching situation dull and routine, and felt there were hardly enough textbooks, all of which made studying difficult. Some of the students, however, felt it was easier to study in prison, owing to the absence of the external temptations in the community.

One former prison student who completed a $\mathrm{PhD}$ thesis during his prison term found that even as late as during the 1990s prison staff attitudes were still subtly marked by a negative attitude towards education (Ulvinen, 1996). He also noted that prisoners were informed about educational options in a relatively passive manner, and then left entirely to their own devices when it came to applying for education and finding out more about educational options. The daily allowance paid to prisoners in educational activities was also sometimes lower than for prisoners in work activities. 


\section{Need for education}

One research report indicated that $71 \%$ of prisoners polled wanted to study while in prison (Kunnari \& Peltonen 1993. In Finnish. English equivalent title: The prisoner's educational background and willingness to receive education in Oulu Provincial Prison, Pelso Central Prison, and Kestilä Open Prison). More than half of those who wanted to study were interested in vocational education, and education they considered useful in terms of preparing them for a trade, or as further vocational training if they already had some occupational skill. Some prisoners (10-20\%) were interested in studying foreign languages, ICT, basic school subjects and upper secondary school courses. The prisoners felt that anyone who wanted an opportunity to study should have it, and they were critical of the educational options in the prisons. They also felt that the conditions applying for day release privileges for schooling should be less stringent. Assessments made at the the Prison Service assessment and allocation units indicated that approximately $40 \%$ of the prisoners serving a sentence of more than two years had educational needs (Hypén, 2002/2).

\subsubsection{The Åland islands}

The Finnish Prison legislation is also applicable to prisoners from the Åland islands, where there is no prison. Prisoners from the Åland islands are received at prisons in mainland Finland.

\section{NORWAY}

\section{$2.1 \quad$ History}

The first Norwegian house of correction was established in Trondheim around 1630 (Lie, Magnus, 1934. In Norwegian. English equivalent title: Three centuries of the Waisenhus Foundation in Trondheim, 1635-1935). From the very outset, education has been an important aspect of the prison system. Educational methods have always been one of the instruments used to socialise prisoners, as well as to give them new knowledge. The prison authorities have always had responsibility for prison education. 
In the eighteenth century houses of correction, the socialisation approach was the main strategy. In accordance with the prevailing international theories of penal sanctions, in the four houses of correction built in Norway between 1735 and 1789, the penal and correctional functions completely overlapped. Many underprivileged children were sent to houses of correction in preparation for church confirmation.

Penitentiaries - houses for isolation and prayer

By the mid-nineteenth century, the idea that a prison term would lead to correction of those who had violated the law had become firmly rooted. In 1841, a government commission report on prisons was published, and was extremely critical of the prison system, finding the enforcement of sanctions not sufficiently intimidating. Prisoners lived under such free conditions that there was no way prisoners would come out of the system having undergone any improvement, and improvement was one of the objectives of a prison terms. The principles underpinning the new Criminal Act from 1842 were those of the American "Philadelphia model", the cornerstone of which is solitary confinement. Other bearing elements of the system were acclimatisation to work and an orderly lifestyle, as well as religious and ethical education and upbringing. The key word was "discipline".

The prison built on the basis of this model and opened in 1851 was the first prison in Norway to operate on the basis of clearly established objectives, and with a true focus to its educational aspects. This was the first attempt to use an educational method as a instrument of prisoner correction. According to the regulations, prisoners were to have daily teaching in reading, religion, bible history and "when circumstances allow and when it is found potentially useful, Writing and Arithmetic". The curriculum developed more or less in accordance with the national educational legislation. Prison education was to be in line with that of the regular school system.

In the late nineteenth century new regulations were issued in relation to education at prisons for men. The central objective was that every prisoner who had not completed comprehensive (primary and lower secondary) school should do so. Prisoners were systematically assessed to determine their educational background. 
Prisoners were tested when their prison terms began and when they ended, in religious studies, reading and writing, and there are statistics through 1918/19 regarding the number of prisoners who were literate upon entering and leaving prison, as well as their knowledge in religion. The 1903 Prison Act established that individuals under the age of 18 should always have education while in prison.

\section{From accountable to disturbed}

The late nineteenth century saw a shift in the view on sanctions, criminality and prisoners. From the position that a person who violated the law was accountable for his or her actions, and therefore to be imprisoned as a punishment, according to the new view a person who violated the law was disturbed, and thus more or less destined to break the law. Deprivation of liberty was considered a way of treating the sick individual for the disease of criminality. The "treatment philosophy" underpinned various penal strategies developed into the early twentieth century, including the 1928 Act on Correctional Treatment of Young Offenders. This legislation led to the setting up of "prison workshops schools", in order to give young offenders, between the ages of 18 and 23 who had committed relatively minor crimes, correctional treatment (to improve their behaviour) and vocational training. For various reasons, no "prison workshops schools" were actually opened until 1951. Although they were intended to be an alternative to serving one's sentence in a closed prison setting, it gradually became clear that the young men placed there experienced the schools as prisons and as punishment. The legislation was revised in 1963, and the schools renamed "youth custody centres". These centres were disbanded in 1975, in conjunction with a legislative reform.

\section{New Prison Act-more education}

A new Prison Act was passed in 1958. Vocational education became an important issue both in the preparatory documents for the legislation and in the Act itself.

Educational activities on the whole, however, received surprisingly little attention and ambiguous treatment in the new Act in comparison with the emphasis placed on them in the preparatory documents. In the Act, the main emphasis was on work activities, 
which were to be pursued as daytime activities, whereas educational activities were to take place outside working hours.

In contrast, however, both the Norwegian Parliament and the Ministry of Justice adopted decisions as a consequence of which cooperation between the prison and educational authorities was to be strengthened, and efforts to this end began to be undertaken in the 1950s and 1960s. The Ministry of Educational, Cultural and Church Affairs approved certain educational options for prisons so that they could be counted for credit as vocational education. At the larger prisons, instead of having teachers employed as part of the prison staff, more and more teachers were hired externally and worked on an hourly basis.

1969 - a milestone year

In 1969 the educational authorities took over responsibility for prison education. The objective was to provide education for young offenders of school age and for young offenders with inadequate educational backgrounds.

This objective was adopted after a long struggle regarding both the content and administration of education. While the Ministry of Justice argued forcefully for the responsibility for prison education being put in the hands of the educational authorities, the Ministry of Educational, Cultural and Church Affairs was not overly eager to have yet another institutional sphere added to its brief. The Ministry already felt quite overwhelmed by all its responsibilities and was not being proactive about taking on new ones. It was, however, responsive to criticism, and gradually came to see how important prison education was for the return of prisoners to the community upon release. The great need of education for young offenders became evident to individuals working in the prison system. They succeeded in making their voices heard and their expertise clear, and their arguments eventually took root at the Ministry.

Prisoners' right to education

When the Ministry of Educational, Cultural and Church Affairs took over responsibility for prison education, this was in line with general developments in society. The 1960 s was the decade that saw the initiation of educational activities at many social and medical 
service institutions. The Ministry found itself taking on more and more educational responsibilities. One new target group at psychiatric wards, drug abuse clinics and prisons was very young people, who had previously often been school dropouts with no follow up. These young people were often already long-term abusers with very little work experience and weak educational backgrounds. This latter factor became a forceful line of reasoning when the prison service argued for prison education to be taken over by the educational authorities. At the time, special arrangements and classes were also the object of criticism, and integration became the key word: individuals with all kinds of learning difficulties were to be mainstreamed back into the regular school system. The argument put forward in relation to prisoners was that they had an inalienable right to the same social services as other citizens, despite the fact that they were in prison. (Langelid 1982, in Norwegian. Equivalent English title: Punishment and Pedagogy - two socialisation systems in conflict? The development of educational options at two Norwegian prisons, and White Paper no. 23, 1991-92).

\section{The import model}

Criminologist Nils Christie launched the import model in a presentation held in autumn 1969 entitled "Models for prison organisation" (Christie 1970). Christie considered the import model as a way of opening up the system, but place responsibility for all functions not related to prison care outside the prisons. According to Christie, the most dangerous aspect of the self-supply model is the likelihood that various groups of professionals will lose contact with the general expertise in their disciplines, as well as losing their own identities by becoming too adapted to the security measures applying in prisons. This philosophy paved the way for putting medical, library and many other services offered in prisons in the hands of external providers in the community, as is clear in a Norwegian parliamentary report On Prison and Probation Services from 1997-98.

1988 - full control by the national authorities

The agreement convened in 1988 regarding national funding of prison education, and implying that there would be $100 \%$ reim- 
bursement of all approved operational costs marked the end of a long struggle between the municipal and county authorities on the one hand and the national government on the other. According to this agreement, the state covers the cost of all approved operational expenses for comprehensive, vocational and upper secondary education for prisoners, including the "follow-up classes" for prisoners wanting to complete a course of study they began in prison after release, and which have been established in various parts of the country. The Ministry of Justice, with delegation to the Prison and Probation Service, also has responsibility for school premises.

The county authorities take over subject content and administrative responsibility

State subsidies were paid out retrospectively, after submission of accounts, on the basis of a budget adopted by the Ministry in advance. Today the system has been revised so that the county authorities are given a budget framework for educational activities, and these budgetary restrictions must be observed. Since this revision, county authorities have also taken over the subject content and administrative responsibility for comprehensive education.

In 1990, the Ministry of Educational, Cultural and Church Affairs had been responsible for prison education for twenty years, and requested a comprehensive review of prison education on the basis of these twenty years of experience. A government commission was appointed, and submitted an extensive report in 1992, containing proposals for improvements, including: a) greater emphasis on life mastery skills, b) that each county should draw up a detailed plan for prison education, c) that a forum for exchange of experience be set up so as to improve cooperation between the relevant stakeholders/authorities, d) that follow-up work be strengthened and e) that more teaching be offered in practical and creative subjects. Today, may of these proposals have been implemented both in terms of educational options and organisation (Norwegian government commission report 1992:19). 


\subsection{Legislation and regulatory documents}

The governing principle of the Norwegian Prison and Probation Service is that prisoners are to have access to the same services as other citizens, provided by other authorities than the correctional service. The import model or administrative cooperation as it is more commonly known today, is to result in normalisation to the greatest possible extent, and to openness in an otherwise closed system. This is also a way of ensuring that other authorities are held accountable for and take responsibility in the re-integration of prisoners into society.

2.2.1 The principles underpinning the work of the Prison and Probation Service

\section{Vision}

The vision for contemporary criminal policy in Norway is known as "active criminal policy - a safe, secure society" and is described in report 27 (1997-98) from the Norwegian parliament, On the Prison and Probation Service. The activities of the service are planned as described below, on the basis of the vision:

The Prison and Probation Service is society's instrument for enforcement of sentences. Sentences are to be enforced so as to ensure the safety of society and in a manner that provides the prisoner with the best possible basis for a crime-free return to society. The work of the Prison and Probation Service is to be characterised by the rule of law and by high professional standards.

The Ministry of Justice goes on to describe the main objectives of The Prison and Probation Service as two-pronged:

- to implement the sanctions determined by the prosecuting authority or the courts

- to set the best possible prerequisites for a prisoner to contribute to breaking his or her own vicious circle of criminal behaviour. 


\section{Progressive sentence serving}

The practical consequence of the parliamentary report is that a prisoner's sentence enforcement time is to be focused on activities such as education and work, and is to provide opportunities to be in contact with the surrounding world. The Ministry recommends, for prisoners who have the motivation to work on breaking their vicious circles of criminal behaviour, that a plan for "progressive sentence serving" be drawn up, by which prisoners can systematically qualify for gradual transitions towards more open facilities with more individual responsibility. The move to more and more open establishment and the use of behaviour modification programmes are important aspects of progressive sentence serving.

\section{Rights}

One important principle in this context is that prisoners are to be ensured of all their rights as citizens according to the law. This applies, for instance, in relation to the health and social services sector, the employment services and the educational system, and makes access to work, education, recreational activities and physical education important elements in paving the way for a way of life free from crime. In order to accomplish this, according to the Ministry of Justice, it is therefore essential that it be possible for other administrative bodies than the Prison and Probation Service to be able to provide the services to prisoners, while they are serving their sentences, to which they are entitled by law.

Prison education is to be implemented in accordance with the guidelines applying to the educational system in society at large. Individuals on probation are to be encompassed in the regular educational system in as far as is possible, in accordance with the principle of normalisation, although with the necessary exceptions.

\subsubsection{The 2002 Enforcement of Sentences Act}

The civil rights of prisoners are stipulated in Article 2 of the Act, and detailed in the preparatory documents, which stated that prisoners have the same rights to services and activities, and the $s$ ame obligations and responsibilities as the population at large. It is 
thus up to the Prison and Probation Service, whenever possible, to ensure that cooperating authorities are able to provide prisoners, as well as prisoners serving sentences of long duration, with the services to which they are entitled.

\section{Regional and local responsibility}

Since 1 January 2001, the Prison and Probation Service has been divided into a national administration plus regional and local administrations. Since this restructuring, the Ministry has become a more strictly political secretariat, and much of the work previously done by the Central Prison Administration has been delegated to the regional and local levels. The Prison and Probation Service has been divided into six regions, each of which is responsible for both prisons and probation services.

The new legislation gives greater clarity regarding the overall division of responsibility. Each regional Director of Prison and Probation Service is responsible for ensuring that a differentiated range of activities is offered to prisoners in the region, based on the objectives and activities plans drawn up for the national and regional Services. At local level, the activities most appropriate for each prisoner are to be determined by the prison in cooperation with the prisoner and the cooperating authorities.

\section{Prisoners' responsibility for their own rehabilitation}

The new legislation puts equal emphasis on the responsibility of the Service and of the individual prisoner for ensuring that a sanction is enforced so that it encourages a return to a crime-free life. The law stipulates that all prisoners must be involved in activities while serving their sentences. These may include:

... work, community service, education, programmes, etc. with a view to discouraging a return to criminality (Article 3 of the Enforcement of Sentences Act).

It is the responsibility of the Prison and Probation Service to ensure that prisoners are offered a range of daytime activities. The term "activities" is new, and includes work, education, programmes, and other activities. All these activities are considered equivalent, and as satisfying the requirement by which prisoners are obliged to participate in activities. 
Different kinds of sanctions

The new Enforcement of Sentences Act stipulates the following forms for implementation of all kinds of sentences involving deprivation of liberty:

a) imprisonment with a high level of security (closed prison),

b) imprisonment with a lower level of security (open prison),

c) halfway house,

d) outside prison with special conditions pursuant to Article 16, or

f) on parole under the conditions stated in Article 43 second indent.

These forms determine what activities can be offered. In accordance with the instructions for the legislation, in the majority of cases enforcement of any prison sentence or sanction involving deprivation of liberty begins in a closed prison. It is, however, at the discretion of the regional Director to assess whether an individual who has been convicted to a sentence of two years or less, but not yet incarcerated, could be placed directly in an open prison.

\section{Transfers}

The overarching principle of the new Act is that, on certain conditions, prisoners may be transferred from closed prisons to prisons with lower levels of security. The Prison and Probation Service may, for instance, consider transfer to a prison with a lower level of security when there is one year remaining until a prisoner is eligible for parole. In addition, prisoners may be transferred from prisons with high or low security levels to halfway houses after having served part of their sentence. In assessing the possibilities for such transfers, planned and initiated activities, such as education or work with a view to re-integration after release are to be taken into account. The Prison and Probation Service is to contact the educational and social service authorities, the employment services, etc., to prepare a transfer being considered, and to ensure continuity of planning for the individual.

The activity options in a prison will always reflect, on a smaller scale, activities offered in society at large. On the basis of the principle of normalisation and of the objective of giving prisoners access to the same services as other citizens, it is important to be 
aware of what is possible, pursuant to relevant legislation, for prisoners to do in terms of participating in activities offered outside the prison. The Act offers two possibilities in this respect: enforcement of a sentence outside the prison on special conditions, and use of day release privileges.

Serving one's sentence outside the prison

"Enforcement of a sentence outside the prison on special conditions" is of particular interest in relation to education and work. The stipulations of the law are that when it is necessary and appropriate to ensure continued positive development and to counteract recidivism, the Prison and Probation Service may transfer a prisoner for implementation of a sentence outside the prison on special conditions after (s)he has served half the sentence. On prerequisite for implementation of a sentence outside the prison is that the prisoner has a permanent domicile and is pursuing activities such as work, education, etc.

\section{Day release privileges}

Day release privileges make it possible for the Prison and Probation Service to give prisoners access to work, education, programmes, etc. outside the prison if there are no security considerations which speak against the use of privileges. Criteria for eligibility for day release privileges have been specified: the prisoner must have been deprived of his or her liberty for at least 4 consecutive months and must have served one third of the sentence duration. As a rule, day release privileges are not to be granted for longer than one year, with one exception: day release privileges for education may be granted for up to two years if the education in question is one aspect of the prisoner's comprehensive educational plan. As a rule, day release privileges are granted to prisoners at prisons with lower levels of security, or at halfway houses. In exceptional cases, however, it is possible for a prisoner in a high security prison to be granted day release privileges.

Prisoners serving prison terms may be granted a daily allowance for participation in work, programmes, education, etc., all of which activities are to be considered as on equal terms. The central administration of the Prison and Probation Service carries out an annual review of the size of this allowance (currently EUR 5,5 per day) and of the detailed terms regulating it. 


\subsubsection{The Education Act}

The Education Act that came into force in Norway in 1998 replaces the following previous legislation: the Primary and Lower Secondary Education Act, the Act on Upper Secondary Education and Vocational Training, and parts of the Adult Education Act.

New rights even for prisoners

All citizens have a right and an obligation to complete comprehensive school, and anyone who has completed comprehensive school has the right to three years of upper secondary, including vocational, education. The most recent amendments to the Education Act are of particular relevance for prison education under the auspices of the Prison and Probation Service. Adults born before 1 January 1978 have a statutory right to upper secondary education. The majority of prisoners are between 21 and 40 years of age. The proportion of the prison population not having completed comprehensive education is far higher than in the general population. The amendment gives more people the right to upper secondary education. And another amendment which came into force on 1 August 2002 states that adults have the right to go back and supplement their comprehensive school, and to special education. These amendments are of particular significance for Norwegian prisoners.

In addition, the Education Act has a separate chapter on "Upper secondary level education at workplaces", which is relevant to prison education. Many of the workshops in Norwegian prisons have been granted the status of "educational workplaces", which means that prisoners can be accepted as apprentices and trainees (Article 4). The prison workshop (or the prison) receives a grant of a specific sum per prisoner/pupil who has been accepted as an apprentice or trainee. If there is good cooperation between the prison school and the prison workshop, prisoners will receive theoretical education in the classroom and practical training in the workshop. This makes it possible for the prison schools and the prisons to make a larger number of educational options available. 


\subsection{Description of the relationship of prison education to the state education system}

\subsubsection{Description of prison education}

\section{Objective of prison education}

The objective of education in the Norwegian Prison system, as stated by the Ministry of Education and Research, is to give comprehensive and upper secondary education to prisoners in Norwegian prisons. In addition, courses that do not result in formal competence should also be offered. Individuals wishing to pursue education beyond upper secondary level, such as university or higher education, are outside the remit of this definition, and must manage on their own or with the support of The Prison and Probation Service. Today, several prison schools and institutes of higher education are assisting prisoners who wish to pursue education at that level (Draft bill no. 12001-2002 from the Ministry of Educational, Cultural and Church Affairs).

\section{Organisation}

The Ministry of Education and Research has delegated national responsibility for education to the Hordaland Office of the County Governor. These responsibilities include: on the basis of specific criteria, to disburse the annual budget as adopted by the Norwegian parliament to the county authorities. In its capacity as supervisory authority, the Office is to audit the annual accounts of the county authorities and submit an annual report of activities. The Office is also to stimulate pedagogical and developmental work in the area of prison education.

With the exception of prison education in Oslo municipality, where responsibility for prison education rests with an adult education centre, prison education is organised as follows: an upper secondary school takes the overall responsibility for the education offered in each prison, and the prison school operates as a branch of that main school. Formally, the teachers are in the employment of the main school, which also issues testimonials and certificates for the prison school students. The same administrative system applies to the teaching given in follow-up classes outside the prison. 
The place of prison education in the Prison and Probation Service Draft bills, parliamentary reports, and allocation assignments in recent years have all stressed the importance of cooperation amongst the relevant authorities - administrative cooperation. One of the overarching goals of this cooperation is to make the release process as positive as possible for the prisoner This is only possible if other authorities beyond the Prison and Probation Service also shoulder their responsibility for reliably providing the services to which they are legally committed. These include the educational authorities, the prison chaplains, the municipal health and medical services, the county dental services and specialist services, the local social services, the library services and the employment services.

\section{Areas of cooperation}

The Prison and Probation Service contains many different personnel categories. This makes it important to find areas of cooperation so that existing resources are well utilised for prisoners. The following areas for cooperation can include stakeholders from the prison education side:

a) At national level - the prison and probation education coordination committee

The prison and probation education coordination committee was established in 1975, and has representatives from the Ministry of Justice, the Ministry of Education and Research and the Office of the County Governor of Hordaland. At their meetings, strategic issues are discussed, and information about each other's activities exchanged (including information relating to the Education Act and the Sentence enforcement Act). Since 2001, the Ministry of Education and Research has delegated the appointment of its representative on the coordination committee, first to the National Board of Education and later to the Directorate for Primary and Secondary Education.

b) at county level

In order to strengthen cooperation in the regions, the Office of the County Governor of Hordaland has asked the other county governors to take the initiative to establishing a specialist forum in each region, with management level representatives from the board of 
education, The Prison and Probation Service, the county employment service, the police, and others. The objective is to bring these people together to discuss and develop prison educational activities, to reinforce follow-up work, and to find good routines for cooperation.

The Office of the County Governor of Hordaland has also requested the county administration with administrative responsibility for education in prison to draw up regional plans for prison education. The working party should include representatives of the regional educational authorities, the Office of the County Governor, the schools, the Prison and Probation Service and other relevant stakeholders. Their remit is, on the basis of the current situation, to: 1) evaluate previous practices, 2) set out recommendations for the content and organisation of education, taking into account: the prison population (duration of sentence, convicted prisoners / individuals being held in remand, etc.), prisoner's educational needs, the labour market situation, the need of follow up after release and 3) set out proposals for cooperation routines for the parties involved.

To date, some counties have drawn up solid plans and set up professional networks that function well, while work in other counties has been less satisfactory. Where things have gone smoothly, efforts are now being made to find new solutions instead of concentrating on the impediments to progress.

\subsubsection{Education for individuals in remand}

Norway does not have separate remand centres. Individuals in remand are incarcerated in the same facilities as convicted prisoners serving their sentences. Approximately one third of the individuals registered at these facilities each year are individuals in remand, and they occupy about one fourth of all the prison places available, and account for a large number of those involved in educational activities (Annual statistics from the Prison and Probation Service, 2003). In 2003 , over $25 \%$ of the incarcerated individuals were individuals in remand, and this group represented approximately $20 \%$ of the individuals involved in educational activities.

No separate statistics are kept regarding which educational activities occupy individuals in remand. Individuals in remand may, under special conditions involving a ban on correspondence and 
visitation, if need be, receive individual tuition. Individuals in remand who are not subject to restrictions can attend prison educational activities together with prisoners serving their sentences.

\subsubsection{Education for prisoners and individuals in remand}

Since 1996, prison schools have submitted annual reports on a standard form to the Hordaland Office of the County Governor. On the basis of the information given in these forms, the County Governor draws up an annual report on education in Norwegian prisons. The form has five main headings: On the prison and the prison population, on the prison school, on prisoners/prisoners who have been released, on the students and prison education summary for the year.

Beginning in 2001, the form also contains qualitative questions on various aspects of cooperation with the prison, the standard of the school facilities, use of ICT, and other comments on educational activities.

\section{Scope}

In 2003, there were prison schools in 34 of the 42 prisons in Norway. There were also ten follow-up classes for prisoners after release, so that they can continue education they begin in prison. The total prison capacity in these 34 prisons was 2,357 places. There were 1,611 prisoners serving sentences and 537 individuals in remand. There were 943 full-time school places: 780 in prison schools and 163 in follow-up classes. The total number of teachers, working full and part-time, was 300, corresponding to approximately 190 full-time teaching positions. Just over one third were filled by women $(37.3 \%)$.

Since 1997 there has been a steady decline in the number of school places for comprehensive schooling. In 2003, only $11 \%$ of the places were for comprehensive schooling, as compared with $16 \%$ in 2000 . There are two possible explanations for this decline: either more prisoners have completed comprehensive school than used to be the case, or prison schools have become more flexible about adapting the educational options to the prisoners' needs, and that this happened at a time when most prison sentences are of short duration. Many prison schools, however, reported that although they had students doing upper secondary level courses, 
they actually spent a lot of time reviewing and brushing up basic knowledge from comprehensive school. Because many adults find going to comprehensive school de-motivating, it can be assumed that although many prisoners are registered as doing upper secondary level courses, a great deal of the teaching being done is basic.

\section{Educational options}

More than half of the study places offered as upper secondary level courses are in upper secondary level subjects. The group doing "other courses" is of about the same size as in previous years.

The distribution of study places into educational options for 2003 was:

- Comprehensive school-9\%

- Upper secondary school - 54\%

- Other courses $-37 \%$ (other courses are defined as short courses, often not credit-giving).

- Upper secondary level courses

The two main study orientations at upper secondary level in prison education are general, business and administrative studies and engineering and mechanical trades. These account for almost three quarters of the study places. In addition, there are courses in woodworking trades, hotel and food processing trades, building and construction trades, agriculture, fishing and forestry, arts, crafts and design, technical building trades, and music, dance and drama.

\section{Other courses}

Under this heading, more, shorter courses are now being offered, with greater variation. These include arts and crafts, Norwegian as a second language, practice in residential skills, painting, welding, music, and computer studies. Courses in creative and practical subjects can be helpful in developing prisoner's self-confidence and motivation, and providing them with a sense of meaning. The fact that many prison schools are offering more and more short courses appears to be better in line with the needs of the prisoners who want to study. Short courses can also be good kick-offs, encouraging prisoners to take an interest in some subject that will, in turn, help them find it easier to go on to more coherent study programmes. 


\section{ICT}

ICT has become and will remain for the foreseeable future, a subject requiring a great deal of attention on the part of both the educational and the prison and probation authorities. The Norwegian government gives high priority to education in and use of new technology in the classroom, see ICT skills programme 2004-2008 (from the Ministry of Education and Research, in Norwegian only). The four main aims of this programme are:

- In 2008, Norwegian educational institutions will have access to ICT infrastructure and service of high quality.

- In 2008 ICT skills will be central to education at all levels. Every student, in schools and at universities and colleges and elsewhere, will know how to use ICT in safe, confident and creative ways to develop the knowledge and skills they need in order to be fully-fledged members of society.

- In 2008, the Norwegian educational system will be one of the cutting-edge systems in the world in terms of the development and educational uses of ICT in teaching and learning.

- In 2008, ICT will be an integral tool for innovation and quality improvements in Norwegian education, based on organisational structures and working forms which promote learning and creativity.

All prison schools have reported that the have integrated use of ICT into subject teaching or as a teaching tool. Some have introduced an ICT "driving licence" course (ECDL), a modular course with tests after each stage, with international certification. However, most prison schools also say that they do not have access to use of the Internet in the teaching situation, and that they experience this as a problem in that they are lagging behind the regular school system.

Today, ICT skills are essential for students. More and more teaching materials are going to be Internet based, and completing diplomas is increasingly going to require access to the Internet. Because most prison education still takes place without access to the Internet, it is not in compliance with the legislation and regulations, and is not keeping step with education in the state school system as a whole. Curricula are national and compulsory. ICT will, in the future, be an integral part of all teaching, and those who do 
not have full mastery of it will be severely handicapped on the labour market and in civil society. It is therefore important to find solutions that satisfy the needs of both the educational authorities and the Prison and Probation Service. In 2003, the Ministry of Justice, through the Central Prison and Probation Administration, authorised use of the Internet and e-mail in prison education under strictly regulated conditions.

Comprehensive level (primary and lower secondary) education for adults

The curricula for this type of education are now module based, in order to satisfy the differing needs of adults for education. Some people wish to study specific subjects, others to study alongside fulltime employment. There are also individuals who find entering a complete comprehensive school programme overly intimidating. The initiative to this change came from the prison schools, as did the idea of making adult upper secondary education curricula module based.

Cooperation between vocational education and prison workshops One recurrent problem for the Norwegian Prison and Probation Service has been how to organise smooth cooperation between prison schools and workshops. The position of the Ministry of Justice is that such cooperation is desirable so that various activities can be combined in a more goal-oriented and flexible fashion. Many prison workshops are authorised educational institutions. This should facilitate cooperation and make it possible for prisoners to receive practical training in the prison workshop and theoretical education in the prison school. According to the Ministry of Justice, the main aim of prison workshops is to contribute to vocational training, education and skills enhancement for the prisoners.

Closer cooperation between the prison workshop, the prison school, the vocational training authorities and the labour market authorities will make it possible to offer a considerably larger range of educational options. In the 2003 annual report on prison education from the office of the County Governor of Hordaland, more than half of the prison schools stated that they had good cooperation with their prison workshops. Thus there is a strong foundation on which to build further cooperation. 
Routines should be implemented to enable the non-formal learning of each prisoner to be assessed. This would enable prisoners to participate in the opportunities offered by the recent "non-formal learning reform". The Norwegian concept of "realkompetanse" refers to all formal, non-formal and informal learning acquired by adults. In practice, this means the sum of all overall skills individuals have acquired through the education system, paid and unpaid work, organisational activities and family life/life in society.. The adult education authorities have granted the formal authorisation to carry out non-formal learning assessments to upper secondary schools. After an assessment has been carried out, the individual can then begin his or her adult education, which can lead to an educational qualifications, vocational qualifications or lower level qualifications (apprentice or craft certificate, or possibly more realistically a certificate of competence as an unskilled or manual labourer). Efforts are also under way to make everyday life in prison more flexible, with a broader combination of work, educational and programme activities.

Cooperation between prison education and other programmes In recent years, the Prison and Probation Service has increased the number of programme activities greatly. This also requires a new approach on the part of the educational authorities. Many schools have reported that it has become more difficult to recruit students because there is so much competition for the prisoners' time. In the 2003 report from the Office of the Hordaland County Governor, it is clear that prison schools have been slow to shift orientation or rethink in relation to other programme activities in the prisons.

Constructive cooperation between the Prison and Probation Service and the prison school should make it possible to find satisfactory solutions for the best of the prisoners / students. For example, it might be possible to divide the day up between schooling, programme activities and work.

\section{Cooperation between prison education and other actors}

Briefly, cooperation differs greatly in different areas, being smoothest with the prison workshop. The employment service is also highlighted as a positive player in cooperation, while cooperation 
between the prison school and the programme activities appears to be worst. There is a need for better cooperation in relation to prisoners' sentence plans. Although there have been improvements in this cooperation, some prisoners still have no comprehensive plan drawn up by the Prison and Probation Service. The prisoner is the loser in these cases, having to decide about various options being offered from different providers without an overview. A great deal remains to be done in this respect, and responsibility for coordination rests with the Prison and Probation Service.

According to the Ministry of Justice, a sentence plan is to be based on:

... the criminal record of the individual prisoner, and is to be individualised and goal-oriented. The plan is to use a solution-based approach and deal with issues relating to work and education for the prisoner, participation in programmes, recreational activities, etc.

Clearly, if sentence plans are to be focused and structured, the prison school must be involved in drawing them up, as well as the other actors. The prison Governor has the ultimate responsibility for administrative cooperation at each prison.

\section{University and higher education}

Many prison schools are beginning to offer structure and counselling for prisoners who wish to take up university or other higher education. The social service officer at each prison can help arrange student grants for textbooks, and sometimes even supplementary tuition. Most prisoners who begin university studies are in closed prisons, and are often prisoners serving long sentences. In many prisons, a number of independent study places are allocated to higher education. Prisoner's access to university and other higher education in Norway is poorly organised and structured today.

\section{Women prisoners}

In 2003, more than one third of the women prisoners were engaged in educational activities, which is a higher figure than in the past. A larger proportion of women prisoners than of men prisoners are involved in education. However, women prisoners have fewer 
other activity options than their male counterparts. For example, there are very few opportunities for women prisoners to participate in vocational training.

Foreign prisoners

Increasing numbers of foreign prisoners are getting prison education. In 2003, nearly one sixth of the students were foreigners. Approximately 50 percent of these foreign students were at the four largest prisons.

The rules for financing are ambiguous for this group. In spite of clear recommendations from the Council of Europe stating that special attention is to be paid to foreign citizens with language difficulties, the Norwegian regulations have shortcomings in this respect. Adult immigrants in Norway have a right lessons in the Norwegian language and civics up to a certain level. It remains uncertain, however, whether foreign prisoners are covered by this stipulation.

Ages

Students in prison schools are adults. Nearly three quarters of the prison students are between 23 and 49. Nearly half are between 31 and 50. The age group $41-60$ comprises $11 \%$ of the total number of students. The student group between 15 and 22 years of age, comprises around $15 \%$ in 2003 . The age distribution in the followup classes is roughly the same as above.

\subsubsection{The transition from prison education to} education/work in the community

Prisoners have problems of many kinds to deal with, and being in prison only adds to them The time around release is the most difficult. Problems include: finances, housing, school/work, leisure time, drink/drug abuse, health, and finding a secure, safe social context. A great deal remains to be done in terms of the transition phase. In a report from 1981, now a classic work on Norwegian prison education, Skaalvik and Stenby wrote: 
Very little was done to prepare for release. Prisoners were left to their own devices from the moment they were released. Prison education was not part of any long-term plan. Neither the employment service, the Probation Service or the school board were involved in any systematic efforts to structure life for the prisoners after release (Einar M. Skaalvik and Hans K. Stenby. In Norwegian. English equivalent title: School Behind Bars, 1981).

Many other evaluation and research reports reached the same conclusions, and it gradually became clear that something had to be done to facilitate things for prisoners upon release. In the 1970s, and even more so in the 1980s, follow-up classes were established in different parts of Norway, much thanks to the research done by Skaalvik and Stenby. Most of these programmes are based on collaboration between the educational authorities and the probation service. Today there are follow-up classes in ten places in Norway. Of the total of 943 student places in prison education, 163 are in follow-up classes. The subjects offered in the follow-up classes tend to be relatively restricted, with virtually only comprehensive and upper secondary courses given. Towards the end of their sentences, some prisoners also have day release privileges from low security establishments to schools in the community, adult education centres, universities, etc.

The good life-more than just education

Fridhov interviewed a sample of individuals on probation regarding the most decisive factors for managing to live a law abiding life in the future. The most important factors given were: fixed domicile, secure job, meaningful leisure time activities and clean, sober friends. The next most important group of factors mentioned were abuse programmes and education, while marriage and faith in God were much farther down the list (Fridhov, 1993. In Norwegian. English equivalent title: The Prisoner in the Prison and Probation Service 1992).

A Swedish researcher has pointed out the importance of developing long-lasting, personal contacts and relationships, and of the timing of programmes, as well as that a prison sentence only has a preventive effect for individuals who have contacts outside the world of crime (Chylicki, 1992. In Swedish. English equivalent title: Cutting Out Crime. Ways out of a Career in Crime). 
A Danish $\mathrm{PhD}$ thesis points out that those who commit crimes in Denmark today are, to a greater extent than in the past, marginalised individuals who have been excluded from ordinary society. The unemployed run a great risk of developing criminal behaviour - he found that individuals who have no contact with the labour market commit three times as many crimes as the general population (Kyvsgaard, 1998. In Danish. English equivalent title: A Criminal Career).

Both research and practical work indicate clearly that education cannot be considered in isolation. There can only be successful rehabilitation if all the other factors: housing, finances, social network, leisure time activities, drug and drink have been handled successfully. In other word, collaboration amongst the relevant authorities is needed. It is also clear in a report from the Norwegian parliament that this is an area where a great deal needs to be done (Parliamentary report no. 23 (1991-92)). The report indicates that criminality costs Norwegian society at least EUR 4.6 billion annually, and highlights the importance of reducing recidivism.

Reinforcement of prison education and follow-up after release Over the courses of the 1990s, the Norwegian parliament and government have reinforced follow-up work in various ways. It has also become clear that prisoners must take as much personal responsibility as possible for living a crime-free life and for their own reintegration in society. The Prison and Probation Service must also cooperate closely with other authorities such as the school board, the social and health and medical services and the employment service if integration is to be successful (White paper no. 1, Ministry of Justice, 1994-95). A report from 1997 points out a number of areas where there are shortcomings in terms of collaboration, distribution of responsibilities, networking, financing, etc. (In Norwegian. English equivalent title Back to Society? Report from the National Education Office in Hordaland 1997).

One important aspect of this work is to find good strategies for change that will help break down the barriers between professional services. Poor inter-agency cooperation leads to resource waste, with major negative consequences for individuals needing help. Another problem is the way in which each service sees the individual requiring help as a "client" rather than as a person. Thus 
the individual goes from service to service and as to start over again from square one each time in his or her efforts to make ends meet. Prisoners and former prisoners have stated the need for a different kind of follow-up. They would like to have one single liaison officer who would help them deal with the different agencies (Gåsemyr, 1999. In Norwegian. English equivalent title: Education for Prisoners). In a pilot project at the follow-up class in Steinkjer a new approach is being tried, by which the student calls the representatives of the relevant authorities for his or her case to a meeting. The student then chairs the meeting, and writes a report after it. This puts the focus on the student, encourages self-confidence, and gives the authorities the opportunity to try a new form for cooperation (Halvorsen, 2001. In Norwegian. English equivalent title: The Student and the Good Assistant. Ingebrigtsen and Susegg, 2001. In Norwegian. English equivalent title: Making Mastery an Experience and Society an Option).

\subsubsection{Financial aspects}

Most of the costs of prison education are covered by the educational authorities. However, the Prison and Probation Service pays the daily allowance to prisoners involved in educational activities as well as the costs for prisoners with day release privileges for schooling.

In 2003, the total budget allocated by the Norwegian parliament for prison education was EUR 12,200,000. This sum covers everything having to do with prison education and follow-up classes. Most of the funding (85-90\%), goes to teachers' salaries and administration. The rest goes to equipment, textbooks, skills enhancement, etc.

\subsection{The results of prison education}

\subsubsection{Quantitative results}

Number of students

In 2003 the number of new prisoners registered in Norwegian prisons was 11,090 . The average number of students per day in 
prison education was 943 , with a total of more than 4,100 individuals (prisoners and released former prisoners) involved in educational activities of short or long duration. It is positive that so many individuals are able to take part in educational activities, and thus gain motivation to go on with their education. There are major differences between the prisons in terms of the stability of the student group. In large, closed prisons where many of the prisoners are serving long sentences, the same students may attend school for the whole year, while in small prisons where many of the prisoners are serving short sentences, there is considerable turnover.

\section{Dropouts}

The large number of people who participate in educational activities in relation to the number of study places reflects some instability in the school situation in may prisons. In 2003 there were a total of 1,527 dropouts from educational activities, a fairly stable figure in comparison with the previous year. Half of these were individuals who dropped out at release. Transfers to other prisons or disciplinary sanctions accounted for $16 \%$ of the dropouts. The dropout rate owing to demotivation (particularly in prison schools) was approximately $7 \%$. Drink and drug abuse (accounts for a dropout rate of $3 \%$ in the follow-up classes) is a problem that often leads to dropping out of follow-up classes.

Number of certificates/diplomas issued

Six hundred students received one or more certificates or diplomas. More than half of these were issued for upper secondary studies, mainly pursued in the prison schools. Some 1,200 students completed short, non-credit courses.

\section{Continued education after release from prison}

Norwegian statistics are not very good in this area. The total student capacity in follow-up classes is 163 places. There are also students who leave prison and enter the state school system (upper secondary school, an adult education centre, a university or institute of higher education) rather than a follow-up class. There is evidence that many former prisoners work hard to establish good contact with the state school system, but there are no statistics as 
to how many actually participate in state schooling. The prevailing principle should be that any educational activity begun in prison should be part of a comprehensive plan, and that the prisoner should have something to go to (work or school) upon release.

\subsubsection{Qualitative results}

Prison routines and rules are obstacles to attending school Skaalvik and Stenby's study, School Behind Bars (see p. 88 above) is based on conditions from the Trondheim regional prison, and contains many interesting conclusions. Not surprisingly, they found that the introduction of schools into the prison system took place on the terms of the established prison institution. They continued:

Routines and rules in the prison contribute to preventing prisoners from attending school, and exacerbate their difficulties in completing their courses. We have found repeated examples of conflicts of interest between the prison and the prison school, which are always resolved to the detriment of the school.

Students are satisfied with prison schools

Another, more positive conclusion was the finding in relation to attitudes towards and satisfaction with prison schooling. Students were pleased with the prison school and their attitudes were extremely positive. According to the authors, this came as something of a surprise to them, but they saw three possible, interrelated explanations:

a) Prison school is a contrast to other prison activities.

b) Prison students are more mature than they were when they attended regular school.

c) Prison schools have succeeded in adapting the teaching and demands to the students, and in providing the students with security and contact.

The results indicate that even prisoners who had quite negative attitudes towards prison in general sometimes had positive attitudes towards prison school. 


\section{Committee for the assessment of school activities}

In 1990, the then Ministry for Education and Research appointed a commission to assess school activities in prisons. Their main aim was to survey prisoners' social and educational backgrounds. Their most surprising finding was that the general prison population was now older than in the past, over 25 rather than under 25 , and there were more unemployed individuals who had not had unemployment benefit. Only $30 \%$ of the prisoners actually had work experience. They also found that there was still a large group with reading and writing difficulties (23\%) and that $50 \%$ of the prisoners studied said that they needed remedial education in mathematics. All in all, prisoners lagged behind in their educations, in spite of the fact that a slightly larger number than before had completed comprehensive school. The main type of education being requested by prisoners was practical courses. Many said they would be interested in courses in computer studies and foreign languages. All the prisoners interviewed were agreed that educational opportunities while in prison were extremely important.

Continuing education projects for teachers and prison officers

Between 1988 and 1992, the Ministry of Educational, Cultural and Church Affairs ran an extensive continuing educational project, in collaboration with the Ministry of Justice, for teachers and prison officers. The aims were to:

- improve cooperation between teachers and prison officers,

- increase the professional competence of teachers and prison officers,

- better utilise the school capacity,

- be able to offer prisoners a broader range of course options.

The evaluation indicates that the project was considered positive. The terms and conditions for further training of teachers and prison officers improved in several prisons. New equipment was acquired and facilities were expanded and refurbished. However, the project probably did not have many positive effects in terms of new alternatives in the range of course options for prisoners. The range was extended with "traditional prison occupations" such as welding, woodworking and mechanical trades. The project also revealed major shortcomings in the prison system, including the 
need to do more to improve the options available to prisoners. According to Rognaldsen, the evaluating author, better management is needed at all levels of the prison system, and central management must ensure that long-term, holistic plans for prison activities are drawn up (Rognaldsen, 1993. In Norwegian. English equivalent title: From prison education to upper secondary school/working life).

Survey of prisoner's living conditions

Skardhammar has carried out a comprehensive survey of the living conditions of Norwegian prisoners, based on a corresponding survey in the general population and, in line with that survey, covering upbringing, education, professional experiences, finances, health, etc. The study was made on a representative sample of 247 prisoners in Norwegian prisons in spring 2000. It found that prisoners as a group are in a substantially weaker position than the general population in virtually all areas investigated (Skardhammar, 2002. In Norwegian. English equivalent title: The living conditions and life situations of Norwegian prisoners).

Prisoners had a much higher opinion of prison schooling than of the prison work arrangements. Formal educational background tended to be poor. Prisoners also have little or negative work experience and very little if any connection to the labour market, which was also putting higher and higher demands regarding all-round competence for many kinds of work. According to Skardhammar, if work activities in prison are meant to have a rehabilitating effect, work should also result in formal competence raising, so that prisoners were able to gain the competence they needed in order to enter the ordinary labour market. Skardhamar refers to Simon (Prisoners' Work and Vocational Training, 1999), who points out that if prison work is to give any real labour market competence, it will have to fulfil certain requirements. Firstly, the work itself must be adapted to the regular labour market outside the prison, such that the work taught in prison is useful even in the community. In the new labour market in the western world there will be very little use for industrial work skills, and more emphasis will be placed on individual competence, with ICT skills needed at all levels. Work contracts of short duration will also be more common in the future, inter alia. Work activities in prison must follow these trends and provide work in areas where it is realistic to believe there will be jobs to be had, in the future, outside the prison as well. 


\section{Research-based evaluations}

By way of conclusion of this section, we would like to describe the extensive research-based evaluation the Norwegian parliament requested the government to commission in 1998. The parliament unanimously requested a research-based evaluation of the role of prison education and proposals for measures to strengthen this area of the Prison and Probation Service. The evaluation examined the system level, the pedagogical organisation and the individual level. The research project was completed in 2003. The summary of the key findings is as follows:

Prison education was consistently positively evaluated by the prisoners. There was consensus among prison school students that attending school was rewarding. Prison school students often have inadequate educational backgrounds and negative experience from their previous school situations in the community. They felt that prison education provided a good opportunity to gain selfconfidence and motivation to continue schooling. With all this in mind, the evaluation reports pinpoint various measures that should be launched by the educational authorities, the Prison and Probation Service and other key stakeholders, to strengthen the area of prison education:

- More subjects could be offered, including more vocational education, creative subjects, short credit-giving courses, ICT courses.

- Better cooperation and integration are needed between the work and school activities offered in prison, in order to provide more educational options.

- Better guidance and advisory services are needed in relation to educational and vocational options.

- Educational options need to be more flexible and varied for different age groups, for women and men, in relation to minority languages, in relation to all prisoners with a right to education, and in relation to prisoners serving both long and short sentences.

- More needs to be done to coordinate measures undertaken by the different stakeholders both in prison and after release, in terms of "sentence plans" and the work done by personal contact officers. 
- Follow up after release needs to be reinforced.

- Day release privileges for schooling should be more regularly used.

- Sentence enforcement has been seen as an end in itself, and as superordinate to all other activities. This poses obstacles to good resource utilisation and makes it difficult to provide prisoners with systematic, integrated, structured education.

According to Skaalvik, Finbak and Pettersen the aim of prison education has not been clearly elucidated. Neither teachers nor other prison staff know what the official objectives are, or in what documents they can be found. The authors describe prison schools as organised according to the same model as and as branches of state upper secondary schools. When prison schools are subordinate to a larger institution with a very special type of organisation unlike most other institutions in society, it becomes difficult to provide continuity and follow up. The linking up of prison education with the municipal system and with state upper secondary schools did not have the expected effects. Both Rognaldsen and Skaalvik et al. are of the opinion that the national level management of prison education (delegated to the Office of the Hordaland County Governor) should be reinforced and extended (Rognaldsen, 2003. In Norwegian. English equivalent title: Assessment of prison education with the emphasis on the systemic level and the full range of educational activities in the prison service), (Skaalvik, Finbak and Pettersen, 2003. In Norwegian. English equivalent title: Education in Prison: on an even keel?).

Educational options for women prisoners have long been criticised as being too restrictive, offering too little variation, and being poorly adapted to the female prison population. In her evaluation of education for women prisoners, Sandvik indicates that like the general female population, the female prison population is a varied group with different educational needs. Sandvik points out many obstacles in terms of structures, traditions, the layout of prison premises, and subject areas, all of which result in discrimination of women prisoners in comparison with their male counterparts. In Sandvik's view, women prisoners should be encouraged to a greater extent to study vocational subjects, more ICT 
courses should be offered, and the range of educational options should be extended to include more practical subjects such as creative arts, music, dance and drama, gardening and animal husbandry (Sandvik, 2003. In Norwegian. English equivalent title: What's Right for Women? Education of Female Prisoners in Four Norwegian Prisons).

The proportion of foreign prisoners in the Norwegian prison population is rising. Viljugrein has evaluated prison education for foreign male prisoners and found that they, too experience schooling in an extremely positive light. In Viljugrein's view, Norwegian language courses should also be offered that are adapted to the needs of the various groups of foreign prisoner. Many prisoners who are second generation immigrants have problems with Norwegian, in spite of having attended state comprehensive and upper secondary school. This is a serious signal to the state school system, that language and Norwegian classes for immigrants need to be reinforced. According to Viljugrein, foreign prisoners who are not interested in learning Norwegian ought to be offered English classes (Viljugrein, 2002. In Norwegian. English equivalent title: Leaingrn, Language, and Prison: Teaching male minority-language prisoners in four Norwegian prisons).

In spring 2005, the Norwegian government will present a White Paper to parliament on prison education. The contents of the bill will be based to some extent on the research-based evaluation described above.

\section{SWEDEN}

\subsection{History}

Prison education has taken different forms in the Swedish prison system over time. In the nineteenth century the clergy were very important, particularly in teaching reading skills. Ambitions in terms of thinking that prisoners should also learn a trade or vocational skills have also been documented. For example, in 1874 the Uppsala county prison employed a person skilled in carpentry to teach vocational skills. An annual report from 1889 reads: 
As long as mechanical, monotonous work from which they [prisoners] can learn very little is all they are offered, it will be easy for their thoughts and lively imaginations to be occupied with demoralizing ideas (as quoted in Arnelund, 1994. In Swedish. English equivalent title: History of the Uppsala Prison).

In the early twentieth century, Arnelund notes, prisoners were only allowed to write one letter per month, although there were also various privileged exceptions. The right of the prisoner to reading was, however, generally extremely restricted. All a prisoner was actually permitted to study were the "cell books", i.e. the New Testament, the hymnal and a devotional volume with the English equivalent title: In Solitary Hours.

The general prison system was based on incarceration in individual cells. Prisoners were not meant to be in contact with each other, because they might influence one another negatively. Once the Comprehensive School Statue was put into effect in 1842, all prisoners under the age of 35 had to participate in educational activities. This made the correctional system quite pioneering in the area of adult education in Sweden. From the early twentieth century a progressive system was introduced, by which good behaviour was awarded with the right to read non-fiction and other literature with religious and ethical or educational and generally useful content from the prison library (Eriksson. Two works, both in Swedish. English equivalent titles: On the Treatment of Criminals, 1966, Prison Custody, 1967). In accordance with the principle of single cell prisons, the classrooms were constructed so that prisoners sat and studied in little cubicles and were able to see the teacher but not their fellow prisoners (Lundberg, 1997. In Swedish. English equivalent title: Härlanda Prison: a mirror of its time).

The dominance of the folk high schools

With the introduction of the 1916 Enforcement of Sentences Act and the reform of sentence enforcement regulations in the 1940s, prisoners began to be allowed to spend time in each other's company and to have more contact with the outside world. From the 1950s through the mid-1970s, folk high schools were the main arrangers of prison education. These institutes of adult education, as representatives of society external to the correctional services, 
were considered the natural organisation to take on the task of providing prisoners with further adult education. In practice, a folk high school in geographical proximity to the prison would set up a branch in the prison, using the school's teaching staff to run courses corresponding to those offered by the folk high school in Swedish, mathematics, civics, English, and Swedish for immigrants. To some extent, each folk high school left its own characteristic mark on the content and organisation of education in the prison where it had a branch. During the same period, there were also teachers employed by The Prison and Probation Service who ran practical, vocational courses, mainly at youth penitentiaries.

Basic education - a civil right

With the introduction of "basic education for adults", in conjunction with the problem that it had proven difficult for prisoners to continue studies they had begun in prison after release, beginning in the mid-1970s the Prison and Probation Service moved responsibility for prison education to the community adult education authorities at municipal level. This was also in accord with the new legislation that came into force after the 1974 reform of the correctional system, based on the principles of normalisation and proximity. Pursuant to these principles, the correctional service was to use the regular community services whenever possible rather than constructing parallel systems of their own, with an emphasis on the proximity of the outside world for prisoners. Therefore, the Prison and Probation Service began to cooperate with the National Agency for Education and the National Labour Market Board. Theoretical education in prison was to be organised under the auspices of the municipal adult education authorities and the national adult education establishments, and vocational education in prison was to be provided on equal terms as in the community, i.e. in the form of labour market training courses. The National Labour Market Board allocated funding for the vocational training, and the National Agency for Education earmarked funding for municipalities with prisons. Towards the end of this phase, the county boards of education took over responsibility for education at the Swedish national prisons and remand centres.

Swedish legislation on the right to basic education for adults (corresponding to the first seven years of comprehensive school, 
primary and early lower secondary) did not distinguish between prisoners and other citizens.

\section{Decentralisation and shift of responsibilities}

Extensive decentralisation in Sweden during the 1980s resulted in the abolition of funding at central level from the National Labour Market Board for special vocational courses in prisons. This responsibility now rested directly with the county labour market boards which, in turn, delegated it to the local employment services, so that the employment services nearest each prison took responsibility for that prison. In the early 1990s, when the National Agency for Education was restructured, direct allocation of funding for theoretical education for prisoners also disappeared. On the basis of a proposal from the Prison and Probation Service, the Ministries of Education and Justice adopted a decision that funding corresponding to the funds previously allocated for prison and remand centre education would be transferred from the former to the latter ministry. This agreement also implied that the funds would be used to procure the corresponding education from the relevant municipal and national adult education institutions. It was assumed that procurement would take place on a not-forprofit basis for the educational provider.

The Adult Education Act was also amended to clarify that municipalities were no longer obliged to provide prison education (the Swedish Code of Statutes 1985:1100 and the Swedish Code of Statutes 1992:232). Although it was not clearly stipulated in the law it appears to have been understood that the Prison and Probation Service would take over this responsibility and obligation to offer education to any prisoner who had a legal right to education, since the corresponding funding was transferred to the Prison and Probation Service.

A government commission report with the English equivalent title Crowning Knowledge (Swedish government commission report 1993:23) found that both national and municipal level procurement of educational services had failed to follow the directives stipulated in the Public Procurement Act Services had been procured from the municipal education providers without being open to competition from other providers of education. As a result, contracts for prison educational services were convened with several 
new providers. Pursuant to the intentions of the Act, contracts were of limited duration, for one or at most two years, with restricted renewal options. In the late 1990s the Prison and Probation Service had contracts with 21 different educational service providers, three of which were also authorised to issue grades and certificates themselves.

Criticism of prison education

The Swedish report from 1998 Prisoner education under the auspices of the Prison and Probation Service - survey, problem description and recommendations (Roitto \& Sjöberg, 2001) analysed the current situation and recommended changes with a view to improving quality and making it more even from prison to prison. The main recommendation was to ensure that there was pedagogical expertise at prison management level, with a clear link to the state educational system, in order to ensure comparable quality. Another proposal was that the new technology be introduced, with Internetbased education complementary to traditional classroom teaching. Use of ICT would enable prisons to offer a wider range of educational options, offer education to more prisoners, and provide better continuity, for example in cases of prison transfer.

\subsection{Legislation and other regulatory documents}

Abolition of a right

Until the early 1990s, prison education was an integral part of Swedish adult education policy and its emphasis on special efforts for adults with inadequate educational backgrounds and the people who have had least access to society's resources. Until then, prisoners had the same rights to basic education as all other citizens. After funding was transferred from the Ministry of Education to the Ministry of Justice, this legal right no longer applied. Chapter 11 of the Adult Education Act stipulates, with regard to municipal adult education, that every inhabitant of a municipality who does not have the skills to be achieved in comprehensive school has the right to participate in basic adult education from the age of 20. However, it also states that "The stipulations in this article do not apply to prisoners." 
Thus, since 1992, prison education has been regulated entirely by the Act on Correctional Treatment in Institutions, which states:

A prisoner shall be offered the options, on working hours, of work, study, education, vocational training, special treatment programmes intended to counteract recidivism or substance abuse, or of some other suitable occupation which, whenever possible, promotes his or her chances of becoming integrated into society after release.

The annual procurement document issued by the Ministry of Justice to the Prison and Probation Service has emphasised, for many years, that it is important to offer prisoners in need of comprehensive and upper secondary education the studies they need (Roitto \& Sjöberg, 2001).

\section{Prison education - still part of adult education in society?}

On the assumption that prison education, from an ideological point of view, remains part of the ambitions of Swedish adult education policy, one ought logically to be able to see prison educational activities as characterised by and in agreement with the policy objectives for adult education established in conjunction with the 1997 Parliamentary Decision on the Draft Bill on Adult Learning (The Swedish Code of Statutes 1985:1100 with later revisions):

The state adult education system shall give adults the opportunity, in harmony with their individual interests, to supplement their education. In this respect, priority is to be given to those who have received least education, with a view to strengthening their position on the labour market and in relation to culture and politics in the community. In every school form, such education is to be equivalent, irrespective of where in the country it is arranged.

In one of its reports, $A$ Strategy for the Adult Education Initiative and Lifelong Learning (Swedish government commission report, 1996:27, in Swedish), the government commission on the "adult education initiative" sets out the idea that all education carried out under the auspices of the "adult education initiative" programme is to be of a bridge-building nature, giving individuals the knowledge and other prerequisites they require to be able to participate in lifelong learning. The commission report recommends that the individual right to adult education also be extended to comprise upper 
secondary education, and that there be a guaranteed right to adult education at upper secondary level on equal terms all over the country.

The report also states that in the lifelong learning society, people need not only formal competence but also non-formal learning, including social, communicative and creative skills, as well as the ability to learn new things and to cope with changes in working and everyday life (Swedish government commission report 1996:27).

Although, to a large extent, prison education is based on the approach enshrined in adult education policy, from a formal point of view it is governed by the regulations set down in the Prison Treatment Act rather than on legislation in the sphere of education. Education for prisoners is touched on in articles 4, 10, and 11 of the Act, which all stress the importance of structuring a prison term from the very outset so as to facilitate the re-integration of prisoners into society. If a prisoner needs education or any other particular kind of treatment, (s)he shall be offered the same, with the necessary adaptations to the length of time (s)he will be in the institution, and his or her own points of departure. One aspect of facilitation re-integration is to give prisoners the opportunity to spend time outside the prison to participate in education, to work, or to take part in a treatment programme. Prisoners who might be liable to escape, return to crime, or to abuse drink or drugs cannot be allowed to spend time outside the prison. For this reason, the number of prisoners with day release privileges is relatively small.

The vision of the Prison and Probation Service - Better Out!

Prison education is an integral part of the Swedish Prison and Probation Service and is thus one aspect of the plan of visions and ambitions for the future, Better Out, according to which the Service is to implement measures to help prisoners return to a life free from crime. The plan also states that the activities run under the auspices of the service are to be characterised by a humane attitude, helping prisoners to develop, and striving actively to influence their development while maintaining a high level of security, as well as respect for individual integrity and legal rights. The work of the Service is to focus on bringing about changes in the life situation of prisoners as well as their attitudes toward the 
life that resulted in their committing crimes. The mission of the service is, at least in some areas, to improve the skills, knowledge or thought patterns of the prisoner so that (s)he will be better equipped to manage to live in society and comply with its laws upon release. The document outlines six basic principles that are to guide the work of individuals in the service including to:

- interact with prisoners and others with whom we work in an honest, open and humane way at the same time as we comply with the regulations regarding the protection of society.

- encourage and assist prisoners to work towards changing their criminal behaviour patterns, and induce them to better respect others.

This means that during the time they are serving their sentences, prisoners are to be encouraged to learn, to gain skills, to raise their educational level, and to participate in activities that help them to reflect upon and find ways out of the lifestyle that led them into criminality (The Swedish Prison and Probation Service vision, 2001. In Swedish. English equivalent title Better Out).

\section{Collaboration with the Swedish National Labour}

Market Administration

For vocational training there is an agreement regarding collaboration between the Prison and Probation Service and the Swedish National Labour Market Administration, which guarantees that prisoners will have the same rights to services and programmes as other citizens. The agreement stipulates that:

- Prisoners in the custody of the Prison and Probation Service have the right to service on the same terms as other users of the employment services.

- Prisoners in the custody of the Prison and Probation Service have the right to service irrespective of the prevailing labour market situation and the economic cycle, prisoners in the custody of the Prison and Probation Service - like other vulnerable groups in society - will require extra support.

- The mission of the Prison and Probation Service requires collaboration with the employment service. 
This concluding bullet point is of particular interest, in that it points out the dependence of the Prison and Probation Service on the Labour Market Administration in order to fulfil its mission. The second bullet point is also of importance, which is underlined in the following passage from the document:

Even in times of a strong labour market, most prisoners will require support in order to find their way into employment. Counselling, courses on applying for work, preparatory and vocational training are all examples of the kind of support the employment service can offer.

The Labour Market Administration and the Prison and Probation Service also have a national forum for collaboration, the $\mathrm{KrAms}$ group, for transfer of knowledge, discussion and analysis of their cooperation.

\subsection{Description of prison education and its place in relation to adult education in society}

The primary function of the Swedish Prison and Probation Service is to enforce the sanctions adjudicated by the judiciary. That role requires combining the protection of society with the rehabilitation of the individual prisoner.

Prison education - one piece of a puzzle

Education is one piece of a larger puzzle where the various pieces/stakeholders are to be described in a sentence plan for each prisoner, adapted to his or her needs and providing a platform on the basis of which the individual will be better equipped to return to life in the community - "better out". Education has a twopronged function in this work with prisoners. It is both part of the whole and, at the same time, it has a very particular and independent value for the individual. The first of these functions is rehabilitating, while the other applies, in fact, to all human beings - education has its value in developing our knowledge, skills, and insights into the potential society has to offer and our responsibility vis à vis society, at a workplace, in the family, amongst friends. The success of the first function can be measured in terms of reduced recidivism, while the other can only be measured in terms of value-oriented parameters. 


\subsubsection{Description of prison education}

Today, education in Swedish remand centres and prisons is arranged by a large number of education providers: folk high schools, correspondence courses, municipal adult education authorities, study associations, private education companies and, to a small extent, inhouse. Participation in prison education is always on a voluntary basis. Priority is given to prisoners with the greatest need of basic education, because these individuals are otherwise seldom reached by the providers of supplementary adult education. In pace with the increasing demand in society for completion of upper secondary school, prison education at upper secondary level has also been emphasised in the educational brief given by the government to the Prison and Probation Service. The lines of demarcation for prison education in Sweden are:

- Basic adult education (primary and lower secondary levels, including Swedish for immigrants)

- Upper secondary education

- Vocational education

- University and other higher education

- Other education (study circles, parenting courses, etc.)

Education within these lines of demarcation is part of the structured activity programmes in Swedish prisons. Thus "programme" is an umbrella term covering various goal-oriented activities including: education (theoretical and practical), work, criminality and abuse-related programmes, library activities, creative activities, physical activities and sports and social skills training.

Contract teaching - fixed requirements at the lowest price

Beginning in the early 1990s, the Prison and Probation Service has procured educational services from external providers. Pursuant to the Public Procurement Act, the education provider who satisfies the specified demands at the lowers price wins the contract. Since 2003, a pilot project has been under way in which the Prison and Probation Service employs teachers, who receive pedagogical guidance from the Swedish Agency for Flexible Learning. The project has been evaluated and these new "Learning Centres" 
will gradually be introduced in all Swedish prisons. The National Labour Market Board still finances vocational education in the form of labour market courses. Decisions regarding these courses are made by the liaison officer from the local employment service in consultation with decision-makers at the relevant prison.

\subsubsection{Education for individuals in remand}

Most individuals in remand are in custody on suspicion of having committed a crime. The duration of their remand will depend both on why they are being held and on how complex their case is to investigate. Average remand duration is one to two months. An individual being held in remand may be subject to restrictions regarding contact with the outside world for reasons relating to the investigation. Such restrictions may include a prohibition on contact with other prisoners, or that letters are censored and packages inspected.

In December 2003, there were 28 remand centres in Sweden with a total of 1,771 places (Official Statistics from the Swedish Prison and Probation Service, 2004). Individuals are placed in remand centres for one of two reasons: either they are under arrest at the decision of the public prosecutor, or they are being held in remand at the decision of the court. Sometimes individuals who have been convicted of a crime may be placed at a remand centre while waiting to be transferred to a prison, to some other treatment centre or, in the case of foreign citizens, to be deported.

In contrast to prisoners, individuals in remand are not subject to any legal obligation to participate in activities, which also means that the Prison and Probation Service does not have to offer activities. Sweden was criticised by the Committee on the Torture of Prisoners of the Council of Europe for keeping individuals in remand overly isolated. Swedish remand centres, as opposed to prisons, often have unsatisfactory premises for activities and groups. Remand times are supposed to be short, and convicted prisoners are supposed to be moved to a prison as soon as they have been sentenced. The criticism received has led to a gradual renovation of remand centres so that individuals not subject to restrictions are able to spend more time in groups. 


\section{Less expensive activities}

Programme activities at remand centres are consciously simpler, primarily owing to cost considerations. This has resulted in fewer criminality and substance abuse programmes being offered (Official Statistics from the Swedish Prison and Probation Service, 2004). Activities available at remand centres include work, studies, and various types of hobby work and other distractions.

\section{Education offered at remand centres in 2003}

Approximately $90 \%$ of the education offered at remand centres, according to the statistics, was basic theoretical education.

\subsubsection{Education for prisoners}

In December 2003, there were 60 prisons in Sweden, with a total of 4,520 places. Of these, 1,223 were in open prisons (Official Statistics from the Swedish Prison and Probation Service, 2004). There is an inevitable, built-in contradiction between the reasons society has for needing to lock people up and the ambitions society also has to rehabilitate these same people so they can live normal lives. Correctional treatment in institutions is therefore structured so as to promote prisoners' reintegration into society as well as counteracting the harmful effects of deprivation of liberty. In Sweden, a prison sentence may range in duration from two weeks to life. When a person is sentenced to life imprisonment, (s)he can, after many years, apply to the government for clemency. If clemency is granted, the sanction is commuted into a prison sentence of a determined duration. Now that various types of alternative sanctions have been adopted (electronic monitoring, community service, etc.) the formerly large group of individuals serving sentences of short durations in Swedish prisons has basically disappeared.

The Better Out programme envisages people who have been in prison leaving the care of the Prison and Probation Service better equipped for a law-abiding life. By participating in work, education, criminality and abuse related programmes, etc. on working hours, as well as in structured recreational activities, prisoners can satisfy their individual needs and prepare for their release.

Prison education is carried out by teachers contracted on a one to two year basis with renewal options. In 2001, the Prison and Pro- 
bation Service had contracts with 21 different education providers. These same parties can participate in a new public procurement procedure, with the possibility of being awarded new contracts if they are able to supply the specified quality at the best price. Thus, in reality, the same teachers may stay at the institutions for a number of years. At the time of writing (2005) a pilot project is underway in the Swedish Prison and Probation Service the result of which is that teachers are being employed by the Prison and Probation Service, but with the pedagogical management, grading, and teacher training done by an external authority under the supervisory responsibility of the National Agency for Education (see also section 2.3.5).

\section{Vocational education}

Vocational education is usually carried out in conjunction with the local employment service, which also procures and funds the vocational education. It is given in the form of labour market courses, with the same quality demands as apply to the corresponding courses in the community. The cooperation between the Prison and Probation Service and the employment services follows a central agreement with the National Labour Market Board stating that prisoners have the right to services on the same conditions as other users of the employment services (Labour Market Board/ The Swedish Prison and Probation Service, 2000). This cooperation agreement also states that, in addition to their criminal backgrounds, many prisoners have the problem of having had very little experience of the labour market. This lack of work experience contributes to their difficulties in getting and keeping a job, as does their often incomplete schooling. Even in times of economic boom, prisoners and former prisoners often need extra support in finding work. Advisory services, job application courses, preparatory and vocational education are examples of what the employment service can offer. In many parts of Sweden there is also a special type of cooperation for former prisoners known as KrAmi which has been very successful. In KrAmi the employment service, the Prison and Probation Service and the local social welfare offices work together to help former prisoners find and keep a place on the labour market (Nyström et al. In Swedish. English equivalent title: Investing in work, 2002). 
The scope of prison education in 2001

In 2001, about 990,000 hours of prison education were carried out in closed prisons (Mistral 2001), which corresponds to $12 \%$ of the total of programme activities (work, education, criminality and substance abuse related programmes, social skills training, creative activities, etc.). A total of 7,366 prisoners participated in education, according to the system regulating prisoners' allowances (Mistral). Approximately $9 \%$ of these prisoners were women. This may be compared with the percentage of women in the total prison population, of $5.5 \%$ (Official Statistics from the Swedish Prison and Probation Service, 2001).

Unfortunately, the system is not able to keep track of overlaps. This means, for example, that if a prisoner participates in both upper secondary and vocational labour market courses (s)he will be counted twice. Thus the actual number of prisoners who studied is smaller, probably around 5000 . This figure includes 252 prisoners with day release privileges for schooling. Education is offered, in principle, at all prisons.

The orientation of prison education in 2001

Most educational courses, approximately $50 \%$ were basic theoretical education corresponding to comprehensive primary and lower secondary school, grades one through nine. The next largest segment is upper secondary education, accounting for approximately $20 \%$. Vocational training and other education (study circles, parenting courses, etc.) represent about $12 \%$ each. A very small number of prisoners, some $2 \%$ study at university or other higher education level (Roitto \& Sjöberg, 2001/Mistral, 2001. In Swedish. English equivalent title: The Prison and Probation Service's system for ongoing documentation of programme activities).

The educational possibilities at open and closed prisons differ. Normally, more education is offered at closed prisons, but some open prisons also have a long tradition of offering a wide variety of studies of both a theoretical and a vocational nature.

Vocational education may either take the form of "labour market courses" organised and financed by the National Labour Market Board or of vocational education procured by the Prison and Probation Service. Such courses may include: welding licensing course, cutting processing, industrial technology, wood products 
technology, fork lift truck licence and the European computer driving licence.

Although Swedish for immigrants is taught at many prisons, there are no separate statistics, as it is generally included in the category of basic adult education.

University and other higher education have not been given very high priority to date, and account for $2 \%$ of the total number of study hours completed. Such studies are completely individualised, and require a great deal of independent work and self-discipline.

Studies - often in groups but individualised

Most education takes place in groups, but not strictly as group teaching. Each prisoner has an individual study plan, and studies his or her subjects while the teacher goes from student to student, helping them with their different subjects at their respective levels. At the large prisons, where there is a big enough student population, there are sometimes group lessons, particularly in the basics: Swedish, mathematics and English. In other subjects there are usually too few students to make a coherent group. There are also major differences from one prison to the next. Every prisoner who participates in educational activities has a personal study plan as a documented part of his or her sentence plan, along with plans regarding other activities.

\subsubsection{The transition from prison education to education in the community}

Educational activities is one of the instruments at the disposal of society to increase the chances that prisoners, under the auspices of the Prison and Probation Service, will be able to create a life for themselves in society, free from crime an drugs. There are various objective for prison education, including development of prisoner's competence, to help them be better able to go on studying after release or to get a job, as well as developing informal competence, helping them take responsibility, take part in teamwork, and function in groups. To put it simply, formal competence can (in the long term) lead to a job, informal competence can contribute to being able to keep that job and otherwise improve one's quality of life. 
In light of the above, all education under the auspices of the Prison and Probation Service should be rooted in the local community, so that studies begun in prison can be continued outside or, if they are concluded while the prisoner is serving his or her sentence, be evaluated on equal terms with studies pursued outside prison. It must be possible to assess performance, so that the individual will not have to start over again. The current system of contract education makes the transition from prison education to education in the community more difficult than it needs to be, since so few of the education providers are authorised to issue grades and certificates themselves. Although there is a testing system by which an individual can be examined by an external examiner (such as the municipal adult education authority), the individual must then be tested on the entire course of studies rather than just a part, as is the case in traditional testing.

Studies in the community with day release privileges

One way of improving prisoners' chances of studying on equal terms is the use of day release privileges so that prisoners can leave the institution and participate in studies at a regular school external to the Prison and Probation Service.

In 2001 , a total of 54,000 study hours with day release privileges were registered, which is some $6 \%$ of the total number of study hours completed. The number of individuals registered as studying with day release privileges in 2001 was 252 .

There are various explanations for the small number of prisoners with day release privileges for studies. The rules are very strict regarding spending time outside the prison. Also, today, most prisoners who would have been eligible for day release privileges a few years ago are serving alternative sanctions such as electronic monitoring or as community service. Furthermore, in order to study in the community an individual usually has to be able to commence studies at the beginning of a school term, while prisoners need a system making it possible to begin when they start serving their sentence. Finally, in pace with the broader range of activities being offered in the prisons, there has been a decline in the willingness of prisons to arrange for day release privileges, since there are other options "closer at hand".

Sweden has no statistics regarding the number of prisoners who continue their studies after release. 
Internet-based education - new opportunities via the "hole in the wall"

In more and more general education, all or parts of a course are web-based. This system is well suited to the efficacy demanded in society today, and to the needs to be able to individualise education and to give people the opportunity to participate in education in a more flexible way. The new technology makes it possible for people to get precisely what they need, neither more nor less. The problem of groups being too small, and thus too expensive in terms of teachers' salaries, vanishes. A whole target group can be offered high quality education (anywhere in the country), and "exclusive" solutions for subjects only of interest to a small number of participants can be arranged. From the perspective of the Prison and Probation Service, the new technology paves the way for offering high quality education and for satisfying individual needs, but to date security problems have prevented this from becoming reality. A small number of pilot projects have been run with a link from some Swedish prisons to universities and other institutions of higher education with stringent security supervision. Various technical solutions for secure Internet connections have been developed, but the Prison and Probation Service has remained restrictive, knowing that it is always possible to abuse a "hole in the wall".

A new agency, the Swedish Agency for Flexible Learning, has been established. Its remit is to stimulate various forms of "distance learning" in adult education. The Agency has shown a great interest in the ambitions of the Prison and Probation Service to find secure, positive solutions for Internet-based education. A pilot project has been launched in collaboration between the Agency and the Service, with a view to investigating the potential and the drawbacks of Internet-based education for providing "distance learning" under the auspices of the Prison and Probation Service.

\subsubsection{Ongoing development work regarding prison education}

The above-mentioned report from 2001 on the Prison and Probation Service (Roitto \& Sjöberg 2001) pointed out many shortcomings in Swedish prison education, including the fact that it was fragmented, with so many providers, the difficulty of being able to set grades in a straightforward manner, and the need for peda- 
gogical management. The central administration committee of the Prison and Probation Service adopted a decision in spring 2002 to set up a project to work with the key problem areas, from number of angles, and to examine the areas of prison education where improvements were most acutely needed. These areas became six subprojects:

- A pilot project in which the Prison and Probation Service would employ teachers on staff in two regions. Pedagogical management would be ensured through collaboration with the Agency for Flexible Learning, which was given the ultimate responsibility for pedagogical leadership and was to see to it that a grading system could be implemented that would be fully valid in relation to the state educational system as a whole. "Learning centres" similar to corresponding centres in the community are established in prisons. Teachers carry out traditional classroom teaching, as well as helping prisoners with their "distance" teaching. This enables students are able to continue their studies even if they are transferred to other prisons.

- A completely new system of Internet-based education in the Prison and Probation Service is being tested at a number of prisons. This is the first time prisoners were allowed to connect to the Internet. It began as a "virtual school" in 2003, giving prisoners the opportunity to utilise the enormous potential for web-based education. However, this does not mean that prisoners are allowed to surf the Internet freely. They are only allowed to use the Internet to take interactive courses procured and funded by the prison school. High security solutions are in use, and prisoners are unable to access other web sites or to carry out other, prohibited, forms of communication. One of the main purposes of the system is for prison teachers to be able to utilise the new technology to individualise study plans, independent study assignments, etc. When the system has been introduced all over the country, there will be other advantages, such as that it will be easier for a prisoner who is transferred to a different prison to continue courses already begun. 
- New vocational training options in collaboration with the Labour Market Board, supplementary to KrAms, the joint working group of the Labour Market Board and the Prison and Probation Service.

- Today, knowledge and experience are being validated in new ways in the community, with a view, for example, to better benefiting from the vocational skills immigrants acquired in their former home countries. This should be an area of potential for the Prison and Probation Service as well, in terms of being able to give prisoners certificates for the vocational skills they learn in prison workshops, and of being able to benefit from their previous experience.

- A handbook will be written on the subject of university and other higher education, so that prisoners and prison staff will be better able to deal with this area. Although very few prisoners have studied at this level to date, it has been very costly because prison staff have had too little familiarity with higher education and the relevant rules.

- Guidelines will be drawn up for prison education, clarifying the aim, orientation and quality management. These should eventually be formalised as regulations and general instructions, with a higher status than simply "guidelines".

The project, with its six subprojects, has been under way since 2002. The final report on each subproject will be published in 2004-2005.

\subsubsection{Financial aspects}

In 2001, educational activities in prisons and remand centres were procured and carried out for a total sum of EUR 7,2 million. The Prison and Probation Service provided the majority of the funding. 


\subsection{The results of prison education}

\subsubsection{Quantitative results}

During the 1980s and 1990s, various attempts were made to find a system that would generate quantitative data such as the number of grades given, courses completed, dropout rates, etc., but no satisfactory system was found. This is probably because the local stakeholders did not see the use of the system and gave too little priority to inputting the necessary information regarding documentation of studies. In a study carried out by the National Agency for Education in the late 1980s, criticism was levelled at the Prison and Probation Service. The study found, after investigating the dropout figures for basic adult education, that dropout figures were particularly high (35-40\%) for students studying under the auspices of the Prison and Probation Service (Thång, 1988. In Swedish. English equivalent title: Who studies in municipal adult education, and what are the results?). However, what the study was unable to see was that a relatively large number of these dropouts were attributable to transfer of prisoners to different institutions. Thus some prisoners who appear to have dropped out may not in reality have done so. Probably many of these transferred prisoners went on to study at their new prisons, in spite of the fact that they were registered in the dropout statistics.

\section{Many explanations for the small number of grades given}

Relatively short durations of prison stays also mean that prisoners are unable to complete studies they begin while serving time. It is essential that the studies undertaken be well documented, so that prisoners can be given partial credit and eventually full credit for courses even if they were begun in prison and completed outside. Thus there should be certificates issued for all studies, even if only a small number of grades can be given. To date, there are no statistics at all, and the current system of contract education has exacerbated the problem of grading. Only three of the 21 education providers is authorised to issue grades independently. All the others have to use a "testing" system managed by the municipal adult education authorities, as described above. Another reason so 
few grades are given is that basic education courses are very long (200 to 300 study hours). The Swedish Agency for Education is in the process of dividing these basic education courses into modules along the lines of the current system for upper secondary level courses.

However, not all the blame can be put on the combination of short sentence durations and long courses. The Swedish National Board of Institutional Care has noted that the same problems exist at youth detention centres, where the duration of stay also tends to be short (more than half of the young people placed at youth detention centres are placed for a duration of two months or less), but these centres have found a far more satisfactory way of being able to give their students grades. Part of the explanation may, thus, have to do with the status of educational activities at the institution. The director of a youth detention centre also has the formal status of headmaster of the school, and the ultimate responsibility for implementing the curriculum. School is also compulsory for young people placed at youth detention centres.

In their 2001 report Prisoner education under the Auspices of the Prison and Probation Service, Roitto and Sjöberg found that although the number of prisons stating that they were authorised to issue grades was 42 , only one third of these institutions actually did so.

One out of every seven prisoners has not completed comprehensive education

A report from 1999 on prisoner's living conditions states that there is a great need for education for prisoners (The Living Conditions of Prisoners, 1999). This study was based on interviews with a random sample of prisoners, 411 in all. Every seventh prisoner, or approximately 15 out of every hundred, had not completed comprehensive school or basic vocational education. This figure may be compared with the corresponding figure of less than $1 / 100$ in the general population. Approximately $7 / 10$ individuals deprived of his or her liberty were unemployed, as compared with $3 / 10$ in the general population.

With so many prisoners having incomplete education and no work life experience, there should be a great interest among prisoners in participating in educational activities. $37 \%$ of the prison- 
ers interviewed stated that they were currently participating in some educational activity. The most common type was comprehensive or upper secondary schooling. Of the prisoners with incomplete comprehensive schooling, $26 \%$ were taking some basic education course(s). Duration of sentence appeared to be the determining factor as to whether a prisoner participated in studies. Of those serving sentences of one year or more in duration, $44 \%$ were involved in studies, while the corresponding figure for those serving sentences of six months or less was only $18 \%$.

\subsubsection{Qualitative results}

A questionnaire survey on Activities for Prisoners in Institutional Treatment was carried out in 1996 (In Swedish. English equivalent title: Report-activities for prisoners, 1996). In this study, all prisoners in institutions were asked as to whether they found the programme activities meaningful, what benefit they thought these activities might have for them after release, how they thought programme activities should be structured in the future to satisfy their needs, etc. The questionnaires were distributed to all prisoners (they were also available in English) one evening when cells were locked, and collected when cells were unlocked the next morning. Response was anonymous, in a sealed envelope. Seventy-three per cent of the 4,157 prisoners who received the questionnaire responded. This is a satisfactory response rate in terms of representativeness, with a reservation for under-representation of foreign prisoners. Almost all respondents (98\%) stated that they would like to study. Approximately $30 \%$ of the respondents stated that they were studying at the moment, primarily at comprehensive or upper secondary level. Of those who were studying, nearly two thirds stated that their studies were meaningful. Significantly more prisoners in high security prisons experienced their studies as meaningful. The studies experienced as most meaningful were vocational courses, upper secondary and post-upper secondary studies, and various combinations of courses.

The questionnaire also contained questions as to whether the prisoners thought they would benefit from their studies after release. The most frequent response was that the studies would pave the way for continued schooling, followed by improved self- 
esteem as well as a better chance to get a job or to be able to make a living.

Ninety-eight per cent of all respondents stated that they would like to study. Fifty-seven per cent of these individuals wanted to take competence-raising courses, mainly vocational courses or upper secondary or post-upper secondary level courses.

The questionnaire also contained an opportunity to freely state what kind of courses, subject areas the respondents would like to study. The five most frequently-stated options were practical vocational courses (28\%), economics/business administration (5\%), drawing/painting (5\%), preparatory courses for driving license $(5 \%)$ and psychology (5\%).

In comparison with prisoners in open prisons, prisoners in closed, high security prisons were more interested in competenceraising courses. Prisoners in closed, high security prisons were also those who experienced their education as the most meaningful.

The last section of the questionnaire gave prisoners the opportunity to state how they thought a prison term could best be utilised to improve their chances of leading a crime-free life after release. More than half the respondents answered this section. Twenty-five per cent of their answers had to do with wanting to continue their education, and $13 \%$ with wanting to work. Some of the recommendations put forward by the group wanting to continue their education were:

- to study in order to get work afterwards,

- to have a chance to get a driving licence,

- courses to raise competence and, consequently, self-esteem,

- education for re-integration into society,

- better planned education, theoretical and practical,

- studies with a chance for day release privileges,

- vocational training

- improving one's previous educational level (from before prison),

- education to learn languages,

- help to start higher education at university or the like,

- meaningful academic education to be able to compete for stimulating, well-paid jobs,

- education adapted to enabling prisoners to compete on the labour market. 
The two responses below were given in English:

- to get chance of studying something which can give opportunity of self employment,

- really want to get the opportunity of studying and be treated as human being on all aspects.

The teacher-student interface

In her research results, Silwa Claesson describes the problem complex relating to the teacher-student interface as resembling the question: "What is the figure and what is the background?" Her report, with the English equivalent title Studying in Prison describes education at three Swedish prisons in terms of classroom focus - the teacher's objectives. The two figures she discerns are subject knowledge and socialisation, which she sees not as in contradiction but as the interplay of figure and background, each sometimes foregrounded. Both subject knowledge and socialisation are necessary aspects of virtually all education. Claesson found that at two of the prisons she studied, subject knowledge was foregrounded, while socialisation was foregrounded at the third. She goes on to discuss why this is the case, and what the consequences are, finding that the prison that foregrounded socialisation was a prison where most of the prisoners were serving short sentences and had abuse problems. This prison focused all its work with the prisoners on motivation, which may have rubbed off on prison education. That prison's policy, according to the study, was to give most encouragement regarding participation in educational opportunities to prisoners who only had a few years of schooling, so they would utilise the opportunity to study while in prison. According to Claesson, both the figures she found represented in the Swedish Prison and Probation Service. Foregrounding subject knowledge allows prisoners who are motivated in their studies to study in peace, concentrate, and focus on the subject matter, while foregrounding socialisation allows prisoners with the weakest educational backgrounds to gain new tools to cope with life in the community, to improve their self-confidence, and to become motivated to continue learning. So both figures are necessary and, according to Claesson, there is no need to judge one or the other as best (Claesson, Dahlgren 2002. In Swedish. English equivalent title: Studying in Prison: education in three prisons). 


\section{ICELAND}

By way of introduction to prison education in Iceland, a few words about the relationship between prisons and Icelandic society as a whole. There are five prisons in Iceland, four of which are very small, with 9-16 places, and one larger with 87 places. The duration of a sentence is determined in consideration of many factors, including age, sex, domicile, and previous convictions. One of the prisons is in Reykjavik, one in nearby Kópavogur, and the remaining three are rural. The large one, Litla-Hraun, is located approximately 60 kilometres from Reykjavík. On an average, there are some 100 men and 7-8 women in prison in Iceland at any given time. Women prisoners are always incarcerated at the 12 place Kópavogur prison, with both men and women. Although small prisons like the Icelandic ones have many advantages over large prisons with hundreds of places, prison education is one of the problematic aspects of small establishments, for various reasons. The small number of prisoners/students may also be very different from each other in terms of age, previous education, duration of sentence, state of health, etc. All this means that the educational options have to be highly individualised, and that both teachers and students need to be very flexible.

Only two of the Icelandic prisons, Litla-Hraun and i Kópavogur, offer organised education, based on the import model, with teachers coming from nearby upper secondary schools.

\subsection{History and legislation}

Prison education in Iceland began as a pilot project at the LitlaHraun prison in the 1970s. Vocational training and tuition in individual subjects and basic comprehensive education were all offered. While the theoretical teachers came from the local comprehensive school in the nearby village of Eyrarbakki, it was the prison officers who provided the practical training in, for example, woodworking and welding. Since 1978 all the prison education at LitlaHraun has been organised under the auspices of the vocational school in nearby Selfoss. In 1979, according to an agreement on co-financing between the Ministry of Justice and the Ministry of 
Education, the latter took responsibility for teachers' salaries and the former covered all other expenses related to educational activities.

In 1981 the school in Selfoss became a combined comprehensive and upper secondary, and since that year this school has also organised all the prison education at Litla-Hraun, with the prison teachers commuting daily between the village school and the prison. In the early years, the facilities for education at the prison were very sparse, and for this reason some of the prisoners were allowed day release privileges to attend the school. In 1990, school facilities on the prison premises were inaugurated, and since then most education for prisoners has taken place there. In special cases, prisoners are allowed to attend school outside the prison to study subjects not available at the prison school.

There has been schooling on a regular basis at the Kópavogur prison since 1997. Since then, the combined comprehensive and upper secondary in nearby Kópavogsby has run the prison school as well. Article 14 of the Icelandic Prison Act (no. 48/1988) stipulates, inter alia, that prisoners have the right to education, and that a prisoner may be granted day release privileges to attend school outside the prison, as well as that regular educational activities in prison can replace the obligation to work. The Ordinance on Work, Education and Daily Allowances for Prisoners (no. 409/1998), states that prisoners attending educational activities are eligible for an allowance of approximately EUR 2,95 per teaching hour. Textbooks and all study materials are also paid for by the prison.

The Ordinance on Day Release Privileges to Attend School, etc., (no. 719/1995) states that a prisoner must have served at least one year of his or her sentence, and that day release privileges are only granted during the last six months before release. In exceptional cases, there may be extensions granted regarding this time limit.

Prisoners serving sentences of long duration may be allowed to serve a maximum of the last 6 months at a halfway house from which they may, for example, apply to attend school. Unless the prisoner's behaviour has prevented it, such applications are normally granted. 


\subsection{Description of prison education}

The two upper secondary schools with responsibility for prison education at Litla-Hraun and Kópavogur, respectively, have appointed prison school administrators, who come to the prison a few weeks before the beginning of the school term, at which times prisoners wishing to participate in educational activities apply to him or her, stating their interests and needs. The prison school administrator then draws up a study plan in consultation with the prisoner. In practice, all prisoners have access to schooling, although the subjects offered may vary from term to term.

At both prisons, educational activities take the form of modules of varying lengths. The students are therefore able to choose the modules they wish to study and which are in accord with their own abilities, in consultation with the school administrator. Prisoners with reading and writing difficulties are offered remedial education. The average number of prisoners at the Litla Hraun prison in 2001 was 70 , including individuals in remand. The spring terms saw 26 of these prisoners begin some educational activity, with 12 completing one or more examination. The autumn terms saw 32 prisoners start schooling, with 16 completing one or more examination. Generally, an average of $35-40 \%$ of the prisoners start studying one or more subjects at the prison school, and approximately $20 \%$ complete the examination in one or two subjects. In most cases, dropping out is voluntary on the part of the prisoners, although there have been cases of suspension owing to disciplinary problems. In cases where a prisoner is released before the end of the school term, the school administrator sees to it that examinations are arranged in the subject(s) the prisoner was taking. In other cases, examinations outside the prison are arranged for released prisoners.

The average number of prisoners at the Kópavogur prison in 2001 was 10 . Two to six prisoners attended school daily, and six completed one or more examinations that year. In all other respects, the prison school operates in the same manner as described above for the Litla-Hraun prison. At Litla-Hraun, other courses than traditional school courses are occasionally offered. These courses have been primarily financed by the Prison and Probation Service, and 
have included navigation for vessels up to 30 tonnes and construction equipment. The aim of these courses is to prepare prisoners for life after release.

\subsection{Financial aspects}

As mentioned above, the costs of prison educational activities are shared by the educational authorities and the Prison and Probation Service. The former finance teachers' salaries, the latter all other expenses. In 2003, funding for all aspects of prison education amounted to EUR 175,700 of which teachers' salaries accounted for EUR 157,400 and other costs EUR 18,300. The additional courses mentioned at the end of the paragraph above are not included in these figures.

\subsection{The prison population}

The average number of prisoners in incarceration facilities per 100,000 inhabitants in Iceland in 2001 was 37 , including individuals being held in demand and individuals whose fines were commuted to serving time in prison. The corresponding averages for recent years have fluctuated between 33 and 41 .

The average age is 33 . In $200135 \%$ of the prisoners were 25 years old or less, the youngest being 18 .

In $2001,8 \%$ of Icelandic prisoners were women, the remaining $92 \%$ men. The percentage of women has fluctuated in recent years between 4 and $8 \%$.

The average number of unconditional prison sentences to be enforced by the Prison and Probation Service in recent years has been 300 per year, of which $12-13 \%$ are sentences of longer than one year's duration. Approximately $50-55 \%$ of the individuals who begin a prison sentence each year have served time previously.

In conclusion, it is worth mentioning that the prison population in Iceland is substantially smaller in relation to the general population than in the other Nordic countries, and that one of the reasons is probably that Iceland uses more alternative sanctions. 


\section{The prison population}

This chapter contains descriptions of the prison populations in the four Nordic countries, of the main developmental trends expected in the future, their possible consequences in terms of educational options and how they could or should be organised.

\subsection{Descriptions of the prison populations in Denmark, Finland, Norway and Sweden}

The prison populations in the four Nordic countries are very similar. Prisoners, in comparison with the general population, are a unique group both demographically and socio-economically. The vast majority of the individuals are men, often with negative life experience, very little experience of working life, substance abuse problems and weak social networks. In addition, many convicted prisoners have previous experience of needing contact with the psychiatric services.

Over the last 20-30 years, the proportion of foreign prisoners has increased dramatically. In Denmark, Finland and Norway, this figure ranges between 8 and $18 \%$, in Sweden it is $25 \%$. During the same period, the number of women prisoners has remained constant, between 5 and $6 \%$ in all four countries, although with a slightly upward trend in the last few years.

TABLe 3.1 Prison place capacity in $\mathbf{2 0 0 3}$

\begin{tabular}{lrrrr} 
& Denmark & Finland & Norway & Sweden \\
\hline Open prison places & 1,310 & 810 & 974 & 1,217 \\
Closed prison places & 823 & 2,485 & 1,997 & 3,381 \\
Remand centre places & 1,641 & - & - & 1,771 \\
\hline Total & 3,774 & 3,295 & 2,971 & 6,269 \\
\hline
\end{tabular}


Proportionally, Denmark and Norway have the most open prison places (32-38\%). From 1997 to 2003 the occupancy of the available places has increased substantially in all countries except Denmark.

TABLE 3.2 Average figures regarding deprivation of liberty in 2003

\begin{tabular}{lrrrr} 
& Denmark & Finland & Norway & Sweden \\
\hline $\begin{array}{l}\text { Average number of individ- } \\
\text { uals deprived of their liberty }\end{array}$ & 72 & 69 & 65 & 73 \\
per 100,000 inhabitants & & & &
\end{tabular}

Average figures regarding deprivation of liberty are relatively similar in the Nordic countries, and are highest in Denmark and Sweden.

TABLE 3.3 Average numbers of sentences begun to be served in 2003

\begin{tabular}{lrrrr} 
& Denmark & Finland & Norway & Sweden \\
\hline $\begin{array}{l}\text { Number of sentences } \\
\text { begun to be served per }\end{array}$ & 167 & 80 & 190 & 105 \\
100,000 inhabitants & & & & \\
& & & &
\end{tabular}

In comparison with table 3:2, the figures for Norway and Denmark are higher in terms of the number of sentences begun to be served per 100,000 inhabitants during the course of a given year. The figure for Finland is lowest in both tables (Source: Nordic Statistics 2003, Statistics from the Swedish Prison and Probation Service, 2004). Our interpretation of these figures is both that relatively more individuals in Denmark and Norway serve prison sentences, and that prison sentences are of shorter duration in Finland and Sweden (where the figures also include individuals sentenced to electronic monitoring).

\section{Durations of prison sentences}

The durations of prison sentences are often measured either in terms of the number of prisoners incarcerated on any given day or of the number of prisoners incarcerated over the course of a year. Both these kinds of figures are of interest in relation to prison 
education, the question being how long a period of time prisoners have to fill in the gaps in their educational backgrounds. Because different methods are used to measure prison sentence durations, the project group has simply determined that for between 70 and 90 per cent of individuals convicted to prison in the Nordic countries the durations of their sentences are shorter than one year.

Sex, age and nationality

As mentioned above, the vast majority of prisoners are men, with just over $5 \%$ being women. Most of the male prisoners are over 30 , and only $3-5 \%$ are under twenty.

TABLE 3.4 Some groups of prisoners on a given day in 2003

\begin{tabular}{lcrrr} 
& Denmark & Finland & Norway & Sweden \\
\hline Women & $105(4 \%)$ & $164(5.4 \%)$ & $140(5 \%)$ & $277(5.2 \%)$ \\
Foreign citizens & $17.1 \%$ & $8.1 \%$ & $18 \%$ & $26 \%$ \\
\hline AGES & & & & \\
- Main age groups & $25-34$ & $30-39$ & $23-40$ & $30-44$ \\
$\bullet<20$ & $3.6 \%$ & $3.2 \%$ & $1.8 \%$ & $5.8 \%$ \\
$\bullet 15-17$ & $0.8 \%$ & $0.1 \%$ & $0.6 \%$ & $0.02 \%$ \\
\hline Serving life sentences & $14(1.6 \%)$ & $97(3.2 \%)$ & - & $119(2.3 \%)$
\end{tabular}

Substance abuse

Studies from all four countries demonstrate that $60-70 \%$ of the total prison populations abuse illegal narcotics and/or alcohol. The number of substance abusers has risen steadily over the last $15-20$ years.

Work experience and educational background

As indicated in the table below, only about one third of the prisoners were employed at the time they began serving their sentences. The figures for Finland and Norway stand out, in that more of the prisoners had completed compulsory school, and from one third to half had completed a three-year upper secondary school or a three-year vocational school. A small number of prisoners were studying at university or other higher education level. 
TABLE 3.5 Work and education

\begin{tabular}{lrrrr} 
& Denmark & Finland & Norway & Sweden \\
\hline $\begin{array}{l}\text { Employed at time of } \\
\text { sentencing }\end{array}$ & $27 \%$ & $30 \%^{2}$ & $30 \%^{3}$ & $32 \%^{4}$ \\
\hline $\begin{array}{l}\text { Completed compulsory } \\
\text { school }\end{array}$ & $32 \%$ & $94 \%$ & $92.4 \%^{5}$ & $32 \%{ }^{4}$ \\
\hline $\begin{array}{l}\text { Completed upper } \\
\text { secondary or } \\
\text { vocational school }\end{array}$ & $4 \%$ & $34 \%$ & $51 \%^{5}$ & $18 \%^{4}$ \\
\hline
\end{tabular}

1 The figures in this table may be compared with the figure of $85-95 \%$ for the total able-bodied employable population in the Nordic countries.

2 The only figures available for Finland apply to prisoners serving sentence terms of more than 2 years.

3 Fridhov, 1991

4 Statistics from the Swedish Prison and Probation Service 1999

5 Eikeland \& Manger, 2004

6 Completed 10 years of education.

This overview indicates that the number of prisoners in the Nordic countries is quite similar. Most are between 25 and 35 years of age. The number of prisoners under 20 is small in relation to the entire prison population, owing to the alternative sanctions used for young offenders. In terms of educational background, the Finnish prison population is distinguished from the others, mainly in that so much larger a proportion of Finnish prisoners than other Nordic prisoners have completed compulsory education. The number of foreign prisoners varies. Although it is substantial in all the Nordic countries, it is greatest in Sweden, where every fourth prisoner is foreign. There are major substance abuse problems in all four countries, with $60-70 \%$ of the prisoners having drink or drug problems, and often both.

Thus the typical Nordic prisoner can be described as: over 30 , having left school early, with a very little experience of the labour market and, in many cases, a substance abuse problem. Not a surprising picture, and readily recognizable.

Against this background, we can also describe some of the characteristic needs which ought to be reflected in the educational options offered at prisons if the aim is to offer education that will give prisoners a better point of departure to return to society, live a life without crime and drugs, and to develop as individuals (see also section 5.2.1, section 5.4 and section 5.7). 


\subsection{Key developmental trends}

In recent years and with the exception of Finland, the size of the prison population in the Nordic countries has basically remained stable. This is attributable to the fact that these countries' correctional systems have been characterised during the time period in question by short prison sentences as well as alternative sanctions to replace deprivation of liberty.

However, this is not to be interpreted as meaning that the prison population has not changed. Far more prisoners are abusers, are or have been mentally disturbed, have behavioural problems, have been convicted of serious crimes (violent crimes, sexual offences, grand theft) today than 20 years ago. Not least important, they are also older. In Denmark a particular increase in "motorcycle gang" prisoners (Hells Angels and Bandidos) have had their own special impact on everyday life in closed prisons. These characteristics of the prison population are expected to remain. In addition, after EU enlargement - from a European Union of 15 to 25 - more of the prison populations can be expected to come from the former Eastern European countries. This may come to mean that an even larger proportion of the prison populations than at present will be comprised of foreigners, and this will pose many challenges, including challenges in terms of prison education. There are many factors underpinning the general increase in the number of prisoners, but in any case the consequences, including overcrowded cells and difficulty in offering prisoners a reasonable range of activities, can have negative effects for the prisoners. Although overcrowding is sometimes solved by temporarily increasing the number of prison places, this is seldom reflected in a corresponding increase in the number of educational and vocational places made available.

Larger prison populations mean increasing costs or deteriorating conditions - or both - in relation to prison education as well. One of the frequent consequences of larger prison populations tends to be a shift away from treatment - in which term prison education is included - and towards simple lock-up or custodial functions. 


\section{Summing up}

As a consequence of these trends regarding the prison populations described above, changes can be expected in terms of educational options, educational methods, and choice of educational materials. Expectations also include increased differentiation and individualisation with a view to satisfying the particular needs and interests of prisoners to an even greater extent, as well as increased flexibility in terms of adaptation of prisoners' working time to enable combining vocational experience in workshops, education and participation in one or more treatment programmes, all as parts of the re-socialisation process. Moreover, there should be better, more focused collaboration with the social services system and with the employment services, with a view to improving both the transition from prison to freedom and integration onto the labour market. 


\section{Relevant international recommendations}

This chapter describes a selection of international recommendations and conventions, ratified by the Nordic countries, and of significance in relation to prison education. These include the European Prison Rules (1987), which are based on the Standard Minimum Rules for the Treatment of Prisoners (adopted by the United Nations in 1984), the Council of Europe's recommendations on Education in Prison and the UNESCO recommendations for adult education, The UN Convention on the Rights of the Child, and the European Convention on Human Rights.

\subsection{The European Prison Rules (1987)}

Pursuant to the European Prison Rules (articles 77-82) every prison shall have a complete educational programme so that all prisoners will have the chance to satisfy at least certain individual interests and needs. The aims of such programmes should be to facilitate successful re-socialisation and to improve the prisoner's own self-image, self-respect and attitudes.

Educational programmes should be considered activities of the same status and eligible for the same allowance as work, on the condition that the education takes place on ordinary working hours and is an integral part of the individual prisoner's sentence plan.

The prison and probation authorities should devote particular attention to education for young offenders, and for foreign prisoners or prisoners with special cultural or ethnic needs.

Special educational programmes should be organised for prisoners with particular difficulties, such as literacy and/or numeracy problems. 
In as far as is possible, each prisoner's educational programme should:

a) be integrated into the national education system in a way that enables the individual to continue his or her education after release,

b) take place at existing educational facilities.

Every prison institution is to have a library for use by all categories of prisoners. The library is to be stocked with a wide selection of books for both entertainment and education. Prisoners are to be encouraged to use the library. Wherever possible, the prison library shall be run in cooperation with the public library system of the community.

\subsection{Education in Prison (1989)}

In 1988, the European Committee on Crime Problems (CDPC) presented an extensive report, Education in Prison, which covered subjects including the aims of prison education, the place of education in the prison system, methodology in adult education, vocational training, creative and cultural activities, and the relationship between education in the prison system and in society at large.

Subsequent to the publication of the report, the Council of Europe published 17 recommendations, appealing to the member states to take them into account in their work with prison education. (Recommendation R (89) 12 adopted by the Committee of Ministers of the Council of Europe on Prison Education, adopted on 13 October 1989). This recommendation refers both to Recommendation R (87) 3 on European Prison Rules and Recommendation $\mathrm{R}$ (81) 17 on adult education policy. These recommendations are aimed at both the school system and the correctional services, and call upon the relevant parties to ensure that prisoners have access to a broad range of educational options, which should also continue after release. The recommendations are as follows:

1 All prisoners shall have access to education, which is envisaged as consisting of classroom subjects, vocational education, creative and cultural activities, physical education and sports, social education and library facilities. 
2 Education for prisoners should be like the education provided for similar age groups in the outside world, and the range of learning opportunities for prisoners should be as wide as possible.

3 Education in prison shall aim to develop the whole person bearing in mind his or her social, economic and cultural context;

4 All those involved in the administration of the prison system and the management of prisons should facilitate and support education as much as possible.

5 Education should have no less a status than work within the prison regime and prisoners should not lose out financially or otherwise by taking part in education.

6 Every effort should be made to encourage the prisoner to participate actively in all aspects of education.

7 Development programmes should be provided to ensure that prison educators adopt appropriate adult education methods.

8 Special attention should be given to those prisoners with particular difficulties and especially those with reading or writing problems.

9 Vocational education should aim at the wider development of the individual, as well as being sensitive to trends in the labour-market.

10 Prisoners should have direct access to a well-stocked library at least once a week.

11 Physical education and sports for prisoners should be emphasised and encouraged.

12 Creative and cultural activities should be given a significant role because these activities have particular potential to enable prisoners to develop and express themselves.

13 Social education should include practical elements that enable the prisoner to manage daily life within the prison, with a view to facilitating his return to society.

14 Wherever possible, prisoners should be allowed to participate in education outside prison.

15 Where education has to take place within the prison, the outside community should be involved as fully as possible.

16 Measures should be taken to enable prisoners to continue their education after release. 
17 The funds, equipment and teaching staff needed to enable prisoners to receive appropriate education should be made available.

This is an extensive list of recommendations with a view to establishing equality of opportunity between education in prisons and education in the outside world.

\subsection{UNESCO Recommendations for adult education (UNESCO 1985)}

One of the cornerstones of the Council of Europe recommendation Education in Prison (Recommendation $\mathrm{R}(89) 12$ ) is the UNESCO recommendations for adult education from the fourth international conference on adult education, held in Paris in 1985. The significant "right to learn" is set out in the final declaration from that conference as one of the prerequisites for individual growth and for the development of citizens. The right to learn is defined as:

- the right to read and write;

- the right to question and analyse;

- the right to imagine and create;

- the right to read one's own world and to write history;

- the right to have access to educational resources;

- the right to develop individual and collective skills.

According to the 1985 UnESCO declaration, this right to learn is not a luxury to be saved for some future date when all other fundamental rights have been satisfied. There can be no human development without the right to learn. The right to learn must be recognized as a fundamental right of every person, without regard to race, religion an inalienable right of every person regardless of race, religious opinions, and social status. In short, the UNESCO declaration sees this right as one of the best possible contributions to solving the fundamental problems of humanity. The declaration is, in its turn, based on a previous declaration drawn up at a UNESCO conference held in Nairobi in 1976 and adopted by 539 delegates from 122 member states. 


\subsection{The United Nations Convention on the Rights of the Child (1989)}

As more and more minors are being convicted of crimes, the Prison and Probation Service have had to become increasingly aware of safeguarding children's' rights in accordance with the United Nations Convention on the Rights of the Child, and in this context particularly article 28 on education and article 37 on torture, capital punishment and imprisonment.

Article 37 on torture, capital punishment and imprisonment reads:

Article 37

States Parties shall ensure that:

(a) No child shall be subjected to torture or other cruel, inhuman or degrading treatment or punishment. Neither capital punishment nor life imprisonment without possibility of release shall be imposed for offences committed by persons below 18 years of age;

(b) No child shall be deprived of his or her liberty unlawfully or arbitrarily. The arrest, detention or imprisonment of a child shall be in conformity with the law and shall be used only as a measure of last resort and for the shortest appropriate period of time;

(c) Every child deprived of liberty shall be treated with humanity and respect for the inherent dignity of the human person, and in a manner which takes into account the needs of persons of his or her age. In particular every child deprived of liberty shall be separated from adults unless it is considered in the child's best interest not to do so and shall have the right to maintain contact with his or her family through correspondence and visits, save in exceptional circumstances;

(d) Every child deprived of his or her liberty shall have the right to prompt access to legal and other appropriate assistance, as well as the right to challenge the legality of the deprivation of his or her liberty before a court or other competent, independent and impartial authority, and to a prompt decision on any such action.

Article 37 concerns deprivation of liberty, torture and inhumane treatment of children, and requires the states parties to guarantee a number of key rights of the child. It requires a firm commitment on the part of the States, and is one of the articles in the Convention that goes farthest in providing concrete protection for chil- 
dren. Article 37 applies to all treatment of children, with special emphasis on protection during deprivation of liberty in conjunction with criminal proceedings.

\subsection{The European Convention for the Protection of Human Rights and Fundamental Freedoms}

The Protocol to the European Convention for the Protection of Human Rights and Fundamental Freedoms of 4 November 1950 entered into force on 18 May 1954, and was signed by governments that were members of the Council of Europe. They agreed, inter alias, to the following:

Article 2 - Right to education

No person shall be denied the right to education. In the exercise of any functions which it assumes in relation to education and to teaching, the State shall respect the right of parents to ensure such education and teaching in conformity with their own religious and philosophical convictions.

All the Nordic countries have enshrined this European Convention in their national legislations. 


\section{Assessment, analysis and recommendations}

In this chapter, the project group provides a more detailed assessment and analysis of the findings based on both our survey and the description given of the prison populations, followed by a number of recommendations. These apply to the legislation, the right to education, the various models for education used by the Prison and Probation Services, descriptions of education in prisons, course options, teaching methods, and the place of education and training in the overall correctional system, the needs and options for lifelong learning, documentation and research, cooperation between the correctional system and other stakeholders, and the costs of prison education. The project group uses the term "prisoner" to apply both to convicted prisoners and to individuals being detained in remand.

\subsection{Legislation and prisoners' rights to education}

DENMARK In Denmark prisoners have a clear, unambiguous legal right to education, which is the same as that of all citizens in Denmark. The Act on General Adult Education stipulates that all adults have the right to education. The Danish institutions regulated by the Prison and Probation Service consequently have the right to provide education in accordance with the Act, upon approved application. This is followed up in the Sentence Enforcement Act, which stipulates that inmates must have the right and the obligation to work, study, and participate in other approved activities.

NORWAY In Norway, pursuant to the Education Act, there is a general right and obligation to attend compulsory school, and anyone who has completed compulsory school has the right to three years of upper 
secondary education. Adults born before 1 January 1978 also have the right to additional upper secondary education. They also have the right to supplementary basic education, and to special education. The recently-adopted Enforcement of Sentences Act also stipulates that the correctional services, in collaboration with other state institutions, must ensure that prisoners receive the services to which they are entitled by law. The instructions accompanying the Act stipulate the details of this obligation, stating that prisoners have the same right of access to services, and the same obligations and responsibilities, as the general population. Thus the Prison and Probation Service in Norway has a maximum undertaking to ensure that the relevant authorities offer the services to prisoners which they are obligated by law to offer, and to ensure that prisoners are able to utilise these services.

FINLAND In Finland basic education (comprehensive education, primary and lower secondary) is regulated by law, and the legislation stipulates that it is a universal right. The authorities are also obligated to ensure the equal opportunity of all to education beyond compulsory education, irrespective of the financial status of the individual and on the basis of his or her needs. Although this is not a legislated right, the aim of educational policy is for everyone, including prisoners, to be offered education beyond compulsory level, on the basis of individual needs.

The Ministry of Education is responsible for determining what schools are to offer upper secondary education, and who is responsible for vocational education. The legislation makes it possible for prisons to offer apprenticeship training in workshops.

SWEDEN In this domain, developments in Sweden have diverged to some extent from those of the other Nordic countries. Until the early 1990 s, education in prisons was an integral part of the general efforts made to offer adult education to individuals with little schooling, or to the educationally underprivileged in society. At that time, inmates had the same rights to compulsory education as all other citizens. After an administrative change, the resources for education in the correctional system were moved from the Ministry of Education to the Ministry of Justice. This resulted in elimination of the general rights of this group. Although the legislation states that: 
... The inhabitants of every Swedish municipality have the right to basic adult education beginning in the second half of the calendar year in which the individual turns 20 , if (s)he does not possess the skills normally achieved through compulsory schooling and is domiciled in Sweden (...) The stipulations in this section of the law do not apply to prisoners.

In Sweden, and with similar developments in the other Nordic countries, a major national project in the 1990s known as the "adult education initiative" was intended to provide individuals with both the knowledge and other necessary skills to be able to participate in lifelong learning. Although education in prisons may be considered to be covered by this perspective, this education is regulated in the Prison Treatment Act. This Act, rather than giving prisoners the right to education, gives them the opportunity for education.

\section{LEGISLATION}

Recommendation The project group recommends that the educational authorities in the Nordic countries ensure that their legislations clearly state the legal right and obligation to provide prisoners with the same right to education as other citizens. The legal authority stipulated in the Education Acts should also be stipulated in the legislation of the different countries relating to enforcement of sentences. When the right to education has been elucidated, this will have consequences in terms of resource allocation.

Considerations It is a basic requirement and provides the overarching perspective for ensuring that inmates receive education on equal terms with others in society that their right to education must be clearly stipulated in the legislation. Although the authorities in all the Nordic countries stress the necessity of lifelong learning and skill enhancement for adults, our survey indicates that the right of prisoners to education is not clearly enshrined in Nordic legislation. Thus it must be clearly stated in the legislation applying to the correctional authorities that the only thing of which an incarcerated individual is to be deprived is his or her liberty. In principle, all other rights are to be upheld. 
NORMALISATION

Recommendation The project group proposes that the principle of normalisation be applied to as great an extent as possible by utilising the public services of society such as schools, libraries, treatment services, etc.

Comments This can be accomplished both by giving more prisoners day release privileges, and by the building of a larger number of open correctional facilities. Day release privileges can even be arranged for some prisoners who serve their sentences in higher security prisons mainly by having special units for prisoners with day release privileges. Future correctional facilities must be built with units for prisoners who have day release privileges.

Considerations Once the right to education has been clearly enshrined in the legislation(s), it will be natural to review the implementation of and criteria for providing optimal teaching conditions in prisons. Traditionally, most of the teaching that takes place in Nordic prisons takes place in closed institutions. Denmark is the exception. There, most inmates are placed in open institutions, and thus they have far greater access to day release privileges for education and work than other Nordic prisoners.

On the basis of the principles of normalisation, integration, openness and responsibility, the view of the project group is that prisoners should have much greater access to the state educational system. One of the ways in which this can be achieved is by greater use of daytime release privileges, enabling inmates to attend community schools and thus to be more involved in and closer to everyday society than when they attend prison schools. They would also have a far greater range of options if they had access to the full range of courses offered in the local schools. Research results from Denmark (Holstein 1986) also indicate that prisoners granted day release privileges for schooling are less inclined towards recidivism. In other words, day release privileges serve as an instrument of crime prevention. Moreover, having prisoners serve their sentences in open correctional facilities is cost-beneficial as compared with the building of a large number of closed institutions to which various services have to be "imported". 


\section{ADMINISTRATIVE COOPERATION}

Recommendation The project group proposes that concrete plans and routines be drawn up for cooperation between the Prison and Probation Service and the various stakeholders at national, regional and local levels.

Considerations Good cooperation between the Prison and Probation Service and other authorities is an important factor in satisfying prisoners' educational requirements. There must be strategic planning for expansion of the range of educational options offered in prisons. Better cooperation and planning would give an overview of the needs for education amongst various groups of prisoners, and thus result in a broad range of educational options with satisfactory utilisation of resources.

\subsection{Models for implementation of education in prisons}

The Nordic countries differ from one another both in terms of the legislation and the right to education for prisoners, and therefore different comprehensive objectives have been set out and different models developed for implementation of education in prisons. These models can also be seen as expressions of cultural differences and differences in emphasis with regard to this area.

Our survey of the prison education systems in the Nordic countries indicates that practices can be described using five different models, each with its own special features. Roughly, these are: in Denmark export and self-sufficiency models, In Finland a combination model, in Norway an import model, and in Sweden a contract model. The implementation of each model is described briefly below.

DENMARK Most of the teaching done in the prison is carried out by teachers employed full-time by the Ministry of Justice. More than $50 \%$ of the teaching done in remand centres is also given by prison teachers, and the rest by teachers who are employed locally and paid on an hourly basis. 
FINLAND In Finland there are three categories of employees: teachers employed by the local educational institutions (the main category), teachers employed by the Ministry of Justice (at three facilities) and contracted teachers.

NORWAY All teaching in prisons is carried out by full and part-time teachers employed by the educational authorities.

SWEDEN Teaching is carried out by a large number of adult education organisations, with 21 different contracted parties in 2001. One-year contracts are convened, with a renewal option for one or two more years. In 2003 a pilot project was launched in south-western Sweden using teachers employed by the Prison and Probation Service under the pedagogical direction of the Swedish Agency for Flexible Learning. In 2005 a decision was made to implement the concept throughout the Prison and Probation Service over the next two years.

\subsubsection{Models for education in prisons}

In the following analysis of the models for implementation of education in prisons described above, the project group describes the advantages and disadvantages of each model as well as the general demands they imply for both the educational authorities and the correctional services.

1 The export model: Teachers employed by the educational authorities In this model, the general educational authorities bear the responsibility for the content, organisation and financing of education. The educational legislation is universally applicable; prisoners are no exception. They have the same range of educational options as all citizens. The teachers are the regular teachers from the local community. The classroom situation is the same as for all citizens.

Requirements that must be fulfilled if the export model is to function well:

- For this model to work, inmates must be allowed to leave the prison in order to participate in education in the community. This requires either the existence of national guidelines 
for education in prisons or very clear stipulations in the legislation governing the Prison and Probation Service regarding the rights of prisoners to leave the premises for education. This, in turn, means that the options regarding day release privileges for prisoners have to be adapted to the needs of each specific inmate. It also ensures a smooth transition to continued schooling in the community after release.

- One important aspect of cooperation between the Prison and Probation Service and the educational authorities is that schoolwork be well integrated into the overall planning work done by the Prisons and Probation Service with and for each inmate, and become a natural element of the formal future plans drawn up for prisoners. This requires the existence of the necessary pedagogical competence in the prisons for the assessment of each prisoner's educational needs, for communication with guidance counsellors, etc.

- Another requirement is a detailed security policy, not least in consideration of the possibility that prisoners might ask those who have been on day release to bring drugs back with them into the prison.

- Education should become a natural element of the sentence plans drawn up by the correctional services.

\section{Advantages}

- This model may contribute to minimising stigmatisation and thus to increasing normalisation, integration and accountability. With day release privileges, it also allows inmates access to the regular course range in the community.

- The system results in utilisation of the full range of educational options in the local community, and thus allows for normalisation, socialisation, sense of accountability, openness, reduces exclusion, and improves contact with day-today community life for prisoners to a greater extent than otherwise in the penal system. In addition, the interface with marginalised, groups, including prison convicts, can lead to development of new pedagogical methods.

- On the basis of the legislation, the Danish Prison and Probation Service can make substantial use of the possibility of prisoner's having day release privileges and thus leaving the institution for both work and education. 
Comments Although the legislation in the three other countries is positive in relation to day release privileges, practice varies greatly.

\section{Disadvantages}

- Day release privileges can be a great strain on the inmate - implying continual fluctuations between freedom and confinement.

- Problems may arise in motivating inmates who have considerable learning difficulties and previous negative experience of the traditional school system to attend school in the community.

2 The self-supply model: Teachers employed by the Ministry of Justice Education for prisoners is regulated in both the legislation on the correctional and the educational systems. Ultimate responsibility is in the hands of the correctional services, as is the financial responsibility for education for prisoners. In as far as is possible, inmates are to have access to the same educational options as the local community. National guidelines are needed for prison education. The Prison and Probation Service and the educational authorities will have to cooperate in order to maintain equality of educational opportunities.

Requirements that must be fulfilled if the self-supply model is to function well:

- Education must become a natural element of the services available to prisoners under the auspices of the correctional authorities. Teachers are appointed by the Prison and Probation services. Pedagogical expertise must be available at management level nationally, regionally and locally. In addition to the competence of the teaching staff, the correctional authorities must have access to specialist competence in adult education. Equal opportunities in education must also apply, as far as possible, in terms of classroom facilities and equipment.

- The system must issue grades and certificates equivalent to those issued elsewhere in the school system, as a quality guarantee for the teaching given. In order to ensure a smooth 
transition to schooling in the community, the teaching offered in prisons must be considered equivalent to the teaching given in the community under the regulation of the educational authorities.

- Education must be a natural element of sentence plans drawn up by the correctional services.

\section{Advantages}

- Services can be better coordinated and regulated. Education becomes a natural part of the total package of services offered to prisoners. The teachers are also an integral part of the prisoner's personnel contact network when serving his or her sentence, and can, for example, help the prisoners find information, etc. relating to their schooling.

- The various levels of the Prison and Probation Service have better access to a comprehensive picture of the services each inmate requires.

- When teachers are employed by the Ministry of Justice, their working hours and conditions are regulated to the services agreement of the Prison and Probation Service, and thus they work in accordance with the rhythm of the correctional facility. They also have the same regulations regarding vacation time as other personnel working in prisons. Teachers also serve on the regular consultation bodies and committees, and are thus considered members of the prison staff. These teachers are subject to a special working time agreement for prison teachers.

Disadvantages

- This system may result in the perspectives of the Prison and Probation Service and the prison professionals being given so much priority that the pedagogical aspects of prisoner's needs may be seen in too narrow a light. There is also a risk that teachers can become so well-integrated into the Prison and Probation Service that they lose their more comprehensive pedagogical perspective.

- There may be too little turnover amongst the teaching staff, and thus the organisation may become static, with too little debate regarding educational methods and creative thinking. 
Because prison schools are small and have few teachers, discussions about pedagogical methods and development work may be restricted or even lacking. There is a risk, over time, that these teachers will become isolated from the state school system.

Comments There are a number of other problems relating to this model that are difficult to pigeonhole as advantages or disadvantages. What are the consequences of putting financial and other responsibility for prison education in the hands of the correctional services? Might this result, in times of financial constraints, in difficulties with giving priority to prison education? There is reason to assume that equality of opportunity will be respected in this area when prison schools are accorded the same status as other adult education facilities, and there is to some extent a guarantee of this in that prison education would be covered in both the education and correctional legislation. Still, the question must be asked as to whether prison education managed in accordance with this model really is equivalent to education offered in the community. If the special pedagogical needs arising in the context of prison education are to be taken fully into account, specialists in education and pedagogy will have to be employed by the correctional services. The model probably also requires national guidelines for prison education.

3 The import model: Teachers employed by the educational authorities In this model, the educational authorities in every county have the overall responsibility, including the financial responsibility, for education in the prisons. The educational legislation does not distinguish between education offered at a correctional facility and in the community. The education offered at correctional facilities is considered equivalent to the corresponding education offered elsewhere in the community. In principle, the same courses are also offered in prisons and in the community, and the teachers have the same levels of competence. 
Requirements that must be fulfilled if the import model is to function well:

- There must be good cooperation between the correctional services/prison and the school administrator(s), and a clear understanding of who decides what (an ideal model would be a "branch" of the local school organised from a school perspective).

- Equivalent demands must be made regarding classroom facilities and equipment as in the community.

- Upon release, there must be a smooth transition to educational options in the community.

- Education must be a natural element of the prisoners' sentence Plans drawn up by the Prison and Probation Service.

\section{Advantages}

- Better normalisation and insight into the system, and greater independence from the penal system.

- Responsibility for and financing of education in the prisons rests with those who normally have responsibility for these matters in the community. The educational legislation does not distinguish between education in prisons and other education in society.

- Teachers have continuous access to a broad pedagogical forum with professional expertise, and do not run the risk of losing contact with the educational environment in the state school system. Although teachers in prisons have the same competence as all other teachers, there is still a risk of institutionalisation. It may be easier for teachers employed under this model to make proposals for changes and ask critical questions. The same salary levels apply as in the general educational system (In Norway, prison teachers also have a "prison supplement" amounting to approximately EUR 2,430 annually).

- This model better ensures the allocation of resources for education. It may also facilitate the acquisition of funding for research and development work.

- Easy transitions to the community school system are ensured, for example by having follow-up classes and good contacts with the regular school system and the employment services. 


\section{Disadvantages}

- In principle, this system implies access to the same course options as in the community, but because the institutions are small, this is never the case in reality, and cannot be so until inmates from closed institutions have day release privileges for education and for work. Situations can easily arise in which no one is prepared to accept responsibility. The Prison and Probation Service encompasses a wide variety of services, and frequently there is no one with responsibility for coordinating them.

- Owing to the fact that education for prisoners is such a small part of education in general, there may be problems at administrative levels nationally, regionally and locally. In cases of "branch schools" problems may arise in terms of inadequate contact with the "main school". If "loose ends" remain untied in the system, there may be integration problems and to schooling may be regarded as separate from other activities in the prison. Sometimes prison schools also find themselves with teachers considered unfit for the normal school system.

- Teachers in this system are subject to the working time agreement of the state school system with regard to school vacation periods. This schedule is in poor harmony with life at an institution that has to function day and night. One example of the consequences of the prison school having a working time agreement that is out of line with other working hours in the prison is that the prison school would be closed during school vacation periods and, in the worst case, the prisoners might have to spend their days locked up in their cells.

- The salary supplement for prison teachers can result in teachers staying in the system for many years. This means little turnover and a consequent lacking inflow of new pedagogical ideas and methods. 
4 The contract model: Teachers employed by the educational authorities who convene contracts with the Prison and Probation Service This system gives access to the same educational options as in the community, with education regulated by the laws and ordinances applying to the correctional system. The Prison and Probation Service have overall and financial responsibility. Good cooperation between the prison/Prison and Probation Service and the educational authorities is required to maintain equality of opportunities.

In 2003 a pilot project was launched in south-western Sweden using teachers employed by the Prison and Probation Service under the pedagogical direction of the Swedish Agency for Flexible Learning. In 2005 a decision was made to implement the concept throughout the Prison and Probation Service over the next two years.

Requirements that must be fulfilled if the contract model is to function well:

- This model requires national guidelines for education in prisons. The Prison and Probation Service must also have specialist competence in the field of adult education, in order to have correct specifications in calls for tender.

- It must be ensured that classroom facilities and equipment correspond to those in the state school system.

- With the right technical specifications for the contracts, it will be possible to ensure a smooth transition to education in the community after release.

- Education should be a natural element of the prisoners' future plans drawn up by the Prison and Probation Service.

\section{Advantages}

- In principle this system affords the same access to educational options as in the community.

- Education is a natural part of the other services offered to prisoners by the correctional authorities. Every inmate has the possibility of receiving the education (s)he requires, although this is contingent upon the length of the contract with the education provider in relation to changes in the prison population and consequent new educational needs. 
The contracting system gives the institutions greater financial autonomy and freedom.

- Diversity of contracting parties may fill a positive function.

Comments Because they are working on the basis of time-restricted contracts, teachers will probably be more motivated and committed to providing good education.

\section{Disadvantages}

- The Prison and Probation Service would have to have pedagogical expertise in order to set out the correct specifications in their calls for tender. The fact that contracting parties will come and go may make it difficult to coordinate services in relation to the correctional authorities. And with individuals coming and going, it may be difficult for the teachers to obtain an understanding of the place of education in the Prison and Probation Service and for the inmates.

- If they will only be staying in the system for a short time, teachers will be less committed in this kind of employment situation. This may lead to a long-term decrease in course options, and a lack of continuity in the teaching staff.

- Prison teachers do not all know each other, and there is a risk that they will not build up a professional identity as a group.

- Prisoners may find that the educational options differ greatly from one institution to another. There is a risk that this system would lead to a lack of equality in educational options.

Comments This model, too, gives rise to questions that are difficult to answer unambiguously. Will it allow prisoners to receive an education equivalent to that available in the community? Does this model assure prison teachers equivalent competence with others? Questions also arise in relation to the teaching environment, whether premises and equipment are properly utilised, or whether in the long run they will deteriorate. There are also questions related to the constantly shifting situation with contracting parties, and whether these parties are able to maintain stable, regular contact with the schools and workplaces in the community. Another question which arises is whether this model can possibly result in the development of firm, structured forms for cooperation between the correctional and the educational authorities. 
5 The combination model: Teachers employed by both the Ministry of Justice and the Educational Authorities

The educational legislation does not distinguish between education in prisons and other education. This model requires national guidelines for education of prisoners, both in the state school system and in correctional institutions. The model also requires a clear distribution of workload and responsibilities. Two parallel organisations have to share both overall and financial responsibility.

Requirements that must be fulfilled if the combination model is to function well:

- There must be no differences as regard teacher competence. The Prison and Probation Service must have expertise in adult education.

- The same courses are offered as in the community. Education becomes one of the many services offered to prisoners by the correctional services. It is important that there be good contact between the prison/Prison and Probation Service and the school system, to maintain equality of opportunity.

- The educational options must be equivalent to those offered in the community in general as regards premises, equipment, etc.

- Education should be a natural element of sentence plans drawn up by the Prison service.

\section{Advantages}

- In this model, education is one integral aspect of the overall activities offered at the institution. This can result in a wider range of course options, and "imported" teachers can also teach part of the time elsewhere in the local school system. At these facilities they can serve as a "social interface - contact officer" for inmates with day release privileges who attend the local schools. This can contribute to continuity in the transition from prison to freedom.

- The fact that the teaching staff consists of individuals employed by two different authorities can contribute to greater inspiration in terms of teaching methods, and to livelier discussions. 
Comments Teachers who work with target groups both within the prison school and in the state school system may be more motivated and challenged. Competition could, however, arise between the groups if inmates tended to choose their teachers more on the basis of personality than subject area (Or they might find that there were advantages in the prison environment if they "chose the prison teacher" instead of a teacher coming from outside, or vice versa).

\section{Disadvantages}

- The involvement of two different authorities subject to different rules and regulations can give rise to ambiguities with regard to responsibility.

- The combination model does not make equal opportunities in education as self-evident as the other models.

- Two groups of teachers with different working hours, etc. can give rise to trade union and policy conflicts.

Comments This model, too, contains variables that are difficult to clarify. Overall and financial responsibility rest with two parallel organisations, which requires clear distribution of workload and responsibility. Good cooperation between the Prison and Probation Service and the schools is important, and there must be clarity as to which of these authorities has the ultimate responsibility for prison education.

\subsubsection{Equal opportunities in prison education}

Recommendation The project group proposes that irrespective of which model is used, there must be pedagogical expertise at management level to provide quality assurance for the educational activities offered. Teaching staff are to have the same status, authority, and competence as in the state school system.

Considerations The main prerequisite for equivalence of educational opportunities for prisoners in closed facilities is, as indicated above, that the legislation is crystal clear. On the basis of the law(s) and international recommendations, guidelines or standards for education in prisons should be drawn up. This should be accomplished in cooperation between the educational authorities and the correctional services. 
Teaching staff must possess competence in line with the special educational needs of prisoners. This may apply to their needs for different teachers and, with regard to prisoners from other countries, to language skills, religion and culture. Teaching staff must be afforded both further training as teachers and updates with regard to working in the prison system, to stimulate debate and thus counteract institutionalisation.

In order for the teaching to be up-to-date and to utilise resources in a satisfactory way, the teaching facilities must maintain the same standards and be as well equipped as in the state school system. Today, many correctional institutions are housed in premises old with no separate educational arrangements.

\subsection{Description of education in prison facilities}

Recommendations The project group proposes that a joint Nordic description of education in prison facilities for the future be made. It should include:

- Compulsory education (corresponding to nine years of basic education, through secondary school)

- Further education (corresponding to upper secondary education)

- Internet-based education

- Full ICT training

- Special education

- Immigrant education, minority group education (Sami, Roma, etc.) and education for second generation immigrants

- Higher/university education.

Comments As part of any teaching, all schools/students should have access to a well-stocked library which, in itself, serves as an information and knowledge database.

Considerations Education in prisons should mirror the national educational system. Research indicates that many convicted prisoners have shortcomings in their educational background which correspond to those found in the general population. On the basis of various perspectives, including the principles of the right to education, humanitarianism and rehabilitation, education in the prison system should be generously defined. It is assumed that well-developed systems for prison education are investments in crime prevention in the 
sense that they will encourage more prisoners to continue their education and training and to be integrated on the labour market after they have served their time.

This survey of education in the prisons of the Nordic countries shows that the definition of the concept of "prison education" varies from country to country. There is a need for education in all the prison systems to implement perspectives that emphasise lifelong learning for the general population, a greater focus on adult education, the needs of the adult population for skill enhancement and the Nordic societies as increasingly multicultural.

A brief summary of descriptions of prison education in the Nordic countries follows:

DENMARK Education in prisons is broadly defined as any education the content of which is pursuant to the various laws issued under the Ministry for Education: These include special education, preparatory adult education in the subjects of Danish and mathematics, basic education in grades 5 to 9 (secondary school), general adult education corresponding to grades 9 and 10, upper secondary adult education, Internet-based courses, university studies, prison workshops (enabling a combination of introductory vocational training and comprehensive - primary and lower secondary - education), vocational education and education for prisoners of foreign origin.

FINLAND As mentioned above, the legislation is crystal clear as regards the right to comprehensive schooling, but it is ambiguous regarding upper secondary education and vocational training. There is also a lack of clarity with regard to who is responsible for prison education. Prison education is described as comprising basic education, upper secondary education and vocational training, and education in the national languages for immigrants, education for Roma, and university level education. To some extent it also includes courses offered by folk high schools and adult education institutions.

NORWAY The legal basis for prison education is clear and unambiguous in terms of primary, secondary and upper secondary education, in both the Educational Act from the Ministry of Education and 
Research, and in the Enforcement of Sentences Act. Accordingly, prison education is described as comprising comprehensive and further education (upper secondary and vocational education). It is stressed in the instructions accompanying the Act that young prisoners with inadequate educational backgrounds are to be particularly encouraged to make use of the opportunity to receive education while in prison. This legislation does not cover university or other higher education for prisoners, nor are the rights of immigrant prisoners to education clarified in Norwegian legislation.

SWEDEN

As described above, the legislation is not clear regarding prison education. Prison education is described as the education needed by each prisoner. This includes basic adult education (grades 1-9, primary and lower secondary comprehensive education), Swedish for immigrants, special education for prisoners with reading and writing difficulties, upper secondary education, vocational training including labour market skills training, university education and higher education, and other forms of education such as study circles and informal education such as courses on parenting.

\subsection{Educational opportunities}

Recommendations The project group sets out the following proposals for educational courses to satisfy prisoners' needs regarding both formal education and informal skills enhancement:

Theoretical education

- Basic education (in Finland of restricted scope).

- Special/remedial education, with a particular focus on the prisoners with the most inadequate educational backgrounds (it is a unique opportunity to spend time with and motivate such individuals while they are serving a prison sentence).

- Adult upper secondary education, with course options as extensive as those offered in the community.

- Being able to study with day release privileges is an important option, giving the individual more freedom of choice, and the prison inmate the chance to spend time in a "normal" study environment. 
- Education which satisfies the needs of foreign prisoners. Correspondence courses with some personal tutoring may play a role in satisfying individual needs.

\section{Vocational training}

- Vocational training in collaboration with the employment service in order to offer training that will prepare the individuals for the labour market.

- Cooperation should be encouraged between schools (theory) and prison workshops (practice). As a result of such cooperation, some activities could earn educational credits. When educational needs assessed, inmates' previous experience should also be taken into account. This can mean a great deal to individuals who do not have many positive testimonials.

- Some vocational training could be given in other languages. This could also be useful to inmates who are going to be deported after release, and who could thus gain competence that will be of value to them when they return to their home countries.

\section{New technology}

- The introduction of new technology (Internet-based solutions adapted to prison security needs) might be a simple way of giving more inmates access to a broad range of further education, university and other higher education.

- ICT courses of the same kinds offered in the regular schools in the community (both to master the techniques themselves and to use the new technologies in other subject studies). The new technology is also a necessary tool to be able to access various educational options outside the prison - a natural tool in relation to the expanding range of Internet-based adult education possibilities in society.

Creative activities, libraries, etc.

- Education in the arts with a view to improving self-development, life skills and motivation raises individuals' social skills. Participation in both creative activities and well-rounded physical activities often encourage prisoners to go on to other kinds of education. 
- There should be access to a well-stocked library and its services in collaboration with the library services available in the community.

Women prisoners

- All the items above apply equally to women prisoners who, precisely like their male counterparts, must be offered a wide range of educational opportunities adapted to their individual needs. For women, who otherwise run the risk of being considered a small, costly target group, the new technologies may be particularly important in terms of opening up a large number of options (unless the possibility of mixing men and women in prison education groups is considered).

Education as one piece of the puzzle

- Education can become more effective if it is combined with work, treatment programmes, and other approved activities. Very few prisoners can cope efficiently with full-time studies. Great flexibility and "tailor-made" weekly schedules should be available for each prisoner. Education is one important piece of a larger puzzle. If that piece falls into place, it may be decisive both for the success of the inmate's schooling and for his or her life as a whole.

\section{General}

- There must be access to purpose-suited facilities and state-ofthe-art equipment equivalent to that available in community adult education facilities or elsewhere in society.

Considerations Irrespective of the educational model used in their prisons, the Nordic countries have a shared basis in the idea that education is there for the benefit of the prisoner, for his or her own personal development, as well being one aspect of the general effort of creating a better platform to stand on after release from prison - hopefully into a life free from criminality and drugs. The orientation, options, methods and priorities of the prison education system should therefore all be based on the situation of each individual prisoner. Who are the users of the prison education system? What are their needs and who determines them? The aim of this 
section is to scrutinise the chain of user needs - how well do educational options correspond to today's needs - what would ideal educational options be? To begin with, it is very difficult to define educational needs. They may differ greatly, spanning the spectrum from subject-specific knowledge to skills required on the labour market, as well as including an individual's personal desire to learn, for example, a language, to know more about his or her country's history, or to understand what his or her lifestyle has to do with global events or with environmental issues. However, when we discuss needs below, we do so on the basis of the first perspective just mentioned - needs as assessed from the outside, when staff and teacher make an objective evaluation of a prisoner's needs. Still, the other perspective must be borne in mind and respected, and should also be part of the overall assessment when possible. The prisoner's needs as others see them must always be based on each individual prisoner's situation.

The discussion of needs below begins with the schematic description of the users of prison educational services in the Nordic countries given in chapter 3 , where it is clear that the prison populations in the Nordic countries are fairly similar. The age of most of the prison populations is 25 to 35 , with a very small number of prisoners under the age of 20 in relation to the overall prison population, owing to the fact that young offenders receive other treatment rather imprisonment. In terms of educational backgrounds, Finnish prisoners deviate from the other groups, with a much larger proportion of Finnish prisoners having completed comprehensive school. The number of prisoners of foreign origin varies, but is a substantial group, particularly in Sweden, where every fourth prisoner comes from another country than Sweden. There are substantial drug problems, with $60-70 \%$ of the prisoners in all the countries estimated as having substance or alcohol abuse problems.

5.4.1 The abusers - "once and never again" prisoners the professional criminals

In a Swedish report from 1998 (In Swedish: English equivalent title: The Prison and Probation Service and Prisoners - a future and societal trends analysis regarding prisoner development and prison populations, 
1998), describes the number of new prisoners as having decreased in recent years (although it has risen again since 1998) and the prison population as ageing. The report also predicts that the number of prisoners serving long sentences and convicted of narcotics crimes and violent crimes will increase, and probably come to account for the majority of prisoners. It paints a picture of the quite resilient welfare state as having distinct problem categories such as young people, immigrants, and single parents. It expresses some concern that when young people find it difficult to gain entry to the labour market, this will result in new kinds of social problems and new environments for drugs, with more and more people trying out drugs and other harmful substances. Immigrants, too, are a risk group for crime, particularly in conjunction with the fact that undesirable developments in terms of welfare are resulting in increasing poverty in many urban residential areas. According to the report, international research indicates that this kind of "poverty" is clearly linked to criminality. The report goes on to claim that developments in terms of legislation, socio-economic variables, social welfare services, psychiatry and the mass media are all relevant to how the groups of prisoners needing access to prison education develop. Thus both societal and individual stakeholders are decisive in determining who the users of the Prison and Probation Service will be.

In an attempt to be forward-looking, the project group presents below a model of future users of the Prison and Probation system: Prisoner abusers, "once and never again" prisoners and Prisoners considered professional criminals.

A The abusers, characterized, for example by having:

- long-term substance abuse problems,

- insecure upbringings,

- social problems (inadequate educational backgrounds, unemployment, etc.),

- been convicted of crimes of violence, assault and battery or intoxication,

- psychological problems,

- older ages (30 or older), and often being recidivists,

- a sizeable need for support from the social services. 
B “Once and never again” prisoners, characterized, for example by not:

- being long-term addicts as in group A above,

- having grown up in as obviously insecure situations as group A above,

- having as obvious social problems as group A above, for example often having better educational backgrounds,

- needing as much support from the social services.

C The professional criminals, who:

- are not currently abusers,

- often belong to criminal gangs such as Hells Angels, Bandidos, the Brotherhood, or OG (Original Gangsters),

- participate in more thoroughly-planned criminality,

- have experience of international criminality,

- do not require support from the social services.

A fourth group, not discussed separately in the report is:

\section{Increasing numbers of foreign prisoners}

According to the Swedish report, all groups A, B and C all contain prisoners of foreign origin, who themselves comprise a heterogeneous group. However, if this group increases, it will pose new challenges for prison education. In Sweden, where this group is already sizeable, not necessarily being able to read and write Swedish already makes these prisoners considerably disadvantaged in terms of educational options.

The report states that category $\mathrm{A}$ are and are expected to remain the dominant category of prisoners, and that category $\mathrm{B}$ are usually prisoners who have been convicted for the first time and who come from relatively orderly circumstances. Still, the crimes for which they have been convicted may be quite serious ones. The category $\mathrm{C}$ is quite a broad one, containing both members of known criminal gangs and individuals who participate in thoroughly-planned criminal activities. The report stresses the importance of deciding what kind of activities this group should be offered being that their primary need is not for the support of the social services. To a large extent their need for education would be for formalised education, although the report also points out a 
need for informal skill enhancement (activities of daily living, functioning as part of a group in society, as a family member, etc.). The general effort in society to give the citizens the lifelong learning perspective must also apply to prisoners within the Prison and Probation Service (See also section 5.7 below).

\subsection{Methods}

Recommendations The project group proposes the following approaches in order to fulfil the needs of prisoners for both formal and informal adult education:

- The same pedagogical points of departure for lifelong learning in adult education shall apply to adults in prison as in society at large - with the same adaptation to the target group as must always be used for any specific educational group, in prison or elsewhere. The methods implemented should be based on the idea of assessing the needs of each individual and, on that basis, giving him or her space in which to develop, in terms of knowledge and experience and also as an individual with civil rights and duties.

- The particular features of prison education - often a short time frame, a great need for individualisation, and students who may be at very different points along the route to acquiring life competence, places high demands both in terms of methodological flexibility and in terms of teachers being adaptable in their educational strategies.

Considerations

It is probable that outreach teaching methods, theme studies linked to the local community and everyday life would motivate and stimulate the inmates in terms of their education more than traditional teaching or individual tutoring that follows textbooks strictly.

This quotation is from a report published by the Swedish National Agency for Education in 1989 (In Swedish. Reports from the National Agency for Education, R89:35). According to Silwa Claesson, this report also states that prisoners require both individualisation and cooperation, for instance group work, as well as training in social skills. It is clearly a challenging task to be a prison 
teacher. Qualities required, according to the report include dedication to the task, patience, kindness, social commitment, firmness, flexibility, self-confidence, and toughness, as well as the abilities to individualise, to be forceful in difficult situations, and to exercise diplomacy. Thus when teachers are recruited for the correctional system, account should be taken of many things beyond the formal qualifications of the applicants. Being a teacher in the correctional system can be extremely demanding. The pressure on those who administrate the system is also great in that, for instance in terms of keeping their teachers competent and committed. Teachers in the correctional system often have relatively few colleagues. Moreover, the further training offered to teachers in the state school system is not always in line with their needs. According to this report, teachers in the correctional service who were polled about their needs most often mentioned the need for working methods that encourage motivation, detailed courses on the prison system, in-depth subject studies, and methods courses.

Many reports often point out that prisoners serving sentences often have negative experience from their own school days. Another subject often raised is dyslexia, and in this context many reports indicate that a large number of prisoners have reading and writing difficulties. However, recent studies indicate that dyslexia is not over-represented in the prison population as compared with the same age groups in the general population (Herkner, 2001. In Swedish. English equivalent title: How common is dyslexia among Swedish prisoners?). Nevertheless, many prisoners do have serious problems in reading, writing, and mathematics. One study contains testimony from prisoners that they found it difficult to help their children with their homework, that they found it embarrassing not to be able to read and write, and that they would conceal their weaknesses (Ohlsson, 2000. English equivalent title: Literacy/dyslexia education at the Malmö prison).

All these issues lead to the question of what teaching methods and what teacher competence is needed in prison education. Claesson refers to the qualities mentioned above, such as dedication to the task, patience, kindness, social commitment, etc. as "didactic tact", a term coined by van Manen in The Tact of Teach- 
ing (van Manen, 1991). Many reports recommend special needs teachers as fulfilling the requirements of the correctional system. In one, the author is of the view that special needs teachers are trained to see the strengths and weaknesses of each individual student, which makes them particularly suited to prison education. Jonasson found, through teacher interviews, that most prison teachers considered themselves more than just teachers. They were also discussion partners, therapists and prison staff. (Jonasson, 2001. In Swedish. English equivalent title: Teaching in prison: four teachers' experience)

According to Claesson, in short, there seems to be an understanding that there are students in prison who have special needs, although opinions are divided as to how the problems should be tackled - but in any case some "didactic tact" is required, and possibly also training in special needs education. Claesson highlights one feature that may distinguish a prison teacher from his or her "normal" teaching colleagues, relating to the social aspects of the teaching profession. This does not mean that there are no social aspects to teaching in the non-prison setting, but that these skills are particularly important for teachers in prisons. However, the fact that many of the prisoner respondents in this study complained that their prison teachers had too little specific subject knowledge, in practice it is necessary to find teachers with a good combination of the qualities needed and well-balanced teaching competence.

Is there a dimension to teaching in a prison setting that distinguishes the prison teacher from other teachers? According to Claesson it may be related to social aspects. She goes on to report on an interview with a prison student who said:

There are three things that make a good prison teacher: firstly being devoted to the teaching profession, really keen to teach, as well as being aware of the social dimension. Secondly, being extremely hands-on and practical, and prepared to be flexible about learning and teaching methods. Thirdly, making you feel it's OK to be bad at schoolwork. Many people in this setting, myself included, have mixed experience of school. And maybe we think that a person who is bad at schoolwork is a bad person. In which case we end up skipping school or dropping out 
or not giving a damn. But it's ok not to be good at everything. It's ok to say I didn't do my assignment if you hear "All right, well, just sit down and give it a try now." I think the feeling that you are welcome anyway, that the teacher isn't going to give up on you, is important.

Skaalvik et al. indicate, in a report from 2002, that there are great discrepancies regarding what school administrators, teachers and prison staff see as the objective of prison education. Administrators tend to put more emphasis on formal aspects such as following the curriculum and getting a diploma, teachers stress the importance of motivation, gaining self-confidence and developing social skills, while prison staff members emphasise the opportunities for prisoners to improve their basic skills such as reading, writing and mathematics. The objective a person feels to be most important will, of course, affect his or her view of what methodology is suitable and what teaching strategies should be used in prison education. This report also points out that teachers experience the classroom situation in prisons as different from the classroom situations in public schools in many ways. For instance, there tends to be rapid student turnover in prison schools, interruptions of schooling for shorter or longer periods are common, and students often have a negative attitude on the basis of their previous educational experience, inadequate basic skills, and poor selfconfidence (Skaalvik et al., 2002. In Norwegian, English equivalent title: Observations and Ambitions Regarding Prison Teaching).

According to this report, if there were a spectrum with the students' points of departure at one end and long-term goals at the other, one would also span the spectrum of opinions about the objectives of prison education amongst prison school administrators and teachers and other prison staff.

\begin{tabular}{|c|c|c|c|}
\hline $\begin{array}{l}\text { Individual points } \\
\text { of departure }\end{array} \rightarrow$ & $\begin{array}{l}\text { Educational } \\
\text { objectives }\end{array} \rightarrow$ & $\begin{array}{l}\text { Formal } \\
\text { objectives }\end{array}$ & $\begin{array}{l}\text { Long-term } \\
\text { objectives }\end{array}$ \\
\hline $\begin{array}{l}\text { - Feeling comfortable } \\
\text { in the classroom } \\
\text { - Motivation } \\
\text { - Self-confidence }\end{array}$ & $\begin{array}{l}\text { - Knowledge } \\
\text { - Skills } \\
\text { - Social } \\
\text { development } \\
\text { - Attitudes }\end{array}$ & $\begin{array}{l}\text { - Diplomas } \\
\text { - Course } \\
\text { certificates }\end{array}$ & $\begin{array}{l}\text { - Mastering } \\
\text { life skills }\end{array}$ \\
\hline
\end{tabular}

FIGURE 5.1 The objectives of prison education seen over time 
For the teacher, the person who works with the students in practice, the "individual's point of departure" is essential to know in order to find the appropriate means of achieving the long-term objectives. For the prison school administrator, on the other hand, coming from experience of the state school system, "formal objectives" are central. In any case, each new inmate must be approached with awareness of all this in mind, and from the perspective of lifelong learning, without bias and in an honest attempt to see where on the spectrum (s)he is starting out, in order to use the most appropriate methods in working with that individual. For one prisoner, working towards a specific goal may be just right, while for another the most important thing is to start with basic skill improvement. It is very likely that prison teachers face greater challenges than "regular" adult education teachers when it comes to finding the right keys to unlock each individual student's learning abilities.

A government commission report (1996:27 in Swedish. English equivalent title: A Strategy for the Adult Education Initiative and Lifelong Learning) highlights the fact that lifelong learning is meant to provide individuals with the competence they require to be able to solve the problems they encounter as citizens in society, in their professional roles and in everyday life. Lifelong learning has a twosided perspective, including both the factual knowledge needed to go on to further education, and the skills needed to continue the lifelong learning process in society. Thus, in the prison setting as well, education must be characterised both by providing opportunities to develop personal skills such as self-confidence, problem-solving abilities, creativity, and by improving the ability to learn, and to take in and assess information.

In cooperation with the other personnel groups in a prison, the teachers are involved in a process of encouraging change, which is often difficult to pursue in a setting that also stimulates other processes. Skaalvik et al describe, for example, how the socialisation process in prisons strives to achieve through education and other activities, is counteracted by what they call "prisonification". Similar processes are described in the report Survival and Change (In Swedish, 2002. Prison and Probation Service research committee), an investigation into the possibilities of achieving change in work with sex offenders. 
Links to the outside world are equally important to teachers as to incarcerated students, and irrespective of whether or not the prison school is run as a branch of a public school. According to Skaalvik et al., a prison school exists in a field of tension between the world of education and the world of institutions, and where the latter is often determinative. This makes further education and other opportunities for renewal and new perspectives all the more important for the teachers whose task it is to keep the learning process alive in the prison environment and to equip prisoners with the tools they need for individual personal development.

\subsection{The place of education in the Prison and Probation Services}

A prison sentence is one of the ways society is able to react to undesirable actions. This reaction builds on the instruments available to the Prison and Probation Service to promote the re-integration of the prisoner into society. Many different professional categories contribute to this effort. In other words, institutions run by the Prison and Probation Service is staffed by representatives of various stakeholders who may also have different, contradictory, objectives. The educational authority is the national agency meant to ensure that convicted prisoners receive the education to which they have a legal right. The Prison and Probation Service have responsibility for coordinating the measures implemented by the various state authorities so that prisoners have well-organised, positive options.

One of the objectives of education in the Prison and Probation Service is to ensure that prisoners have the same range of course options as is available in society at large.

Recommendations The project group proposes that:

- The educational authorities and Prison and Probation Services at the national, regional and local levels together discuss the scope of and need for educational opportunities (seen from the point of view of the needs of both the prison population and the institutions) and what courses are to be offered. 
There should be equal opportunities for work, education and other approved activities in the prisons, available during normal working hours. From the point of view of equality, the same remuneration should be paid to prisoners for the different activities, not least so as to avoid competition between the activities offered.

- The recognised need of prisoners for activation (as part of the process of resocialisation) is to be the main starting point when the different prison activities are prioritised. There should be flexible teaching arrangements. A prisoner should be able to organise his or her activities as a combination of work, schooling, programmes, and other approved activities.

- Teaching shall be provided by trained educational staff with certified subject area competence. Education should be part of each prisoner's future plan, extending up to and beyond release. A person with pedagogical expertise should assess the needs of the prisoner for education. Release or conditional release, to a situation with work, schooling or other activities - must be prepared in good time and in consultation between the prisoner and other parties involved.

Considerations DENMARK

All prisoners are required to participate in activities: work, education or some other approved activity. The national Prisons and Probation Service in collaboration with local prison management draw up the "activity regulations" determining how many fulltime students each prison is to have. The "activity planning" for each institution determines the balance between education, programmes and other activities, on the basis of the needs of the prison population. The physical dimensions of the institution set the limits for all the various occupations, including work, schooling and other activities. This is reflected in the number of inmates able to be offered educational activities which, in turn, determines the level of activity and, in turn, the number of teachers employed. The "occupation plans" are discussed and revised at the annual "contract meetings" held between the management of the national correctional authorities and local prisons. Experienced prison administrators are quick to see when their prison populations change, and immediately notify the authorities of necessary 
changes in the activities offered. Every prisoner serving a sentence longer than 60 days must have a future plan containing, amongst other things, the activities (including schooling) in which (s)he will participate while in prison and upon release. (There is a proposal pending that this minimum sentence time should be increased to 4 months). As a rule, a member of the prison staff is responsible for seeing to it that a plan is drawn up. That staff member continues to take responsibility for its being implemented, and for collecting the necessary information.

FINLAND Every prisoner serving a sentence is obliged to participate in activities, i.e. to participate in work, education or programmes. A work and functional capacity assessment is carried out for all prisoners serving sentences of at least 6 months. Prisons are to have facilities for appropriate vocational training and necessary education. The activities and their scopes are decided in annual discussion between the regional and local authorities. The regional authorities and the local prison authorities strive to coordinate the schooling offered to inmates in each region. Prisoners are to be placed at work or other activities corresponding to their individual aptitudes, and with a view to maintaining and developing their vocational skills and/or improving their abilities to function in society. It is up to the director or assistant director of each prison to decide who will be offered schooling, but the matter is also discussed in the advisory committee, which includes representatives of the various prison staff groups and, in some places, also of the teachers. For prisoners serving sentences of longer than two years, the analysis of individual risks and needs, including educational needs, and the drawing up of the ongoing sentence plan takes place in special "assessment and allocation units" Each long term prisoner has a personal contact officer responsible for drawing up and implementing his or her sentence plan. According to the government bill for a new Imprisonment Act, a sentence plan is to be made for every prisoner.

Norway It is the task of the Prison and Probation Service to ensure that prisoners are offered daytime activities. Prisoners may satisfy the requirement of doing activities through work, schooling, programmes or other measures. The Norwegian Parliament allocates earmarked funds annually for education under the auspices of the 
correctional services. On behalf of the Ministry of Education and Research, The County Governor of Hordaland distributes these budgeted funds to the county administrations. The budget distribution and educational options are discussed every year by the educational authorities and the Prison and Probation Service at national, regional and local levels. Every prisoner serving a sentence longer than 6 months must have a "sentence plan", stating what activities the individual will participate in while in prison and after release. A personal contact officer at the prison is responsible for collecting and coordinating information from the various stakeholders in the prison system.

SWEDEN The Ministry of Justice has signalled clearly that it is incumbent upon the Prison and Probation Service to ensure that prisoners have access to basic education, upper secondary education and vocational training. Education is one aspect of what the Swedish Prison and Probation Service define as "programme activities". All prisoners are required to participate in activities, defined as work, schooling, "criminality and abuse related treatment programmes" and other structured activities. The regional and local authorities meet three times a year to discuss the organisation and scope of required activities/activities offered by each prison. The decision of who participates in education is made collegially by the local director, the prison contact officers, and possibly the head teachers or programme inspector. Owing to decentralisation, local prison managements have a great deal of power.

\subsection{Options and needs for lifelong learning}

Recommendations The project group proposes that:

- Prisoners always have their non-formal learning assessed.

- Once a convicted prisoner/prisoner in remand has had his or her non-formal learning assessed, educational options must be provided that correspond to the needs of each individual, and individuals must be sent to the prisons that can offer the options they require or give them the opportunity to have day release privileges for work or schooling. 
- Education must be defined broadly enough to include, in addition to subject competence, social skills and activities of daily life.

Comments It is important to organise the education for each prisoner on the basis of what (s)he knows and has mastered. This is the starting point from which it is possible to give each prisoner a long-term chance of having his or her educational needs satisfied. It is incumbent upon each prison school and/or the Prison and Probation Service to ensure that each school has sufficient expertise to assess the prisoners' real competence, or has contract with an organisation in the community that can perform such an evaluation.

Considerations In the European Union as a whole and in individual European countries, authorities focus on providing young people and adults with the qualifications and skills enhancement they require to be able to perform the new tasks in a society in constant change. Individuals unable to utilise these opportunities for skills enhancement will find themselves marginalised from the general educational and labour market. In this context, prison populations are vulnerable groups. It is a prerequisite for satisfying the needs of different groups regarding education and skills enhancement that the educational authorities have the ability and instruments to be able to quickly asses the educational options required by the different groups. The state school system has various means of assessing an individual's skill enhancement needs.

A Norwegian report from 2002 draws the conclusion that approximately $1 \%$ of the adult population needs remedial comprehensive school level education (primary and lower secondary). International and national studies of the reading and writing skills of young people and adults have pointed out that there is a large proportion of the population with inadequate basic skills. The Norwegian report states that there is every reason to believe that there will be more adults who will need remedial education in the future, and that this need will persist for many years. (Final report from a national project, equivalent English title Survey and Organisation of Options in Basic Adult Education, 2002). A Swedish report from 1999 indicates that the corresponding proportion of the prison population is 15\% (In Swedish. Equivalent English title: The Living Conditions of Prisoners, 1999). 
Another Norwegian project, The non-formal learning project 1999-2002, was initiated by the Norwegian government in order to implement the decision adopted by the Norwegian parliament: "to establish a system giving adults the right to document their non-formal learning without having to pass examinations". As described above, non-formal learning includes all formal and informal competence an individual has acquired through the school system, paid and unpaid work, being active in clubs and associations, and through family and community life. A report, Documentation and assessment of non-formal learning, concludes with the statement that when all adults have the right to documentation of their non-formal learning, the national system will have to adapt to new needs and interests. Documentation is more firmly rooted in some groups than others, and so some groups' needs will only require small adjustments, while for others entirely new ways of doing things will have to be introduced. The report also focuses particular attention on individuals with the weakest educational backgrounds and who have been excluded from the labour market. When non-formal learning assessments have been implemented in relation to prison education, this may mean that, to a much larger extent than in the past, prisoners will be able to plan and structure their educational options on the basis of what they already know and of their needs (The Informal Learning project 1999-2002 - At the finish line or on the starting blocks? Final report, vox, Norwegian National Institute for Adult Education, Oslo 2002).

Similar work with assessment of non-formal learning or validation of knowledge and experience is also under way in the other Nordic countries.

As mentioned by way of introduction, skill enhancement has been extensively implemented in the ordinary adult education system. The prison population is a marginalised group in society. Prisoners have a great deal of competence in many areas, but often use the knowledge they have in inappropriate ways, which results in negative consequences for themselves and others as well as for society as a whole. They frequently lack the necessary motivation and self-confidence to enter into a regular school or work situation. Also, many recidivists have been in and out of prison work and school facilities year after year, without having made any par- 
ticular progress. A basic prerequisite for their having a chance to succeed is that their needs and points of departure in terms of education be assessed, so that each prisoner can carry on from the level that suits him or her best.

\subsection{Documentation and research}

Recommendations The project group proposes that systematic reporting, evaluation and research on education in prisons be carried out with a view to:

- documenting the work being done on education in prisons in comparison, for example, with treatment programmes and other activities,

- evaluating whether the range offered as prison education corresponds to the educational needs of the prison population,

- obtaining a clear picture of which prisoners do and do not participate in, how students are recruited to prison education,

- assessing teaching methods and quality,

- obtaining a systematic evaluation of prison workshops in relation to the applying curricula,

- determining the place of prison education in the correctional services,

- expressing an opinion regarding whether new programmes, etc., such as classes and treatment programmes, should be evaluated, or whether research into them should be carried out.

Comments Research into prison education may provide new knowledge that can be applied in the state school system. Such knowledge may, in the long term, contribute to crime prevention in society.

Considerations Crime is a major expense to society, but in spite of its being a significant societal problem, very little research has been carried out regarding the correctional services.

\begin{tabular}{lll} 
Country & Annual reporting & Evaluation/research \\
\hline Denmark & Statistics submitted annually. & In the 1970s and 1980s there \\
& $\begin{array}{l}\text { No systematic reporting on } \\
\text { prison education. In some areas }\end{array}$ & $\begin{array}{l}\text { was some research into } \\
\text { prison education, but not }\end{array}$ \\
& $\begin{array}{l}\text { systematic information is sub- } \\
\text { mitted, for instance as regards }\end{array}$ & in recent years. \\
& daytime release privileges. &
\end{tabular}




\begin{tabular}{|c|c|c|}
\hline Finland & $\begin{array}{l}\text { Systematic annual reporting } \\
\text { of prison education. For } \\
\text { prisoners with sentences longer } \\
\text { than } 2 \text { years (in the future for } \\
\text { all prisoners) risk and needs } \\
\text { analyses, including educational } \\
\text { needs, are carried out. The work } \\
\text { and mental capacity of short- } \\
\text { term prisoners is assessed. }\end{array}$ & $\begin{array}{l}\text { Relatively little research on } \\
\text { education. No research planned } \\
\text { by Ministry of Justice. Research } \\
\text { on special educational needs } \\
\text { of prisoners is planned and } \\
\text { some cooperation projects on } \\
\text { developing the skills of prison } \\
\text { staff to cooperate in education } \\
\text { is ongoing. }\end{array}$ \\
\hline Norway & $\begin{array}{l}\text { Since } 1996 \text {, annual systematic } \\
\text { reporting on prison education. } \\
\text { Very little systematic evaluation } \\
\text { of prisoners' points of depar- } \\
\text { ture and educational needs. }\end{array}$ & $\begin{array}{l}\text { A major research project was } \\
\text { concluded in } 2003 \text {. This project } \\
\text { was decided on in unanimity } \\
\text { by the Norwegian parliament. } \\
\text { A White Paper on Education in } \\
\text { Prison will be presented by the } \\
\text { Government in spring } 2005\end{array}$ \\
\hline Sweden & $\begin{array}{l}\text { Systematic reporting through } \\
\text { a comprehensive documentation } \\
\text { system which includes prison } \\
\text { education. ASI/MAPS is a tool } \\
\text { for documentation of inmates, } \\
\text { activities and treatment. }\end{array}$ & $\begin{array}{l}\text { There are and have been some } \\
\text { research projects initiated by } \\
\text { the research committee of the } \\
\text { Swedish Correctional Services. }\end{array}$ \\
\hline
\end{tabular}

\section{Summary}

As the table presented here shows, with the exception of Denmark the Nordic countries already have systematic reporting regarding prison education. Only in Norway and Sweden is there any substantial amount of assessment and research into prison education. And yet there is a comprehensive requirement in the Nordic countries that there be quality assurance in educational activities on the basis of various kinds of reporting, evaluation and research in order to ensure agreement between the resources allocated and the education offered, and to give a clear picture of what educational activities are offered. 


\subsection{Cooperation between the Prison and Probation Service and other stakeholders}

Recommendations The project group proposes increased contact between prisons and society at large and that:

- The state social service authorities must provide the services as required by law, which would result in structured, systematic, inter-agency cooperation. There must be better contact and cooperation between agencies such as the educational authorities, the correctional services, the labour market authorities, the main trade unions and the employment services.

- There should be more frequent placement of inmates in open institutions allowing more day release privileges for education and work, which would result in automatically making better use of traditional social services.

- There should be better utilisation of the expertise and options of the labour market authorities for prison convicts, in order to ensure smoother transitions back into society.

- Internet-based education with satisfactory security solutions will provide a supplementary tool for utilisation of the state educational services. Internet-based education will: a) be a contribution to normalisation b) offer more options - enable prisoners to participate in a wider range of courses $\mathrm{c}$ ) reach more inmates - facilitating individualisation and d) enable greater educational continuity and thus increase the possibility of completing certificates and being awarded diplomas. Information and communication technology (ICT) must be used as a tool in prisons in the same way as in society at large.

- Cooperation between prison school administrators, workshop managers and representatives of the employment services must be improved. Prisoners must be given vocational experience in the workshop and education in the classroom. This would give them more options and probably increase their motivation, because they would know that the activities in which they were involved would be beneficial after release. This would also make vocational training in prison an integral part of the skills enhancement work that continues after release. See also sections 5.1 and 5.6. 
Considerations A prison term served in a closed institution automatically reduces contact with society at large to some extent. Every year, substantial resources are spent on prison institutions where individuals are incarcerated for periods of time of varying duration.

Historically, these resources have been utilised in a far too segmented way, with too little being invested in programmes to promote normalisation and integration. In a comprehensive societal perspective, it is important that future measures and programmes be coordinated so as to promote re-integration of prisoners into society.

DENMARK Normally, a prison sentence will be served in an open institution. Prisoner's needs of various social services such as dentistry, drug treatment and education are to be met in the local community. The principle of normalisation is implemented by extensive use of day release privileges from these open institutions. (Danish prisons have an average of 1,200 inmates, 100 of whom exercise day release privileges - approximately $8 \%$ ). The principles of normalisation and openness are regulated in the "Principles Programme". It is general practice that prisoners in open institutions have full access to Internet-based education (with use of the Internet and email).

FINLAND Finland uses day release privileges very little, and less and less in recent years. In 2003, a total of 142 inmates had day release privileges (for education). Long-term prisoners approaching release are to have a release plan, drawn up in consultation with the social services and other relevant stakeholders. If the prisoner is to be released on parole, the probation services are also involved in the planning. If the prisoner has been involved in prison education, the teacher and study counsellor should encourage the prisoner to continue his or her studies upon release. Vocational training is organised in modules, making it easy to continue at a later time.

NORWAY Very few prisoners in Norway have day release privileges for school and work. In 2001, 184 prisoners, mainly in open institutions, made the transition to day release privileges. Norway has a unique arrangement referred to as "follow-up classes" in the community. These classes were established to enable prisoners receiv- 
ing prison education to continue attending the same classes upon release. One follow-up class has developed a model for interagency cooperation with the student in focus, where the social services have more responsibility than elsewhere. The labour market authorities have become far more involved in re-integration of prisoners into society since agreements between the labour market and correctional authorities were drawn up at national, region and local levels.

SWEDEN Very few Swedish prisoners have day release privileges: the figure for 2001 was 252 . There is an interesting national project known as $\mathrm{KrAmi}$, with systematic cooperation between the correctional services, the labour market authorities and the municipal social services. In Sweden, too, there is a national agreement between the Prison and Probation Service and the labour market authorities, followed up with local action plans drawn up by every correctional agency and the relevant employment service. A project regarding Internet-based education has been initiated at a number of institutions in order to assess security problems, and technical and pedagogical issues.

\subsection{The cost of prison education}

Recommendation The project group suggests continued, extended funding for prison education.

Comments Today the demand for prison education far outstrips supply.

The group with the greatest educational needs is a group which is also often difficult to recruit to schooling in the state school system, and thus the opportunity should be taken to begin to fulfil the ambitions expressed by society in terms of the "adult education initiative" and lifelong learning when the individuals belonging to this group are institutionalised. Today, education accounts for only a small fraction of the costs of a prison sentence. From a socioeconomic point of view it would undoubtedly be beneficial to invest more in prison education. 
Considerations It is difficult to compare statistics on the cost of prison education. Education is organised differently from country to country, and it is sometimes also financed by different authorities. Moreover, it may be difficult to distinguish the costs of prison education from the costs of other education. Nonetheless, the project group has attempted to collect either actual or estimated figures for each country. Owing to the inherent uncertainty, we have restricted our statistics to the few specific measurements we considered most interesting to consider. The statistics submitted by each country and not considered in this report are material for further study.

One interesting figure to compare is the cost of prison education in each country relative to the total cost of a prison term per inmate and day. These figures may provide an indication of the level of ambition regarding prison education in each country.

TABLE 5.1 The costs of prison education (in Euro)

\begin{tabular}{lrrrr} 
Cost & Denmark & Finland & Norway & Sweden \\
\hline $\begin{array}{l}\text { Total cost of prison } \\
\text { education }\end{array}$ & $6,447,580$ & $4,203,857$ & $11,130,913$ & $8,037,500$ \\
\hline $\begin{array}{l}\text { Annual cost of full- } \\
\text { time education per }\end{array}$ & 19,839 & 13,723 & $17,272^{2}$ & 16,263 \\
study place? & & & & \\
\hline $\begin{array}{l}\text { Cost, per day prison } \\
\text { education per } \\
\text { prison/ remand place }\end{array}$ & 5.0 & 3.6 & 10.8 & $3.6^{3} / 5.0^{4}$ \\
$\begin{array}{l}\text { Prison education } \\
\text { as percentage of } \\
\text { total cost per day }\end{array}$ & $3.3 \%$ & $3 \%$ & $5.6 \%$ & $2 \%$ \\
\hline
\end{tabular}

1) Estimated on the basis of the total number of classroom hours in relation to the number of hours per year considered full-time activity for a prisoner (1,850 hours in Denmark, 2,000 hours in Finland, 1,425 hours in Norway and 2,000 hours in Sweden).

2) in Norway, full-time studies are 38 weeks per year (1,425 hours), which raises the relative cost per student per year.

3) including remand prison places.

4) excluding remand prison places.

5) total cost of one prisoner per day (average). 


\section{Comments "A pack of cigarettes a day"}

As indicated in the table, the cost of prison education relative to the total cost per prisoner and day is small, in spite of the fact that millions per year are allocated by each country to education. Proportionally, prison education accounts for between $2 \%$ and just over $5 \%$ of the total cost for a prison place. Seen from a different perspective, education can be described as costing the Prison and Probation Service in the Nordic countries the equivalent of one package of cigarettes per prisoner and day.

Another variable that would be an interesting challenge to measure would be the total cost of the educational needs in the prison systems. This could be measured either on the basis of the actual needs or on the basis of the expressed ambitions of each country regarding the educational needs of the prisoners. It would at least have to include the needs for supplementary basic and further education, since this corresponds to the basic competence required at most workplaces in society. Below, we sketch a theoretical model to service as a point of departure for further discussions.

\section{Invest more now to reduce future costs}

Using the example of the Swedish correctional services, we can say that there are approximately 4,327 places in prisons today, and most of the year the occupancy figures for these places are 90-95 per cent. Extrapolating from our arguments above (see Chapter 2 regarding each country as well as Chapter 3 on the prison population), a rough and conservative estimate is that at least half of the prisoners need remedial basic and further education. This level of ambition is also in good accord with the ambitions expressed in the official instructions regarding appropriations, etc. decreed by the governments to the Prison and Probation Services, as well as with the general demands of society regarding the Adult Education Initiative and lifelong learning. This means that educational activities should be offered corresponding to a total of approximately 2,150 full-time classroom opportunities. Over the course of the years, these places will be accessed by a substantially larger number of prisoners, owing to variations in sentence serving time.

In the table above (see also the section of Chapter 2 on Sweden), the figure given for the total number of study hours for 2001 
is 990,000 , which corresponds to a total of approximately 495 fulltime classroom opportunities (one full-time classroom opportunity being about 2,000 study hours). Following from this argument, it is clear that in Swedish prisons in 2001 the educational activities corresponded to less than 35 per cent of the real need which, in this model, is estimated conservatively.

Is it reasonable, in a time of financial constraints, to discuss increasing the educational activities in prisons? Raising the arguments put forward here to a socio-economic level, we can say that every single prisoner who breaks a vicious circle of drug dependence and criminality means a benefit of several million Euro. A report from the Swedish National Board of Health and Welfare describes the estimated socio-economic benefit of a number of cooperative projects run by the correctional services, the employment services and the municipal social services as follows: the return on investment to society for every Euro invested in these projects was between 10 and 18 . These are fantastic results seen in relation to the perspective of the budget of each of the agencies concerned. Thus we conclude that if the broader perspective were considered in relation to allocations for prison education, decision makers in society would have a sounder basis for planning both investments and cutbacks (Nyström et al. In Swedish. English equivalent title: Investing in Work, 2002). 


\section{Crime prevention in the short and long term}

By Inger Marie Fridhov, Deputy Director,

Norwegian Crime Prevention Council

Crime prevention is a complex concept. It is beyond the scope of this chapter to define it in detail. Prevention can take place both at societal and individual levels - in relation to individuals and groups of individuals. The vast majority of the crime prevention projects in the Nordic countries have been individual-oriented, with a focus on helping people move towards a law-abiding way of life. Only a very few projects have had the overarching ambition of changing the conditions under which individuals live and develop.

Traditionally, crime prevention - like prophylactic medicine has had three subcategories: primary, secondary and tertiary. When we discuss the crime prevention activities carried out by the prison and probation services, these are not means of primary crime prevention, which is aimed society as a whole. These activities are both secondary crime prevention, focused on individuals at risk of being in the vicious circle a criminal lifestyle implies, and tertiary crime prevention, for individuals who are already incarcerated. The term crime prevention, as used in the Prison and Probation Service, is synonymous with the more frequently used term rehabilitation.

\subsection{Crime prevention in prisons}

The Nordic Prison and Probation Service is based on a shared set of ideas and values relating to both key terms universal prevention and individual prevention. When a prisoner serves a prison sentence, it is assumed (s)he will receive elements of both. One change that has taken place over the last 150 years is the growing realization that incarceration and deprivation of liberty do not 
have individual preventive effects in themselves, and in fact often have the opposite result. If a sentence served under the auspices of the Prison and Probation Service is to have preventive effects, programmes must be offered in relation to which it may be assumed that prisoners will have lasting benefit when they have been released to live and function in society at large.

As we have seen, the prison population in the Nordic countries is reasonably homogeneous and Nordic prisoners have roughly the same problems. To varying extents, these individuals suffer from inadequate opportunities to become integrated on the labour market, educational shortcomings, ill health and housing problems, as well as poverty, debt, substance abuse, and the absence of a social network. At the other end of the spectrum there is a small group of convicted prisoners who can be considered as possessing strong resources. The proportion of foreign prisoners differs amongst the Nordic countries, as do their countries of origin.

\section{Crime prevention through educational and work experience}

To date, the two main types of rehabilitation and crime prevention measures in the Nordic prisons have been work and educational programmes. We know very little, however, about the extent to which participation in such activities has contributed to reducing recidivism, owing to the fact that there have been no longitudinal studies to follow up prisoners long after release with a view to investigating the effects of participation in one programme as compared with another.

Nor is it helpful to use recidivism as an indicator of the preventive effects of work and educational programmes in prison, as there has been no registration of the correlation between recidivism and the programmes in which prisoners have participated. There are no comparative studies of what has become of one prisoner or one group of prisoners after their return to the community. Such studies pose special methodological problems and difficulties in terms of research ethics. Another problematic issue is how the concept of "recidivism" is defined. The Swedish Crime Prevention Council is currently running a project with the ambition of reducing recidivism. When the results of this study have been published, we should have a better basis for studying the effects of programmes than we have today. 
Although it has not always been the case, prison education is no longer, in principle, meant to be used for the purpose of reducing recidivism. Education is a right of Nordic prisoners as of all other citizens. Thus educational programmes have an inherent value irrespective of their long-term effects. Only in Sweden, as opposed to the other Nordic countries, is this right at all restricted in comparison with state adult education. Of course we continue to hope that education in itself can have preventive effects, i.e. can help a prisoner to manage better after release. In today's competence-oriented society, it is undoubtedly advantageous to have a diploma when applying for work, in competition with individuals with no formal competence, particularly if the person with a certificate in hand also has the social skills needed to assert him or herself in the competitive situation.

In the twentieth century, work opportunities in prison were dominated by sanitation and maintenance work, assembly, wood products manufacturing, and manual labour. Nor was participation in programmes evaluated to determine whether a prisoner with work experience managed better after release than a prisoner without such experience.

There is, however, well-documented evidence that, in comparison with isolation, participation in work and educational programmes is positive for the mental health of prisoners in both the short and long term.

The death of the concept of treatment - a renaissance for the concept of prevention

A number of studies published in the Nordic countries in the 1960s and 1970s dealt the death blow to the concept of "treatment". The conclusion of these studies was that as long as the primary prison form remained incarceration, it made very little difference if the prisoner participated in programmes and activities while serving his or her time.

The expression "nothing works" in rehabilitation was coined by R. Martinson (1974) and quickly took hold. According to Martinson, with very few exceptions, the rehabilitation programmes studied had resulted in very few positive effects on recidivism. Many researchers claimed, and continue to claim, that no matter what measures are taken, recidivism figures change very little. 
The pessimism about prisons that consequently spread throughout the Nordic region brought two good things in its wake. Firstly, enthusiasm increased with regard to crime prevention measures, and more resources were allocated to them, which also led to the establishment of crime prevention councils in all the Nordic countries. The second positive result was a growing recognition of the decisive significance of the transition from prison to liberty. It was found that even when prisoners had acquired new competence while serving their time, this helped very little when they were released to a life on the streets. Released prisoners lacked the social and financial structures to be able to make use of their acquired competence. Therefore, in recent years, more emphasis has been placed on the importance of "administrative cooperation", through which the various services enter into formal, long term cooperation regarding prisoners, and to draw up future plans and programmes for each individual in participation and consensus, rather than merely having transient cooperation at the time of release.

\section{Programme activities}

Since the days of deep pessimism in the 1960s and 1970s described above, the number of prisoners in the Norwegian and Swedish prisons has steadily increased. In Denmark the figures have remained stable, at 3,500-3,600 from 1970 to the present. Finland succeeded in reducing the number of individuals serving time in prisons dramatically for some time, but today the figure is on the rise again. With the exception of Denmark, we can say that the increasing numbers of prisoners has resulted both in a need to build new prison premises and in greater optimism regarding treatment, including crime prevention.

The optimism is of a new kind, with a focus on programme activities. This same ideological wind has blown across the entire Nordic region, with similar programmes initiated in all four countries. While earlier treatment ideologies came from the us and England, Canada is now an important source. The aim of programme activities today is to achieve behavioural changes by utilising cognitive psychology. These programmes are mainly facilitated by prison staff with further training, also endowing the role of prison officer with some new, positive content. Programmes 
may be organised as short courses, with a small number of sessions lasting a couple of hours each, to longer courses lasting a number of weeks. Participation in such programmes is now seen on equal terms with participation in educational and vocational training programmes in terms of the "daily programme allowance" paid to the prisoner.

Relatively few prisoners - fewer than 5\% in Norway and slightly more in the other Nordic countries - are offered the opportunity to participate in these programmes today, but the aim is for the programmes to expand, and to succeed. Their effects have already been proven to be positive for the participants - as long as they remain incarcerated. Although there is very little documentation as yet on a Nordic basis as to whether participation can have any long-term rehabilitating effects, reports from the us and Canada indicate that such programmes can have recidivism-reducing effects. Still, since the basic prerequisites in the Nordic countries both in prison and in society as a whole are so different from the prison reality and the prison population in Canada and the us, it is not possible to extrapolate Nordic country conclusions from these results.

\section{Meta studies}

A number of studies and meta-analyses have been carried out in the relevant countries since 1980 , with positive findings. These studies present a relatively strong consensus regarding the prerequisites for a programme to succeed. It should:

- be based on a cognitive behavioural approach,

- be based on the principles of "risk, need"-programmes with a focus on criminogenic factors,

- be oriented towards mastery and skills,

- take account of the principle of "responsiviness" - meaning that they should be sensitive to the learning style of each inmate, be multimodal,

- focus primarily on the inmates with the greatest risk of recidivism.

Since the mid-1990s and until the present day, the Nordic countries have initiated a number of programmes based entirely or partially on these principles. The earliest such program was developed 
in Canada and known as the Reasoning and Rehabilitation Programme (Cognitive skills). During the course of the 1990s the model began to be imported to and utilised in all the Nordic countries.

New Start/Cognitive skills

All the Nordic countries have implemented the model, although the degree of use has varied. In an extremely detailed handbook the aim of the programme is described as follows:

The social profiles of many individuals who have violated the law indicate that they have personal shortcomings in terms of values, attitudes, logical reasoning and social skills to an extent that prevents them from functioning successfully in a social setting. These are functions that can be learned.

Thus the programme offers teaching in the following areas:

- Problem solving

- Social skills

- Negotiation skills

- Emotional control
- Creative thinking

- Value reinforcement

- Critical thinking

Role playing, practical exercises, discussions, etc. are used. The most important factor, however, is the ability of the course facilitator to create a positive dialogue amongst the participants. Development of reflection skills and consciousness-raising are emphasised.

\section{Evaluation}

There has been a major evaluation of the effects of the programme in Canada (Robinson 1995). The evaluation concluded that the programme had led to a reduction of recidivism in most groups. The programme was also evaluated in the Nordic countries, but not with controlled studies, and not in terms of effects after release. In 2002, the Swedish Crime Prevention Council published an evaluation of Cognitive Skills in the correctional services. The study comprised 523 prisoners, and the results indicate that recidivism amongst individuals who completed this kind of programme was $5-10 \%$ lower than amongst non-participants. However, it is pointed out that the results are associated with a number of uncertainty factors. 
The Norwegian evaluation concludes that the programme had positive effects for many of the participants. However, it is a prerequisite for long-term effects that the programme also results in changes in the institutions as a whole, and in this respect a great deal remains to be done. It is also pointed out that better-organised cooperation is needed so that personal contact officers, block officers, workshop managers, teachers, social welfare officers, etc. are able to follow up each programme participant. The programme should be better integrated into the sentence-serving and future planning work, as well as into the ordinance on personal contact officers, and it should be combined with other support tools and activities offered by the prison services. The importance of developing follow-up programmes in prisons as well as in the probation service is also emphasised (Meek-Hansen and Danielsen, 1997. In Norwegian. English equivalent title: New Start for the Norwegian Prison Service?).

In the Nordic context, the programme has also been carried out under the auspices of the probation service, the school system and the labour market authorities.

\subsection{Programme activities in Danish prisons}

The principles underpinning the work of the Danish Prison and Probation Service is normalisation, openness, accountability, security, minimal intervention, and optimal resource utilisation (1993, A Programme and Principles for Prison and Probation Work in Denmark). This means that prisoners are given greater opportunities than previously to bring an influence to bear on their everyday activities while they are serving their sentences. This implies, in turn, that prison officers not only provide security services, but also participate in the recreational and vocational training activities of the inmates. Unit officers also serve as personal contact officers, and provide some social welfare and counselling services.

The aim of this reform was to provide each inmate with the support (s)he needs during the incarceration period with a view to facilitating a life without crime after release. 
After the Prison and Probation Service introduced Cognitive Skills, an internal evaluation indicated that the behaviour of the programme participants changed, and that in comparison with non-participant prisoners they displayed more tolerant attitudes. They became better at handling conflicts and at finding other, more appropriate ways of making contact with their fellow prisoners and the staff than by provoking conflict. Overall, the evaluation indicated that prisoners who participated in the programme found the remainder of their sentence more meaningful upon completion.

In recent years, the Prison and Probation Service has also implemented other treatment methods for substance abusers. This area has been given priority in Denmark, on the basis of the theory that treatment will contribute to increasing the possibility that prisoners will break their vicious circle of criminality.

One of the options for substance abusers is the establishment of a "contract" by which the inmate commits to being clean and sober while serving his or her sentence. Another option relating to crime prevention is for individuals convicted of a crime to be able to serve their sentences outside prison premises. Alternative sanctions as crime prevention instruments are in increasing use in Denmark.

\subsection{Programme activities in Finnish prisons}

The Prison Service have developed a risk and needs analysis based on tried and true methods from Canada and elsewhere. Such an analysis is made for all prisoners serving sentences of longer than two years. The analyses are carried out by specific "assessment and allocation units", where prisoners spend approximately one month at the beginning of their sentence term. The results of the analysis are then used to draw up a sentence plan with a view to discouraging further criminal behaviour and improving the prisoner's possibilities of living a life free from crime upon release. The sentence plan is revised at the relevant prison, where prisoners also have a personal contact officer, who is responsible for the revision and implementation of the plan. 
Four different cognitive crime prevention programmes are offered in Finland:

- Cognitive Skills.

- Stop - a programme for sex offenders.

- Cognitive Self Change - a programme for inmates with violent behaviour.

- Anger management - a programme for inmates who have trouble controlling their feelings.

The effects of these programmes have not yet been evaluated in Finland, but they are scientifically-based and have been evaluated in other countries.

Because the majority of prisoners in Finland are substance abusers, and breaking with addiction is one of the most important factors in discouraging criminal behaviour, a great deal of effort has been focused on working with this problem complex. A substance abuse strategy was adopted in 1999. Pursuant to this strategy, the Prison Service now aim to:

- Restrict access to narcotics

- Reduce demand for narcotics

- Prevent the injurious effects of addiction

- Ensure, in cooperation with each prisoner's municipality of residence, that rehabilitation can continue after release if needed.

Almost every prison offers rehabilitation programmes for abusers. Rehabilitation includes analysis, information, withdrawal, substitution therapy, motivation, various programmes, community treatment and preparation for life after release. There are a number of different substance abuse programmes, based on different theoretical principles and models, many based on cognitive psychology. All open prisons are to be drug free, so only inmates who commit to abstinence from substance use and who agree to regular drug testing are allowed to be placed in open facilities.

Since 1999 prisoners in Finland have had the placement option of serving the last part of their sentence in outside rehabilitation institutions.

Many projects have been initiated in Finland with a view to improving prisoners' life mastery skills. According to an evalua- 
tion report, the greatest degree of success is achieved when the representatives of the various service providers cooperate in networks. The point of departure can then be a specific solution tailored to meet the needs of individual prisoners (Järvelä et al., 2002. In Finnish. English equivalent title: Projects on lawbreakers 19962002. Project report - together towards a crime-free life plan).

\subsection{Programme activities in Norwegian prisons}

There are no major differences between the situation in Norway and in the other Nordic countries. Beyond educational and vocational options, the main instruments used in crime/recidivism prevention are the Personal Contact Officer Ordinance, sentence plans and programme activities.

The function of the personal contact officer is to provide the inmate, during the time in which the sentence is being served, with support and motivation in working with the issues involved in successfully conquering the challenge of life after release. Another function is to analyse the resources and needs of the prisoner, assist him or her with future planning, and serve as a link both within the prison and in relation to relevant external service providers. A prisoner's future plane is intended to contribute to making the sentence enforcement time goal-oriented and solution-focused, and it is to include work, education and participation in programmes.

Programmes deal, for example with: violence, substance abuse, emotions, ethics and recidivism in general.

Pursuant to a major reform of the prison system, the obligation of a prisoner to work while in prison has now been replaced with a more general obligation to participate in activities. As in the other Nordic countries, the obligation to participate in activities includes various types of crime prevention measures, such as workshops, education and programme activities.

Today, the Prison and Probation Service is putting a great deal of effort into development of administrative cooperation. There is a new realization that crime prevention is not only the task of the judicial system. This makes increased cooperation with other public and private agencies and service providers very important. For example, in 2002 a national level cooperation agreement was 
signed between the Prison and Probation Service and the labour market authorities in accordance with which prisoners who had participated in the Cognitive Skills programme were followed up after release by representatives of the employment services who were specially trained as New Start instructors. The project has been evaluated by the Labour Market Institute and the results were published in summer 2003.

A study carried out by Jan Tore Pedersen stresses the importance of offering convicted prisoners work experience. In his study of 1000 prisoners, the approximately 500 who had been offered work experience had less recidivism, measured in number of days in prison ( 60 per cent fewer days), than those who had not. The study covered a 4-year period (Pedersen, 2002. In Norwegian. English equivalent title: Rehabilitation of the Welfare Administration).

\subsection{Programme activities in Swedish prisons}

Sweden is the only one of the Nordic countries to use electronic monitoring as an alternative sanction. With electronic monitoring it is possible for an individual convicted to a maximum of three months in prison can serve his or her sentence at home. The individual is prohibited from leaving his or her home except at stipulated times and for given purposes, which may include work, school, or programme participation. On the basis of what is known of the deleterious effects of serving a sentence in a prison and about the importance of maintaining existing networks and jobs, electronic monitoring may be seen as an instrument of crime prevention.

Crime prevention/recidivism and substance abuse/addiction programmes in Sweden operate on the principles of "what works" - in other words by choosing programmes and vocational opportunities on the basis of well-documented positive experience and with a view to reducing recidivism. The strategy has the following components:

- A risk and needs analysis is to be carried out at the beginning of the sentence service, using the ASI/MAPS (Addiction Severity Index/Monitoring Area Phase System) tool. This is an interview questionnaire in which the client's needs are assessed as well as his or her criminal background and attitude towards change. 
There is also a clarification of realistic objectives, and a description of what the Prison and Probation Service can offer. A sentence plan is then drawn up. At the time of release the prisoner is interviewed again, to obtain a picture of what (s)he has accomplished.

- Motivational Interviewing (mi) is a counselling method focused on change, which contributes to affecting a prisoner's attitude towards change and to utilising new personal skills.

- The Swedish Prison and Probation Service use quite a broad definition of programme activities, which are divided as follows: Work, prisoner education, recidivism and substance abuse programmes, and other structured activities. In contrast to the other Nordic countries, education and work are included as programme activities, rather than being seen separately.

- The recidivism and substance abuse programmes are subdivided as follows: alcohol-related programmes, narcotics-related programmes, violence programmes, ethics and morality programmes, other programmes. Most of the programmes offered in Sweden have been used and evaluated in Canada, England and the us, while a few are based on long experience from the Swedish correctional services. The Swedish government has allocated EUR 11 million over a three-year period as specially earmarked funds for anti-drug activities. In this context, prisons and wards have been classified into three groups in relation to the level of motivation of the prisoners.

The year 2001 saw the initiation of a pilot project with a view to improving prisoner's prerequisites upon release. The Swedish Council for Crime Prevention found in its evaluation that:

- The introduction of an inter-agency future plan has improved the possibilities of planning for the prisoner's release.

- While contact with the social welfare and employment services have improved, problems related to housing and employment remain.

- There is a great need for transition solutions in anticipation of release.

- Methods should be developed to increase prisoner motivation for participation in programmes. 


\subsection{Crime prevention outside the prison and probation services}

\section{Means of crime prevention}

TECHNICAL MEASURES RELATING TO SECURITY There are many ways of categorising crime prevention methods. In the early 1970s, when prevention theories took root in the Nordic countries, security-reinforcing techniques were amongst the most popular measures. The idea was to determine the best ways of making buildings, equipment and objects in society secure and safe from vandalism and destruction. Today, this need has come to apply to IT systems and computers as well, and the security industry has become very profitable. Clearly, technical measures relating to security also make people feel more secure. However, the down side is that such measures have an anxiety-producing effect when people feel that they are locking themselves in as much as that they are locking potential robbers out.

SITUATIONAL PREVENTION comprises measures implemented in relation to situations where crime tends to flourish. Substance abuse and violence are important aspects of such prevention. These measures are often used in urban areas, and are implemented through cooperation among the police, the local associations, and the business community. No extensive systematic studies of situational prevention have been made in Scandinavia, but experience indicates that these interventions have good short-term effects.

HOUSING AND NEIGHBOURHOOD PLANNING are kinds of situational prevention with the aim of achieving more long-term effects. This kind of planning is intended to create residential, school and leisure time settings that provide opportunities to see and be seen in secure, pleasant surroundings, so as to have a positive impact on the inhabitants of a given area. Denmark and the Danish Crime Prevention Council have spearheaded situational prevention in the Nordic region. A number of studies indicate a documented positive effect of such measures. Ultimately, this is a kind of physical planning in the broadest sense of the term. It is a matter of the interplay 
between human beings and their environment, between aesthetics and ethics. And, in the final analysis, accomplishing it is a matter of funding.

Nevertheless, INDIVIDUAL PREVENTION is the commonest type of prevention, and the arena of primary prevention. This area includes all kinds of measures intended to affect people's attitudes, and all kinds of methods focused on achieving behavioural change. Individual prevention comprises family, school and the local environment in interplay. Children and young people are often the focus of individual preventive interventions, and schools are often the facilitators of these instruments. In all the Nordic countries, handbooks and other materials for working with attitude change have been drawn up. The concluded programmes have been evaluated in terms of processes but not of results, since it is extremely complicated from a methodological point of view to determine, several years after the measures were used, the concrete results of attitude-changing measures implemented at individual level.

Individual prevention also takes place at secondary and tertiary levels in relation to young people with behaviour problems or who have already been convicted for violating the law. These young people are placed in institutions where they can be given intensive treatment. Some evaluations have been made by the relevant authorities, i.e. the health authorities. However, it is difficult to document results in the form of behavioural change and possible cessation of undesired activities in comparison with corresponding results from other types of treatment or no treatment.

THE STAKeholders Crime prevention can be carried out both directly and indirectly. Interventions in the health care, culture and social welfare spheres can all have crime preventive effects even when that is not their main ambition or if they are not classified as such. Day care and recreation centres are examples of activities with another primarily ambition but in relation to which it is clear that when municipalities make cutbacks, that they also have crime prevention effects. This is especially evident with regard to activities for young people. 
In the Nordic countries, there are three main stakeholders in the arena of direct crime prevention: the police, the municipal authorities, and community organisations and associations. The national authorities commission them to administrate and run a large number of activities or "programmes". The Nordic national councils for crime prevention have no external "agencies". Instead, they commission programmes to be run by national authorities and ministries or by municipalities and municipal authorities. They sometimes also run "attitude-changing campaigns" in collaboration, for example, with the police, community organisations and associations, and insurance companies. The governments - particularly under the auspices of the Ministries of Justice - also take the initiative to establishing occasional programmes in, for example, conflict negotiation, arbitration in school settings and "clean and sober contracts" for young offenders. Many such activities are subsidised by the governments. Others, particularly in Denmark, are subsidised by the business community.

ORGANISATIONS AND ASSOCIATIONS have programmes of their own - which often come into being as a result of some specific event, such as a violent crime or a murder. Such programmes often begin at local level but then expand to be national or even Nordic. NGOs working in this field also maintain that their work has general crime prevention effects in that they often have a positive prophylactic impact on children and young people.

Many people, both policemen and others, consider THE WORK OF THE POLICE to be a form of crime prevention. The Nordic police work actively with crime prevention, traditionally by making school visits. In recent years, the police have begun to structure their crime prevention activities as "problem-oriented police work", shifting focus from primary prevention in the form of behaviouraffecting strategies oriented towards society as a whole to secondary prevention - interventions in relation to events that have occurred or focused on a specific group of individuals at risk of falling into a vicious circle of criminality.

In addition to activities stipulated by law at municipal level, the municipalities also offer a large number of activities and programmes, some not-for-profit, others profit-making, some devel- 
oped in Scandinavia, most in the us or Canada, or elsewhere in Europe.

\section{"The Crime Prevention Kitchen"}

In an article by Yngve Carlsson published in Swedish in the Scandinavian Journal of Crime and Criminology the author discusses the problems associated with crime prevention in a Nordic perspective (Carlsson, Nordisk Tidsskrift for Kriminalvidenskab 2002. In Swedish. English equivalent title: The Crime Prevention Kitchen).

One of Carlsson's main points is that the range of "recipes" offered by Nordic municipalities has expanded rapidly, and that many of the programmes must be seen as specific "recipes" for preventing and solving problems. He writes:

In recent years a number of programmes have been developed elsewhere in the world which can be of use to Nordic municipalities, including РМ (parental management training), MST (multi-systemic therapy), safe communities, home-start, zero-tolerance, courage, and Second Step. (...) Most of these programmes have been developed by experts on specific problems about which individual municipalities can rarely have expertise of their own . (...) Introducing such a programme in a municipality, with solid scientific backing, also has positive external symbolic effects, demonstrating that the municipality in question has state of the art information and is prepared to utilise cutting edge methods in relation to their local problem areas (Carlsson p. 285). (Home Start is a programme with a focus on parents, Zero-tolerance is a general reaction programme, Courage focuses on tolerance, and Second Step focuses on bullying.)

In addition to the programmes described by Carlsson, there are many others, some imported, some developed locally. One example is CRA - the community reinforcement approach.

According to Carlsson, programmes with a focus on the individual may have an unfortunate side effect: major political and/or ethical issues may be sidelined, as well as the importance of underlying factors and the structural causes of crime. There is also the question whether it is meaningful to invest in crime prevention measures without also dealing with the basic crime development factors in society.

The Nordic welfare states and municipalities have developed in the direction of increasing specialisation of services, activities and programmes, with the consequent coordination problems that naturally arise. 


\section{On evaluation of crime prevention instruments}

A need for scientific research is a general problem associated with all areas of crime prevention. It is difficult to hold factors constant when studying aspects of human behaviour. There are also problems of research ethics in relation to long studies with an experimental design. And, finally, it is problematic to seek the effects of an intervention in an individual who is simultaneously exposed to so many other potentially impacting factors. When behaviour is modified, for example in the form of reduced risk of recidivism or substance abuse, it is difficult if not impossible to attribute this behaviour modification to any single intervention. For all these reasons, most of the evaluations that have been carried out are process evaluations

\section{Organisation and coordination}

There are clearly a large number of proposals and ideas regarding crime prevention activities. Sometimes overlapping activities are initiated, and competition arises between one good intervention and another in terms of both resources and approval. This problem is managed by the crime prevention authorities, who provide advisory services for coordination of measures with a view to optimal effects.

As early as the 1980s, the Danish Council for Crime Prevention developed a model known as SSP (school, social services and police) for coordination of all the various activities offered at local level. The other Nordic countries have all had similar models. SSP is not an activity programme, it is an instrument for coordination of efforts so as to give each activity its own place in a larger context, and thus the potential for greater effects. In this model, responsibility for crime prevention work is clearly established at the top level of the police authority and the municipal authorities, which gives such work high status and greater potential for having longterm effects.

A supplementary aim is to clarify the range of crime prevention instruments available locally. They can then be implemented in an inter-agency, inter-sectoral fashion in each municipality. Sectors concerned may include the school system, the social services, the police, the institutions, the housing authorities, the recreational authorities and the cultural authorities. 
SSP - cooperation focused on three levels of prevention:

- General measures

- Specific measures

- Individual-oriented measures

\section{Evaluation}

In 1999 there was a Danish evaluation regarding perceptions of this kind of cooperation by the relevant stakeholders. The findings were positive, and suggestions were also made for improvements. In the municipalities where the model is functioning, coordination and inter-agency interaction were perceived as having improved. The evaluation also indicated that this results in a shared understanding of the problems and a reduction of difficulties associated with the obligation to observe confidentiality. The other Nordic countries have documented similar experience.

\subsection{Society and criminality}

As we have seen, most crime prevention measures focus on individuals or on groups of individuals. This is, in turn, related to what are assumed to be the causes of crime. Fundamentally, these causes have been sought and found in individuals or groups. Although there is a wide range of variation, physical, psychological, ethical, familial and environmental theories have dominated, and prevention strategies selected on the basis of these theories.

Occasionally other explanatory models and corollary measures have been presented. With the rise of sociology, societal explanations indicating factors in society that encouraged criminality were highlighted. However, although this highlighted the links between crime and the way societies are structured, there was no automatic continuation to the setting up of prevention strategies. There may be agreement that the causes thus pointed out are correct, but there is no strong will do anything concrete.

Nils Christie, Norwegian professor of criminology, puts it as follows:

No one is fated to commit crimes, it is a matter choice. This is true at individual level and it is true at societal level (Christie 1993, p. 32). 
Not everyone shares Christie's liberalist view of the individual level. No one would choose a life of crime given a full range of choice. There is far more support for Christie's view of the societal level.

That view is in perfect accord with research findings about the link between criminality and behaviour. Today there is general consensus that choices about the general organisation of society have an impact in terms of encouraging or discouraging criminality. In this perspective, crime prevention becomes a far more comprehensive project that simply setting up programmes for children and young people. It is an integral part of the policy work that provides a basic framework for the society in which children and young people grow up. The formulation of crime prevention policies will have consequences in relation to the formulation of family, educational, social, environmental, labour market and, not least, economic policies.

In 1997, Norwegian crime prevention council commissioned Per Hage to compile a literature survey of existing studies in the Nordic region on crime prevention (Hage 1997). He described the existing studies as following four main trajectories: urbanisation, alcohol and violence, unemployment, marginalisation and stigmatisation.

\subsubsection{Urbanisation}

There is far more registered crime, both economic crime and violent crime, in urban than in rural areas. Per Hage indicates two primary explanations:

- Less social control: "In urban environments, the very structure of society encourages social distancing and weakened social control".

- More temptations and conflicts: Urban environments also provide an "aggregation of both temptation and conflicts".

One consequence of the close correlation between the degree of urbanisation and the increase in crime rates, from a crime prevention point of view, would be to establish policies that discourage urbanisation. However, the fact that urbanisation is one of the fundamental characteristics of contemporary society as well as being a logical consequence of current economic policy makes this unre- 
alistic. A more realistic crime prevention strategy would be to increase social control in urban areas. This can be accomplished in many ways, not least by implementing state-of-the-art principles of city planning, with neighbourhood support, local police stations, etc.

\subsubsection{Alcohol and violence}

In all the Nordic countries, a clearly documented correlation has been found between violence and alcohol consumption. This applies to violent domestic crime and, even more so, to crime associated with drinking in public settings, about which there is more documentation.

Logically, one of the most effective methods of preventing crime would be to implement measures to restrict consumption of alcohol in public settings (Hage, p. 28). In reality, the trend is precisely the opposite: more and more eating places are being granted liquor licenses, and opening hours are also being extended. There is clearly a profit motive involved here. Alcohol policy is a difficult area to study, but an essential one if we are to succeed in reducing violent crime.

\subsubsection{Unemployment}

Although there is a clear correlation between unemployment and crime rates, and although Nordic criminological research expresses no doubt as to the link, there is no research in this area.

A recent Norwegian study covering a four-year period and carried out by Jan Tore Pedersen stresses the importance of offering convicted prisoners vocational training programmes. (Pedersen 2002). His study followed 1,000 prisoners, and he found that recidivism was lower amongst the $50 \%$ who were offered vocational training (with 60 per cent less time in prison) than in the control group

It is also an established fact, not only in the Nordic region but throughout the Western world, that unemployment is higher amongst people who have served prison sentences than in the general population. Individuals in trouble with the law thus have a weaker bond to social norms than individuals in work. According 
to Hage, this tends to be explained by saying that individuals in this group stand to lose less than others if they fall into crime, and that they are also without the natural type of social control that exists the employed. It is easy to see the relationship between these factors and the consequences of urbanisation. If decision makers were to take these findings seriously they would have to reconsider aspects of labour market, educational and social policy.

\subsubsection{Marginalisation and stigmatisation}

For criminals, violating the law often becomes a vicious circle. One significant reinforcing factor in relation to this circle is the negative reactions in society at large to violations of the law and to the individuals who commit them. Often, this means that an individual who breaks the law becomes frozen in a negative self-image, and accepts his or her own criminal identity. The situation is exacerbated when (s)he commits new crimes. Over time, the risk develops that the individual will be rejected by "good company" and continue to behave in line with the preconceptions of others. In this perspective, a prison sentence is perceived as directly harmful. In this area, crime prevention thus becomes an aspect of criminal policy in the broadest sense of the term, and part of the discussion regarding how we punish those who commit crimes and the consequences of penal sanctions. If these issues were reconsidered, prison sentences might be used less, and replaced by other, less stigmatising sanctions.

\subsubsection{Other explanations}

There are many other explanatory models regarding crime, based on the interaction between individuals and society. These theories have traditionally been very little used as points of departure for developing crime prevention strategies. The media play an important role in these contexts as an interface between individual and society, and affect how the general public perceives crime and criminals. One area where this has proven to be of importance is public perceptions of segregation and of foreigners, or "non-ethnic Scandinavians". All the above-mentioned mechanisms: urbanisation, unemployment and stigmatisation are relevant in this respect. 
Another striking aspect has to do with the paradoxical contrast between society's efforts to prevent crime, using behaviour modification, situational prevention and studies of culture and violence, and the fact that the children and young people in our societies, at the same time, have ready access to violent films and games that exalt criminal behaviour. This exposes our children and young people to seriously contradictory messages: we reject violence at the same time as we glorify it. Bringing about a change in this respect is a matter of will power, money and policies.

\subsubsection{Concluding comments}

There are many crime prevention programmes focusing either on individuals or on groups - both within and outside the Prison and Probation Service. There is far less awareness of and will to change fundamental aspects of society which may be a breeding ground for crime. If crime prevention is to have any clout, all these programmes must be seen in their societal contexts.

There is a striking absence of effect evaluations of such programmes both within and outside the correctional services. The fact that such evaluations cannot always be carried out under strictly scientific conditions should not prevent the initiation of joint Nordic projects with a holistic aim: behaviour modification work, situational prevention and social planning. 


\section{Joint Nordic recommendations}

This chapter presents an overview of the recommendations set out in the previous chapters. Together with the international recommendations and conventions, these recommendations provide a platform for development and further development of prison education in the Nordic countries and adjacent areas and to other countries in their efforts to develop their prison education systems.

\section{Legislation}

The project group recommends that the educational authorities in the Nordic countries ensure that their legislations clearly state the legal right and obligation to provide prisoners with the same right to education as other citizens. The legal authority stipulated in the Education Acts should also be stipulated in the legislation of the different countries relating to enforcement of sentences. When the right to education has been elucidated, this will have consequences in terms of resource allocation.

\section{Normalisation}

The project group proposes that the principle of normalisation be applied to as great an extent as possible by utilising the public services of society such as schools, libraries, treatment services, etc. This can be accomplished both by giving more prisoners day release privileges, and by the building of a larger number of open correctional facilities. Day release privileges can even be arranged for some prisoners who serve their sentences in higher security prisons mainly by having special units for prisoners with day release privileges. Future correctional facilities must be built with units for prisoners who have day release privileges. 


\section{Administrative cooperation}

The project group proposes that concrete plans and routines be drawn up for cooperation between the Prison and Probation Service and the various stakeholders at national, regional and local levels.

Equal opportunities in prison education

The project group proposes that irrespective of which model is used, there must be pedagogical expertise at management level to provide quality assurance for the educational activities offered. Teaching staff are to have the same status, authority, and competence as in the state school system.

\section{Description of prison education}

The project group proposes that a joint Nordic description of education in prison facilities for the future be made. It should include:

- Compulsory education (corresponding to nine years of basic education, through secondary school)

- Further education (corresponding to upper secondary education)

- Internet-based education

- Full ICT training

- Special education

- Immigrant education, minority group education (Sami, Roma, etc.) and education for second generation immigrants

- Higher/university education.

Comments As part of any teaching, all schools/students should have access to a well-stocked library which, in itself, serves as an information and knowledge database.

\section{Educational opportunities}

The project group recommends the following proposals to meet the need for formal and informal skills. 


\section{Theoretical education}

- Compulsory education (corresponding to nine years of basic education, through secondary school, in Finland only needed to a limited extent).

- Remedial education in literacy and numeracy skills, with special priority given to prisoners with the most inadequate educational background (as it is a unique opportunity to meet and motivate these individuals while they are in prison).

- Further education (corresponding to upper secondary education) with a broad range of educational options, corresponding to those offered in the community.

- Day release privileges for educational activities is important, both in terms of offering prisoners more educational options and in giving them the opportunity to study in a "normal" study environment.

- Education and training that meets the needs of foreign prisoners.

- There must be opportunities for independent study with tutoring, to meet individual needs.

\section{Vocational training}

- Vocational training in collaboration with the employment service in order to offer training that will prepare the individuals for the labour market.

- Cooperation should be encouraged between schools (theory) and prison workshops (practice). As a result of such cooperation, some activities could earn educational credits. When educational needs assessed, inmates' previous experience should also be taken into account. This can mean a great deal to individuals who have positive testimonials.

- Some vocational training could be given in other languages. This could also be useful to inmates who are going to be deported after release, and who could thus gain competence that will be of value to them when they return to their home countries.

New technology

- The introduction of new technology (Internet-based solutions adapted to prison security needs) might be a simple 
way of giving more inmates access to a broad range of further education, university and other higher education.

- ICT courses of the same kinds offered in the regular schools in the community (both to master the techniques themselves and to use the new technologies in other subject studies). The new technology is also a necessary tool to be able to access various educational options outside the prison - a natural tool in relation to the expanding range of Internet-based adult education possibilities in society.

Creative activities, libraries, etc.

- Education in the arts with a view to improving self-development, life skills and motivation raises individuals' social skills. Participation in both creative activities and well-rounded physical activities often encourage prisoners to go on to other kinds of education.

- There should be access to a well-stocked library and its services in collaboration with the library services available in the community.

\section{Women prisoners}

- All the items above apply equally to women prisoners who, precisely like their male counterparts, must be offered a wide range of educational opportunities adapted to their individual needs. For women, who otherwise run the risk of being considered a small, costly target group, the new technologies may be particularly important in terms of opening up a large number of options (unless the possibility of mixed groups men and women at prison schools is considered).

Education as one piece of the puzzle

- Education can be more effective if it is combined with work, treatment programmes, and other approved activities. Very few prisoners can cope efficiently with full-time studies. Great flexibility and "tailor-made" weekly schedules should be available for each prisoner. Education is one important piece of a larger puzzle. If that piece falls into place, it may be decisive both for the success of the inmate's schooling and for his or her life as a whole. 


\section{General}

- There must be access to suitable premises and modern equipment which bears comparison with adult education elsewhere in society.

\section{Methods}

The project group proposes the following approaches in order to fulfil the needs of prisoners for both formal and informal adult education:

- The same pedagogical points of departure for lifelong learning in adult education shall apply to adults in prison as in society at large - with the same adaptation to the target group as must always be used for any specific educational group, in prison or elsewhere. The methods implemented should be based on the idea of assessing the needs of each individual and, on that basis, giving him or her space in which to develop, in terms of knowledge and experience and also as an individual with civil rights and duties.

- The particular features of prison education - often a short time frame, a great need for individualisation, and students who may be at very different points along the route to acquiring life competence, places high demands both in terms of methodological flexibility and in terms of teachers being adaptable in their educational strategies.

The place of education in the Prison and Probation Services

The project group proposes that:

- The educational authorities and Prison and Probation Service at the national, regional and local levels together discuss the scope of and need for educational opportunities (seen from the point of view of the needs of both the prison population and the institutions) and what courses are to be offered. There should be equal opportunities for work, education and other approved activities in the prisons, available during normal working hours. From the point of view of equality, the same remuneration should be paid to prisoners for the 
different activities, not least so as to avoid competition between the activities offered.

- The recognised need of prisoners for activation (as part of the process of resocialisation) is to be the main starting point when the different prison activities are prioritised. There should be flexible teaching arrangements. A prisoner should be able to organise his or her activities as a combination of work, schooling, programmes, and other approved activities.

- Teaching shall be provided by trained educational staff with certified subject area competence. Education should be part of each prisoner's future plan, extending up to and beyond release. A person with pedagogical expertise should assess the needs of the prisoner for education. Release or conditional release, to a situation with work, schooling or other activities - must be prepared in good time and in consultation between the prisoner and other parties involved.

\section{Options and needs for lifelong learning}

The project group proposes that:

- Prisoners always have their non-formal learning assessed.

- Once a convicted prisoner/prisoner in remand has had his or her non-formal learning assessed, educational options must be provided that correspond to the needs of each individual, and individuals must be sent to the prisons that can offer the options they require or give them the opportunity to have day release privileges for work or schooling.

- Education must be defined broadly enough to include, in addition to subject competence, social skills and activities of daily life.

\section{Documentation and research}

The project group proposes that systematic reporting, evaluation and research on education in prisons be carried out with a view to:

- documenting the work being done on education in prisons in comparison, for example, with treatment programmes and other activities, 
- evaluating whether the range offered as prison education corresponds to the educational needs of the prison population,

- obtaining a clear picture of which prisoners do and do not participate in, how students are recruited to prison education,

- assessing teaching methods and quality,

- obtaining a systematic evaluation of prison workshops in relation to the applying curricula,

- determining the place of prison education in the correctional services.

- expressing an opinion regarding whether new programmes, etc., such as classes and treatment programmes, should be evaluated, or whether research into them should be carried out.

\section{Cooperation between the Prison and}

\section{Probation Service and other stakeholders}

The project group proposes increased contact between prisons and society at large and that:

- The state social service authorities must provide the services as required by law, which would result in structured, systematic, inter-agency cooperation. There must be better contact and cooperation between agencies such as the educational authorities, the correctional services, the labour market authorities, the main trade unions and the employment services,

- There should be more frequent placement of inmates in open institutions allowing more day release privileges for education and work, which would result in automatically making better use of traditional social services,

- There should be better utilisation of the expertise and options of the labour market authorities for prison convicts, in order to ensure smoother transitions back into society,

- Internet-based education with satisfactory security solutions will provide a supplementary tool for utilisation of the state educational services. Internet-based education will: a) be a contribution to normalisation $b$ ) offer more options - enable prisoners to participate in a wider range of courses c) reach more inmates - facilitating individualisation and d) enable 
greater educational continuity and thus increase the possibility of completing certificates and being awarded diplomas. Information and communication technology (ICT) must be used as a tool in prisons in the same way as in society at large.

- Cooperation between prison school administrators, workshop managers and representatives of the employment services must be improved. Prisoners must be given vocational experience in the workshop and education in the classroom. This would give them more options and probably increase their motivation, because they would know that the activities in which they were involved would be beneficial after release. This would also make vocational training in prison an integral part of the skills enhancement work that continues after release. See also sections 5.1 and 5.6.

\section{The costs of prison education}

The project group suggests continued, extended funding for prison education.

\section{Concluding comment}

Today the demand for prison education far outstrips supply.

The group with the greatest educational needs is a group which is also often difficult to recruit to schooling in the state school system, and thus the opportunity should be taken to begin to fulfil the ambitions expressed by society in terms of the "adult education initiative" and lifelong learning when the individuals belonging to this group are institutionalised. Today, education accounts for only a small fraction of the costs of a prison sentence. From a socioeconomic point of view it would undoubtedly be beneficial to invest more in prison education. 


\section{Bibliography}

The sources listed below are given under the country section where they are relevant, and are listed only by their original language titles. In this English text, references are mentioned at first occurrence by their year of publication and with an English equivalent title, by way of information. To find the original title of a work referred to in the running text by an equivalent English title, please use the author's name and year of publication to make the match with the Nordic original.

\section{DENMARK}

Andersen, E. (1992): Den lange vej. Kriminalforsorgens Uddannelsescenter.

Andersen, S.E., Holstein, B., Skadhauge, F. (1979): Forskningsrapport nr. 10 - om uddannelsesmiljøet i åbent og lukket fængsel. Justitsministeriet.

Andersen, S.E. (1985): Forskningsrapport nr. 26 - Strafafsoning i pædagogisk perspektiv. Justitsministeriet.

Andersen, S.E. ,Holstein , B., Skadhauge, F. (1980): Uddannelse 7 - om uddannelsesmiljøer, læring og medlæring. Undervisningsministeriet.

Bekendtgørelse af 3. juli 2000: Bekendtgørelse af lov om specialundervisning for voksne. Undervisningsministeriet. Bekendtgørelse nr. 370 af 17. maj 2001: Om indsattes adgang til at medtage, besidde og råde over egne genstande og penge $\mathrm{i}$ Kriminalforsorgens institutioner (genstandsbekendtgørelsen).

Bekendtgørelse nr. 110 af 4. marts 2002: Om udgang til indsatte, der udstår fængselsstraf eller forvaring i kriminalforsorgens institutioner (udgangsbekendtgørelsen).
Betænkning nr. 1058 - 3 bind (1986): Arbejde, undervisning og fritid. Udvalg under Justitsministeriet.

Betænkning nr. 683 (1973): Betænkning om undervisning, erhvervsuddannelse og fritidsaktiviteter for indsatte i fængselsvæsenets anstalter. Statens Trykningskontor.

Dansk Videnscenter for ordblindhed (1997): Nyt om ordblindhed 12.

Deimlich, Gerhard (1982): Strafvollzug, Randgruppen, Sociale Hilfen. Verlag Peter Lang.

Det kriminalpræventive Råd (1998): ssPsamarbejde - om forudsætninger og organisation. Scanprint.

Det kriminalpræventive Råd (2000):

Udvikling og perspektiver.

Direktoratet for Kriminalforsorgen (1993):

Kriminalforsorgens principprogram.

Direktoratet for Kriminalforsorgen (2001):

Kriminalforsorgens statistik 2000.

Direktoratet for Kriminalforsorgen (2001):

Nyt fra kriminalforsorgen nr. 6.

Direktoratet for Kriminalforsorgen (2000):

Placering af indsatte. Differentieringsudvalget. 
Direktoratet for Kriminalforsorgen (april 2000): Vedrørende brug af internet.

Direktoratet for Kriminalforsorgen, 1998:

"Vedrørende halvåbne afdelinger i Statsfængslet Møgelkær og Statsfængslet ved Horserød", Differentieringsudvalget.

Direktøren for fængselsvæsenet (1952):

Reglement for undervisning. Justits-

ministeriet.

Direktøren for Kriminalforsorgen (1974): Indstilling om fængselsdømtes adgang til undervisning eller beskæftigelse.

Holstein, B., Skadhauge, F. (1976): Rapport nr. 1 - om uddannelses- og/ eller beskæftigelsesplanerne omkring statsfængslerne i Nyborg og på Søbysøgård.

Holstein, B., Skadhauge, F. (1977): Rapport nr. 2 - om uddannelses- og/eller beskæftigelsesplanerne omkring statsfængslerne i Nyborg og på Søbysøgård.

Holstein, B., Skadhauge, F. (1978): Rapport nr. 3 - om uddannelses- og/eller beskæftigelsesplanerne omkring statsfængslerne i Nyborg og på Søbysøgård.

Holstein, B. (1986): Uddannelse og recidiv - en undersøgelse af sammenhængen mellem uddannelse under afsoning og kriminelt recidiv hos 1325 løsladte. Justitsministeriet - Kriminalpolitisk forskningsgruppe.
Klewe, Lars (2002): Frafald fra undervisningen og fravalg af prøver på avu og hf-enkeltfag, Danmarks Pædagogiske Universitet.

Kildemoes, Vagn (1959): "Statsfængslet i Vridsløselille”, Nordisk Tidsskrift for kriminalvidenskab.

Lov nr. 457 af 20. juni 1996 - om almen voksenuddannelse (avu-loven).

Lov nr. 252 af 26. maj 2000 - om forberedende voksenundervisning: (fvu-loven).

Lov nr. 432 fra 31. maj 2000: Lov om fuldbyrdelse af straf m.v. Folketinget. Schultz Grafisk.

Lov af 15. april 1930: Lov om ikrafttræden af borgerlig straffelov m.v. Gads forlag.

Narkotikarådet (1999): Hvad er god forebyggelse?

Nyt fra Udrykningsholdet (2001): Ny ungdomssanktion - behandlingsdom til unge kriminelle.

Rasmussen, T. (1992): Undervisningen i de danske fængsler.

Skadhauge, Flemming B. (1980-81): (side 102) Undervisning af indsatte.

Nordisk Vuxen Utbildning. Liber Laromedel, Malmö.

Ungdomskontrakter - Et inspirationshæfte om anvendelse af sanktionsformen over for 15-17-årige lovovertrædere (2001): Socialministeriet, Undervisningsministeriet og Det kriminalpræventive Råd.

\section{FINLAND}

Aikuiskoulutuskomitean II osamietintö. Komiteanmietintö 28:1975.

Autio, S., Hautamäki, T., (1991): Opiskelijana vankilassa. Peruskoulu- ja lukio-opintoja suorittavien vankien opiskelukokemuksia. Helsinki: Vankeinhoidon koulutuskeskuksen julkaisuja 4/1991. vAPK-kustannus.

Arviointiraportti, vankilaopetus. Julkaisematon raportti. Opetushallitus 2003.
Finlands grundlag 731/1999. Finlands lag. Fångvårdsförordning 431 / 1975. Finlands lag. Fångvårdsförordning 878/1995. Finlands lag. Fångvårdsväsendets och Kriminalvårdsföreningens principprogram och riktlinjer för verksamheten under den närmaste framtiden i Finland. Helsingfors 1999. Förordning om fångvårdsväsendet 1925, 1936 och 1950. Finlands lag. 
Förordning om verkställighet av straff 28/1866. Finlands lag.

Förordning om verkställighet av straff 39/1889. Finlands lag.

Förordning om yrkesundervisningsanstalter 5/1959. Finlands lag.

Gymnasielagen 629/1998 och förordning $810 / 1998$. Finlands lag.

Hartoneva, A., Kuivajärvi, K., Muilu, M-L. (1999): Alan miehestä ammattimieheksi,

Vankien ammatillinen koulutus 1948-1997, Helsinki: Oikeusministeriön vankeinhoito-osaston julkaisuja 4.

Hypén K. (2001) Assessment Method for Evaluating the Working Capacity of Prison Inmates. The Criminal Sanctions Agency.

Hypén K., (2002/1). Vankeusaikana tapahtuva opiskelu. Julkaisematon muistio. Rikosseuraamusvirasto 28.11.2002.

Hypén K., (2002/2): Riski- ja tarvearviointi sijoittajalaitoksissa. Julkaisematon muistio. Rikosseuraamusvirasto 14.11.2002.

Hypén K., (2002/3): Vangit. Julkaisematon muistio pohjoismaista vankilaopetuskartoitusta varten. Rikosseuraamusvirasto 28.6.2002.

Joukamaa M. (1991) Suomalaisten vankien terveys. Kansanterveystieteen julkaisuja M $107 / 91$.

Justitieministeriets föreskrift om beviljande till en intagen av tillstånd att för studier avlägsna sig utanför straffanstalt (tillstånd till studier) $25 / 011 / 95$.

Järvelä, S., Kääriäinen, J., Valokivi, H., (2002) Lainrikkojien projektit 1996-2002. Projektiselvitys Yhteistyössä rikoksettomaan elämään- hankkeelle. Rikosseuraamusviraston julkaisuja 2/ 2002.

Kallinen, R., (1982): Kasvatusta ja keskitystä, Helsinki: Vankeinhoidon historiaprojektin julkaisuja 10.

Kauppinen, A. (1997): Opiskelu Oulun lääninvankilassa. Tutkielma kriminologian ylintä kurssia varten. Vankeinhoidon koulutuskeskus.

Kauppinen, H., Halonen, M., Syvälahti, M, Yli-Heikkilä O., (2002): Tarinoita
SULLEVISTA. Näkökulmia syrjäytymisvarassa olevien ryhmien kokonaisvaltaiseen lukikuntoutukseen. Turun Kristillisen Opiston Säätiö. Turku 2002.

Kivi, T., Mahlberg, S. (2002): Ulos osallisuuteen. Kuntoutuskokeilu Riihimäen vankilassa. Julkaisematon moniste.

Kuivajärvi, K., (1995): Basic education in Finnish prisons. Teoksessa Basic education in prisons. UNESCO institute for education. Hamburg.

Kuivajärvi, K., Sunimento, K. (2002) Vankilaopetusjärjestelmän kuvaus, suhde ja kytkökset muuhun koulutusjärjestelmään. Julkaisematon muistio pohjoismaista vankilaopetuskartoitusta varten. Rikosseuraamusvirasto 30.5.2002.

Kunnari, T., Peltonen, M., (1993): Vankien koulutustausta ja koulutushalukkuus Oulun läänin-, Pelson keskus- ja Kestilän varavankilassa. Kasvatustieteen ja kasvatuspsykologian syventäviin opintoihin kuuluva tutkielma. Oulun yliopisto. Kasvatustieteiden tiedekunta. Käyttäytymistieteiden laitos 1993.

Kurtén-Vartio, S., (1999): Fängslande program. En utredning över de intagnas verksamhetsprogram i fängelserna $i$ Norden. Nordisk Ministerråd. TemaNord 1999:582.

Kyngäs, M., (2000): Vankeus miehen elämänkulussa. Tutkimus nuorena rikoksentekijänä vankilaan tuomittujen miesten lapsuudesta, vankeusajasta ja vankeuden jälkeisestä elämästä. Acta Universitatis Lapponiensis 36. Lapin yliopisto. Rovaniemi 2000.

Lag 630/ 1998 och förordning 811/1998 om yrkesriktad grundutbildning. Finlands lag. Lag 631 / 1998 och förordning 812/ 1998 om yrkesriktad vuxenutbildning. Finlands lag.

Lag 628/1998 och förordning 852/ 1998 om grundläggande undervisning 628/ 1998 . Finlands lag.

Lag om arbetskrafspolitisk vuxenutbildning $763 / 1990$. Finlands lag.

Lag om läroavtalsutbildning 1605/ 1992. Finlands lag. 
Lag om rannsakningsfängelse 615 / 1974. Finlands lag.

Lag om yrkesundervisningsanstalter 154/1939. Finlands lag.

Lag om yrkesundervisningsanstalter 184/1959. Finlands lag.

Lag om ändring av förordningen om verkställighet av straff 128/1995. Finlands lag.

Lag om ändring av lagen om rannsakningsfängelse 129/1995. Finlands lag.

Lag om ändring av lagen om verkställighet av straff 137/2001. Finlands lag.

Lag om ändring av lagen om verkställighet av straff 580/2001. Finlands lag.

Mohell, U, (2002): Vankilaopetusta koskevat säännökset. Julkaisematon muistio pohjoismaista vankilaopetuskartoitusta varten. Rikosseuraamusvirasto 29.5.2002.

Numminen, L, (1995): Suonkuokkijasta konepuusepän ammattiin. Koulutustoiminnan kehittyminen Huittisten varavankilassa vv. 1935-1995. Kasvatustieteiden pro gradututkielma. Marraskuu 1995. Kasvatustieteiden tiedekunta. Turun yliopisto.

Parlamentaarisen aikuiskoulutustyöryhmän mietintö. Opetusministeriö 21.2.2002.

Peruskouluopetuksen järjestäminen vankilaaikana. Vankien koulutusasiain yhteistyöelimen muistio. Oikeusministeriön vankeinhoito-osaston selvitteitä 3/1989. Helsinki 1989.

Regeringens proposition till riksdagen om reformering av lagstiftningen om fängelsestraff och verkställighet av dem i straffanstalter samt lagstiftningen om rannsakningsfängelse 239/1972.

Rosti, J., (2002): Nuorten vankien koulutus Keravan vankilassa. Julkaisematon muistio pohjoismaista vankilaopetuskartoitusta varten. Rikosseuraamusvirasto 2.12.2002.

Saharanta, A-M., (2002): Vankien koulutus Turun tutkintavankilassa ja Käyrän työsiirtolassa. Julkaisematon muistio pohjoismaista vankilaopetuskartoitusta varten. Rikosseuraamusvirasto 19.11.2002.

Siika-aho, L. (1994): Vankilakoulun resosialisaatiotehtävä. Vankilan valta-asetelma tarkastelun lähtökohtana. Kasvatustieteen syventäviin opintoihin kuuluva tutkielma. Oulun yliopisto. Kasvatustieteiden tiedekunta. Käyttäytymistieteiden laitos. Sysselsättningslag 275 / 1987. Finlands lag. Tietoja vankien opiskelusta, toimintaohjelmista, vapaa-ajantoiminnoista ym. vuonna 2003. Helsinki. Rikosseuraamusvirasto.

Toivonen, Merja, Opiskelu vankilassa - kurjuuden maksimointia vai avain parempaan huomiseen? Julkaisematon muistio pohjoismaista vankilaopetuskartoitusta varten. Rikosseuraamusvirasto 15.11.2002.

Tvångsmedelslag 450 / 1987. Finlands lag. Ulvinen, V.-M., (1996): Vankilaelämän kasvatukselliset alueet vankeinhoidon tavoitteiden kehyksessä - estettyjä kuvia? Tohtorin väitöskirja. Oulun yliopisto. Kasvatustieteiden tiedekunta. Käyttäytymistieteiden laitos.

Vankeinhoidon vuosikertomukset 1991-2000. Oikeusministeriön vankeinhoito-osaston julkaisuja. Sarja A. Helsinki: Oikeusministeriö.

Vankeuslakikomitean mietintö. Komiteanmietintö 6:2001.

Vankien ammatillisen koulutuksen järjestäminen. Työryhmän muistio. Oikeusministeriön vankeinhoito-osaston selvitteitä 2/1989. Helsinki 1989.

Vankien koulutuksen ja vankilakirjastojen kehittäminen. Oikeusministeriön vankeinhoito-osaston julkaisuja 3/1977. Helsinki 1977.

Vankilaopetustoimikunnan mietintö. Komiteanmietintö 1973:111. Helsinki 1973.

Vankilaopetustyöryhmän muistio. Opetusministeriön työryhmien muistioita 1988:27. Helsinki 1988.

Vankisäännöstoimikunnan mietintö.

Komiteanmietintö 7:1975.

Vuosikertomus 2003. Kriminaalihuoltolaitos $\&$ Vankeinhoitolaitos.

www.minedu.fi. Undervisningsministeriets hemsidor. 


\section{NORWAY}

Avtale om statlig tilskudd til fengselsundervisningen. Brev fra Kirke- og undervisningsdepartementet 23.06.1988 til Fylkeskommunene og Fylkesskolestyrene.

Bermann, Anne H: Teaching a new way of thinking. An evaluation of the Cognitive Skills programme in the prison and probation service, 1995-2000. Brottsförebyggande rådet, 2002.

Boolsen, Merete Watt: SSP-samarbejdet. Udvikling og perspektiver. Det kriminalpræventive råd, 2000.

Bødal, Kåre: Fra arbeidsskole til ungdomsfengsel. Klientell og resultater. Oslo 1969.

Carlsson, Yngve: Forebyggingskjøkkenet. I "Nordisk Tidsskrift for Kriminalvidenskab” 2002.

Christie, Nils: Kriminalitetskontroll som industri, Universitetsforelaget, 1993.

Christie, Nils: Modeller for fengselsorganisasjonen i "I stedet for fengsel" Pax 1970.

Chylicki, Pavel: Att upphöra med brott. Vägar ut ur den kriminella karrieren. Lund University Press 1992.

De europeiske fengselsregler, Rekommendasjon nr. R (87) 3, Europarådet, Strasbourg 1987.

Den europeiske menneskerettskonvensjonen i Lov 1999-05-21 nr 30: Lov om styrking av menneskerettighetenes stilling i norsk rett (menneskerettsloven).

Dokumentasjon og verdsetting av realkompetanse. Realkompetanseprosjektet 1999-2002.

vox Voksenopplæringsinstituttet 2002.

FN's konvensjon om barnets rettigheter $i$

Barnekonvensjonen, Rettigheter for barn i Norge, Redd Barna 1993.

Fridhov, Inger Marie: ALT SOM FøR?

Om norske fangers sosiale- og skole bakgrunn. Justisdepartementet 1991.

Fridhov, Inger Marie: Klient i kriminalomsorgen 1992. Kriminalomsorgens utdanningssenter, Oslo 1993.
Fængselsstyrelsens Aarbog 1901-1902. II. Aarsberetning 1901-1902 nosiv 87 Krist. 1904.

Gåsemyr, Kari: Opplæring for straffedømte og bygging av identitet. Statens utdanningskontor i Hordaland/Senter for samfunnsforskning. 1999.

Hage, Per: Samfunnsmessige årsaker til kriminalitet. Det kriminalitetsforebyggende råd, 1997.

Halvorsen, Gudrun: Eleven og de gode hjelperne. Bergen: Statens utdanningskontor i Hordaland. 2000.

Ingebrigtsen, Oddbjørn og Susegg, Brit Arna: Med mestring som erfaring og samfunnet som mulighet. Statens utdanningskontor i Hordaland 2001.

"Kartlegging av behov og organisering av tilbud om grunnskoleopplæring for voksne" Sluttrapport fra det nasjonale prosjektet. Grunnskoleprosjektet. Statens utdanningskontor i Møre og Romsdal 2002.

Kirke-og undervisningsdepartementets (KUD) rundskriv 6 As L 1969 24.10.69. Undervisning for unge innsatte i fengselsvesenets anstalter.

Kriminalomsorgens årsstatistikk 2003

Kyvsgaard, Britta Den kriminelle karriere. København: Jurist- og Økonomforbundets Forlag 1998.

Langelid, Torfinn: Straff og pedagogikk - To sosialiseringssystem i konflikt? Utvikling av undervisningstilbod ved to norske fengsel 1945-1980. Hovudoppgåve i Historie. Historisk Institutt, Universitetet i Oslo, Våren 1982.

Lie, Magnus: Waisenhusstiftelsen i Trondheim gjennom 300 år 1635-1935. Trondheim 1935.

Lov om fængselsvesenet av 12. des. 1958. Lov om gjennomføring av straff 01.03.2002. Martinson, R: What works? The Public Interest, 1974. 
Meek-Hansen Wilhelm og Danielsen Trond: Ny start for norsk fengselsvesen? Kriminalomsorgens utdanningssenter. 1997. NOU 1992:19 Opplæring i norske fengsler. Kompetanse og livsmestring.

Opplæring i fengsel, Rekommendasjon nr R (89) 12, Europarådet, Strasbourg 1990.

Opplæringsloven med forskrifter. Pedlex Norsk Skoleinformasjon 2001.

Pedersen, Jan Tore: Rehabilitering av velferdsforvaltningen, 2002 Kommuneforlaget, 2002.

Program for digital kompetanse 2004-2008. Programbeskrivelse. Utdannings- og forskningsdepartementet 2004.

Rapport Opplæring innanfor kriminalomsorga 2003, Fylkesmannen i Hordaland 2004.

Ravneberg, B: Undervisning og opplæring i det moderne fengslet. Dannende eller disiplinerende? Fylkesmannen i Hordaland, 2003.

Realkompetanseprosjektet 1999-2002 - i mål eller på startstreken? Sluttrapport. vox Voksenopplæringsinstituttet 2002.

Reglement for Fengselsvesenet. Gitt av Fengselsstyret 12. december 1961.

Robinson, D: "The Impact of Cognitive Skills Training on Post-Release Recidivism among Canadian Federal Offenders”. Research report 1995.

Rognaldsen, Svein: Evaluering av prosjektet "Frå undervisning i fengsel til vidaregåande skole/ arbeidsliv" Rvo rapporter 8/1988.

Rognaldsen, Svein: Noen tanker om pedagogisk virksomhet i fengslene med utgangspunkt i evaluering av "Etterutdanningsprosjektet for lærere og verksbetjenter” Universitetet i Bergen 1993.

Rognaldsen, Svein: Evaluring av fengselsundervisningen med vekt på systemnivået $\mathrm{og}$ kriminalomsorgens totale opplæringsvirksomhet. Fylkesmannen i Hordaland, 2003.

Sandvik, A.B: Hva passer for kvinner? Undervisning for kvinnelige fanger i fire norske fengsel. Fylkesmannen i Hordaland, 2003.
Skardhammar, Thorbjørn: Levekår og livssituasjon blant innsatte i norske fengsler. Institutt for kriminologi og rettssosiologi, Avdeling for kriminologi, Universitetet i Oslo K-serien nr. 1/2002.

Simon, Frances H.: Prisoners' Work and Vocational Training. London and New York, Routledge 1999.

Skaalvik, E.M, Finbak L. og Pettersen, T: Begrunnelse og formål med fengselsundervisningen.

Statens utdanningskontor i Hordaland 2002.

Skaalvik, E.M, Finbak L. og Pettersen, T: Undervisning i fengsel. På rett kjøl? Fylkesmannen i Hordaland 2003.

Skaalvik, E.M og Stenby, H.K: Skole bak murene. Trondheim: Tapir 1981.

Statsbudsjettet 2000 Kap 430 Kriminalomsorg - Kriminalomsorg i anstalt - Tildeling av bevilgning, brev fra Justisdepartementet 29.12.99.

St. meld. nr 23, 1991-92, Om bekjempelse av kriminalitet.

St meld nr 27, 1997-98, Om kriminalomsorgen.

St prp nr 1, 2001-2002, fra Justis- og politidepartementet.

St prp nr 1, 1994-95, fra Justis- og politidepartementet.

St prp nr 1, 2000-2001, fra Kirke-, utdannings- og forskningsdepartementet.

St prp nr 1, 2001-2002, fra Kyrkje-, utdannings- og forskingsdepartementet.

“Til-bake til samfunnet?” Kartlegging, vurdering og forslag til tiltak for styrking av oppfølgingsarbeidet i fengselsundervisningen. En arbeidsgruppes vurderinger og forslag. Bergen: Statens utdanningskontor i Hordaland 1997.

Unesco - Rekommendasjoner for voksenopplæring.

Viljugrein, T.: Skole, språk og fengsel. Undervisning av mannlige minoritetsspråklige fanger i fire norske fengsel. Statens utdanningskontor i Hordaland 2002. 


\section{SWEDEN}

Alm, J \& Andersson J, Läs- och skrivsvårigheter på kriminalvårdsanstalter i Uppsala län. Uppsala AMI 1995.

amv/kvv, Arbetsförmedlingen och Kriminalvården i samverkan, Kriminalvårdsstyrelsen 2000.

Arnelund H, Uppsalafängelsets historia

Länscellfängelset 1865-1912, Kriminalvårdsstyrelsen 1994.

Claesson S, Dahlgren $\mathrm{H}$, Att studera i fängelse - klientutbildning vid tre kriminalvårdsanstalter, idp rapport 2002:05, Institutionen för pedagogik och didaktik, Göteborgs universitet 2002.

Eriksson T, Om brottslingars behandling hur modern kriminalvård arbetar, särtryck, Medéns Förlag ab 1966.

Eriksson T, Kriminalvård, Idéer och experiment, P.A. Norstedt \& Söner förlag 1967.

Fvb 1878:26, Fångvårdsstyrelsens verksamhetsberättelser, Sveriges officiella statistik.

Herkner Birgitta, Hur vanligt är det med dysleksi bland intagna på svenska fängelser? D-uppsats, Institutionen för Beteendevetenskap, Linköpings universitet, 2001.

Jensen J, Lindgren M, Wirsén-Meurling A, Ingvar D och Levander S, Dyslexia among Swedish prison inmates in relation to neuropsychology and personality, Journal of International Neuropsychological Society, 5, 1999.

Jonasson C, Att vara lärare på en kriminalvårdsanstalt - fyra lärares upplevelser av sin lärarroll och undervisning, Institutionen för statsvetenskap Göteborgs universitet, 2001. Ju Regleringsbrev för kriminalvården 2002, Justitiedepartementet 2001.

Kriminalvårdens Officiella Statistik 2001/2003, Kriminalvårdsstyrelsen Förlaget $2002 / 2004$.

Kriminalvårdens Redovisning Om Drogsituationen 2003, Kriminalvårdsstyrelsen Förlaget 2004.
Kriminalvårdsstyrelsen, Fångars levnadsförhållanden, rapport från Kriminologiska Institutionen Stockholms universitet 1999. Kriminalvårdsstyrelsen Insatser mot narkotika, forskningsbaserad narkomanvård - ett förslag till handlingsplan, Kriminalvårdsstyrelsen Förlaget 2001.

Kriminalvårdsstyrelsen Kriminalvården och klienterna - en framtids- och omvärldsanalys om klientutvecklingen och klientsammansättningen i kriminalvården, Kriminalvårdsstyrelsen Förlaget 1998.

Kriminalvårdsstyrelsen Kriminalvårdens årsredovisning 2003, Kriminalvårdsstyrelsen Förlaget 2004.

Kriminalvårdsstyrelsen Nordisk statistik för kriminalvården i Danmark, Finland, Norge och Sverige, Kriminalvårdsstyrelsen Förlaget 1999/2003.

Kriminalvårdsstyrelsen, Visionen "Bättre ut", informationsmaterial 2001.

Lundberg S, Härlandafängelset - en tidsspegel, Tre Böckers Förlag AB 1997.

Mistral, kriminalvårdens system för löpande dokumentation av programverksamhet, 2001. Nyström, Soydan \& Jess, Med arbete som insats, klienteffekter och samhällsekonomisk lönsamhet i socialt arbete, Socialstyrelsen, Centrum för Utvärdering av Socialt arbete, 2002.

Rapport Klientverksamhet i anstalt, Kriminalvårdsstyrelsen Förlaget 1996.

Ohlsson Lisbeth, Rapport angående "Läs och skriv/dysleksi undervisning” på kriminalvårdsanstalten i Malmö. Pedagogiska uppsatser nr. 33. Pedagogiska Institutionen, Lunds universitet, 2000.

Roitto, Svensson \& Wedin, Undersökning av läs- och skrivsvårigheter bland kriminalvårdens klienter våren och sommaren 1996, opublicerad rapport.

Roitto M \& Sjöberg H, Kriminalvårdens klientutbildning - kartläggning, problembeskrivning och förslag till åtgärder, Kriminalvårdstyrelsen 2001 . 
Sarnecki, J, Predicting Social maladjustment, The National Council for Crime Prevention. Report nr 17. Allmänna förlaget, Stockholm 1985.

Skollag 1985:1100, omtryck sfs 1997:1212, ändringar t.o.m. sfs 2002:159.

SOU 1996:27, En Strategi för kunskapslyft och livslångt lärande, Utbildningsdepartementet 1996.

SOU 1993:23, Kunskapens krona, Utbildningsdepartementet 1993. sö-rapporter. Planering, uppföljning och utvärdering. Kommunal och statlig utbildning för vuxna i häkte och anstalt. R89:35 Stockholm: Skolöverstyrelsen 1989.

Thång, P.O. Vem går i grundvux och hur går det? Rapport nr 1988:04, Institutionen för pedagogik, Göteborgs universitet 1988. UNESCO, 4th International Conference on Adult Education, Final Report, Paris 1985 van Manen, The Tact of Teaching: The meaning of pedagogical thoughtfulness. London, Ontario: Althouse Press, 1991. 


\section{Figures}

FIGURE 1.1 Prisoners and prison education in relation to society

FIGURE 1.2 The objectives of prison education seen over time

FIGURE 5.1 The objectives of prison education seen over time

\section{Tables}

TABLE 3.1 Prison place capacity in 2003

TABLE 3.2 Average figures regarding deprivation of liberty in 2003

TABLE 3.3 Average numbers of sentences begun to be served in 2003

TABLE 3.4 Some groups of prisoners on a given day in 2003

TABLE 3.5 Work and education

TABLE 5.1 The costs of prison education (in Euro) 
